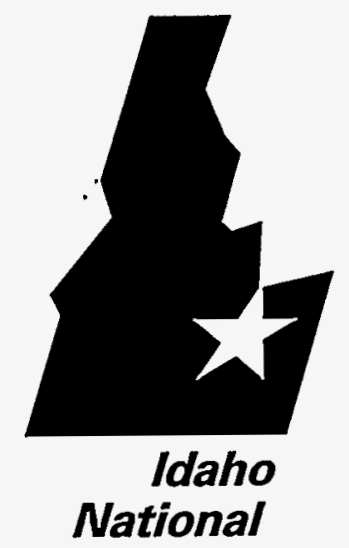

Engineering Laboratory
REGEVED

December 1995

FEB 23 1980

OSTI

\title{
Inverse Modeling for Field-Scale Hydrologic and Transport Parameters of Fractured Basalt
}

S. O. Magnuson

三니ockheed 


\section{Inverse Modeling for Field-Scale Hydrologic and Transport Parameters of Fractured Basalt}

S. O. Magnuson

December 1995

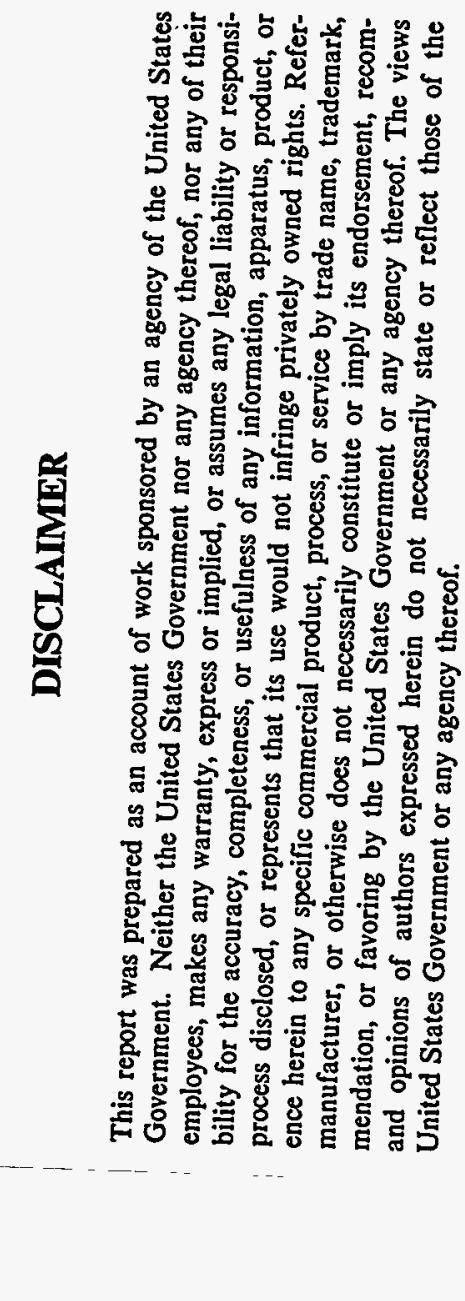

Prepared for the

U.S. Department of Energy

Assistant Secretary for Environmental Management

Under DOE Idaho Operations Office

Contract DE-AC07-94ID13223

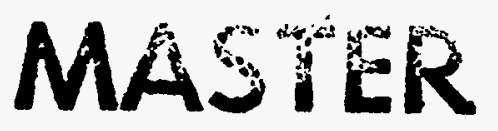

HH 


\section{ABSTRACT}

A large-scale test of infiltration into a thick sequence of fractured Snake River Plain basalts was performed during the summer of 1994 on the Idaho National Engineering Laboratory. Monitoring of moisture and tracer movement during this test provided a set of quantitative measurements from which to obtain a field-scale hydrologic description of the fractured basalts. An inverse modeling study using these quantitative measurements was performed to obtain the representative hydrologic description. This report describes the results of the inverse modeling study and includes the background and motivation for conducting the infiltration test; a brief overview of the infiltration test; descriptions of the calibration targets chosen for the simulation study, the simulation model, and the model implementation; and the simulation results with comparisons to hydrologic and tracer breakthrough data obtained from the infiltration test. 


\section{CONTENTS}

ABSTRACT $\ldots \ldots \ldots \ldots \ldots \ldots \ldots \ldots \ldots \ldots \ldots \ldots \ldots \ldots \ldots \ldots \ldots \ldots \ldots$

ACKNOWLEDGMENTS $\ldots \ldots \ldots \ldots \ldots \ldots \ldots \ldots \ldots \ldots \ldots \ldots \ldots \ldots \ldots \ldots \ldots$

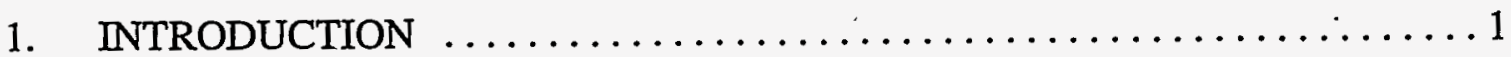

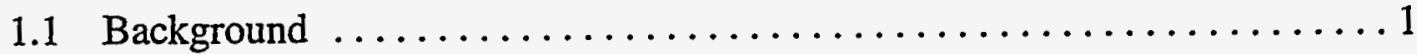

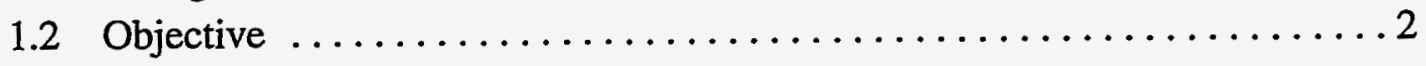

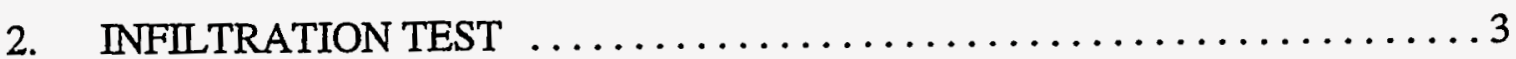

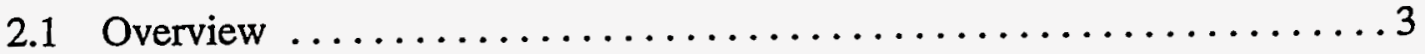

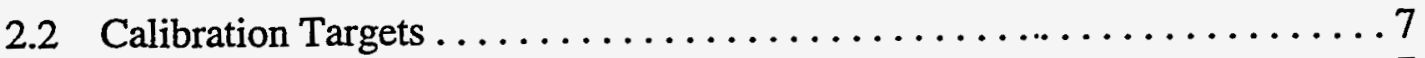

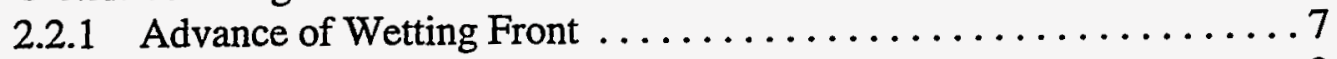

2.2.2 $B$ and $C$ Ring Perched Water Hydrographs $\ldots \ldots \ldots \ldots \ldots$

2.2.3 B Ring Conservative Tracer Concentration History . . . . . . . . 10

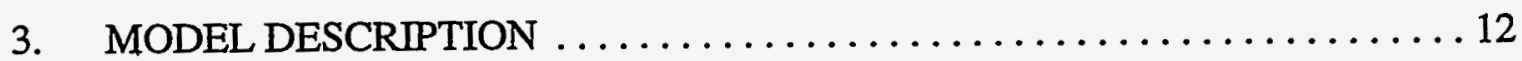

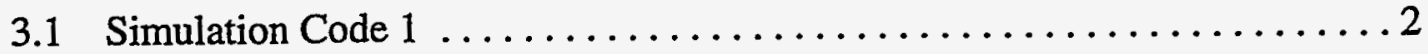

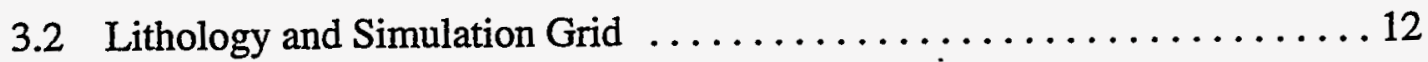

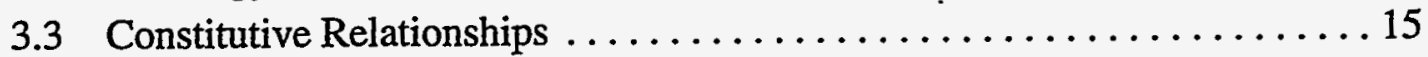

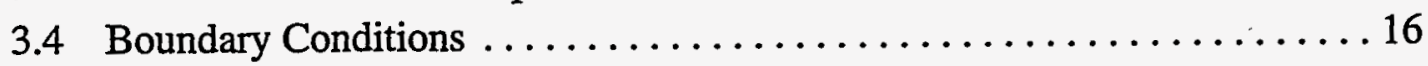

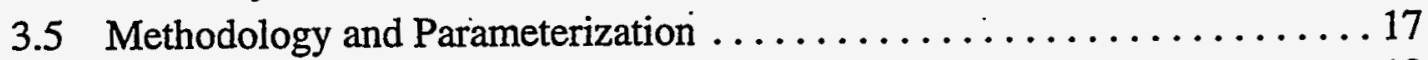

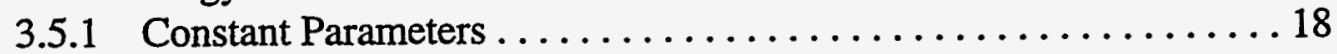

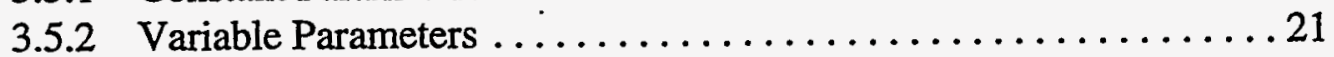

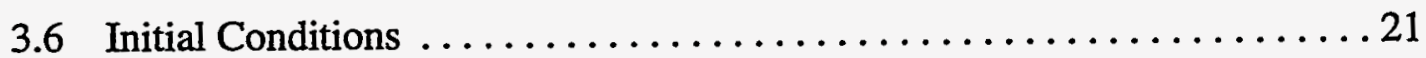

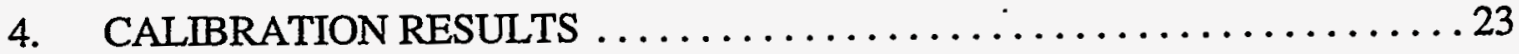

4.1 Wetting Front Advance and Hydrograph Comparison. ............ 23

4.2 B Ring Breakthrough Curve Comparison ................... 29

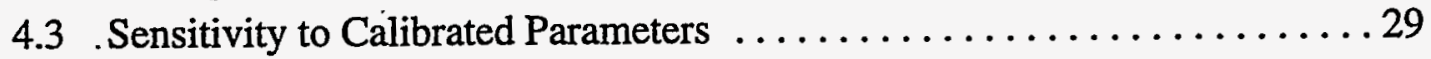

4.4 Sensitivity to Fracture Relative Permeability Curvature ........... 32

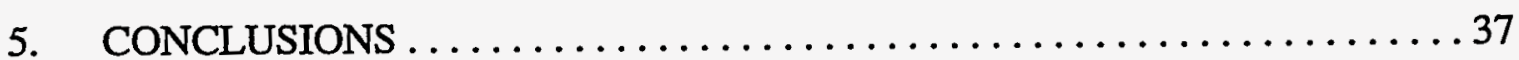

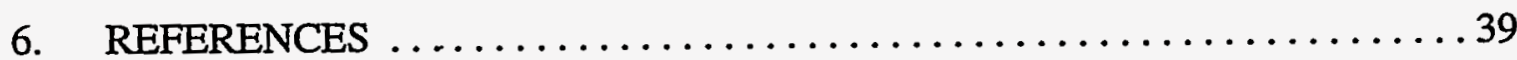

Appendix A: TETRAD Simulation Decks $\ldots \ldots \ldots \ldots \ldots \ldots \ldots \ldots \ldots \ldots \ldots \ldots \ldots \ldots$

\section{FIGURES}

1. Location of the large-scale infiltration test. $\ldots \ldots \ldots \ldots \ldots \ldots \ldots \ldots \ldots$

2. Large-scale infiltration basin showing monitoring well locations. . . . . . . . 5

3. Perched water hydrographs from large-scale infiltration test. $\ldots \ldots \ldots \ldots \ldots$.

4. Conservative tracer breakthrough curves for $B$ ring wells. $\ldots \ldots \ldots \ldots \ldots \ldots$

5. Axi-symmetric simulation domain showing lithology. $\ldots \ldots \ldots \ldots \ldots \ldots \ldots 12$

6. TETRAD computational grid for infiltration basin simulation. . . . . . . . 14

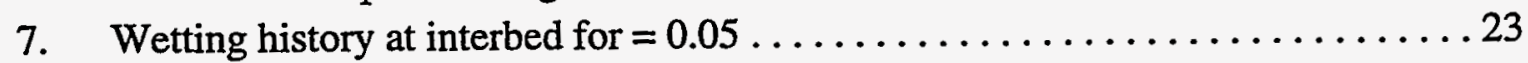


8. Comparison of simulated and observed hydrographs for $\mathrm{B}$ and $\mathrm{C}$ ring

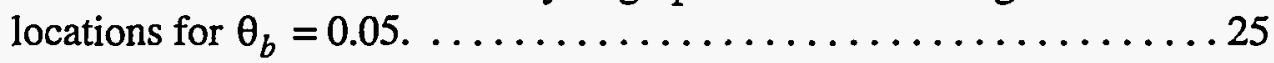

9. Comparison of simulated and observed hydrographs for $\mathrm{B}$ and $\mathrm{C}$ ring

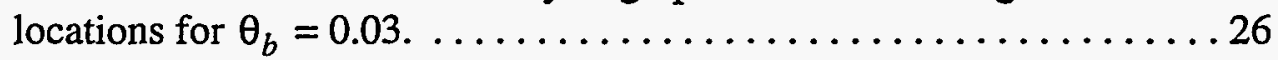

10. Comparison of simulated and observed hydrographs for $B$ and $C$ ring

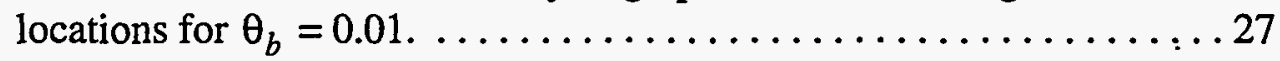

11. Comparison of simulation BTCs to nearly-symmetric B ring well BTCs for single and dual porosity models. . . . . . . . . . . . . . . . . . . 30

12. Sensitivity to longitudinal and transverse dispersivity. ................ 31

13. Sensitivity to basalt fracture horizontal permeability. ............... 33

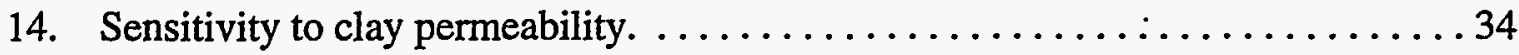

15. Effect of curvature exponent for basalt fracture relative permeability. $\ldots \ldots \ldots 35$

16. Sensitivity to degree of curvature of basalt fracture relative permeability. $\ldots \ldots 36$

\section{TABLES}

1. Infiltration basin wells with interbed surface elevations above $4895 \mathrm{ft}$ amsl. . . .6 6

2. Interbed surface elevations for close well pairs. .................. 6

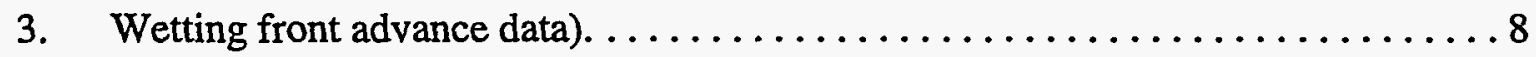

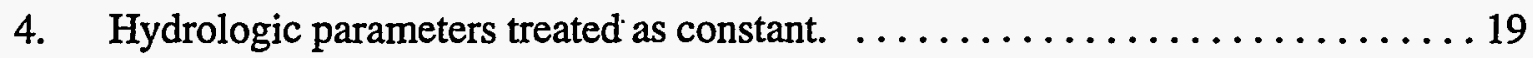

5. Hydrologic parameters treated as variable. .................... 21

6. Calibration results for variable basalt fracture effective porosity. $\ldots \ldots \ldots \ldots 28$

7. Recommended parameters based on calibration results. $\ldots \ldots \ldots \ldots \ldots \ldots$ 


\section{ACKNOWLEDGMENTS}

I would like to thank the DOE-ID Operations Office, especially Patti Kroupa, for funding the LargeScale Aquifer Stress and Infiltration Test. I would like to especially thank the scientists who persisted in conducting the test and analysis of the results. These include Frank Dunnivant, Meredith Newman, Indrek Porro, Carolyn Bishop, Dave Burgess, Robert Starr, Mike Rohe, Allan Wylie, and Cathy Pfeiffer. Their perseverance through a project of this magnitude and resulting difficulty is amazing. Thanks to Tom Wood as one of the early initiators and proponents of the idea for the test and to both he, Greg Norrell, and Kirk Dooley for providing the project management and skills to get the water "into the basin." Thanks to James McCarthy for his contributions to the selection of calibration targets from the mass of available information. I also would like to thank Doug Jorgensen, WAG 7 BRA Project Manager, for his willingness to fund this modeling study. Lastly, thanks to the INEL Renewable Energy Program for making the TETRAD simulator available for environmental applications. 


\section{Inverse Modeling for Field-Scale Hydrologic and Transport Parameters of Fractured Basalt}

\section{INTRODUCTION}

\subsection{Background}

The Subsurface Disposal Area (SDA) is located at the Radioactive Waste Management Complex (RWMC) on the southwestern portion of the Idaho National Engineering Laboratory (INEL). The SDA is a radioactive disposal site that has received and buried transuranic and low-level waste in shallow pits, trenches, and soil vaults since 1952. Transuranic wastes have been stored abovegrade since 1970. In 1989, the INEL was added to the Environmental Protection Agency's National Priorities List of Superfund sites. A Federal Facility Agreement and Consent Order for the INEL was signed by the Department of Energy, Idaho Operations Office, the Environmental Protection Agency, and the State of Idaho in December 1991.This agreement requires evaluation of potential health impacts of the disposed SDA wastes through a risk assessment process.

Previous risk and performance assessments conducted for wastes disposed at the SDA used a greatly simplified conceptual model to represent water movement and contaminant transport in the vadose zone (Burns et al., 1994: Maheras et al., 1994). The simplified model ignored the majority of the vadose zone that is composed primarily of fractured basalts and considered only the sedimentary interbeds. The fractured basalts were ignored because there was a very limited basis by which to describe representative water movement within them. Although the basalt matrix had previously been hydrologically characterized at the core-scale (Bishop, 1991) and had a low saturated hydraulic conductivity, on the order of $10^{0}$ to $10^{1} \mathrm{~m} / \mathrm{yr}$, describing representative water movement in the basalts is made difficult by having to include the effect of the fractures in a partially saturated flow regime.

A large-scale infiltration test was conducted to provide a set of field-based observations to use in developing a valid description of the hydrological and transport properties for the fractured basalt portion of the vadose zone (Starr and Rohe, 1995). Monitoring for this same purpose has occurred and continues to occur inside the SDA (McElroy, 1993; Bishop, 1995), but the hydraulic responses to changes in seasonal infiltration at the surface appear slow compared to those that were induced under the ponding conditions of the infiltration test.

\subsection{Objective}

This report describes results of an inverse modeling study of the large-scale infiltration test. The objective in this post-test modeling study was to calibrate simulations of flow and transport to the field results of the infiltration test. Through this calibration exercise, the appropriateness of conceptual models could be determined. Two hydrologic conceptual models were considered. The first conceptual model treated the fractured basalt portion of the vadose zone as an equivalent 
porous media in which only fractures contributed to flow. The basalt matrix was considered to have a permeability low enough that it did not effect flow and was therefore neglected. This conceptual model was first applied for vadose zone hydrologic simulations by Walton et al. (1989). The second conceptual model treated the fractured basalt as a dual-porosity media in which both the matrix and the fractures influence the movement of water and contaminants.

In addition to modeling the advance of the infiltrating water, breakthrough of a conservative tracer applied in the infiltration test was also simulated. The objective in this portion of the simulation study was to obtain an estimate of the field-scale dispersivity for the fractured basalt portion of the vadose zone.

It is important to realize that, in a modeling study of this type, the objective is not to exactly match each and every hydrologic or tracer concentration measurement. The data are too voluminous and small-scale spatial heterogeneity cannot feasibly be taken into account. Rather, the overall objective is to obtain field-scale hydrologic and transport descriptions that can be used in flow and transport simulations for risk assessments at the SDA. As such, the intent is to mimic the general character of flow and transport observed in the infiltration test.

This report presents a brief overview of the infiltration test, a description of the calibration targets chosen for the simulation study, the simulation model used for the study, the model implementation for both conceptual models, the simulation results including comparisons to hydrologic and breakthrough data obtained from the infiltration test, and lastly, a discussion of the implications regarding appropriateness of the models for use in future simulations of water and contaminant movement through the fractured basalt portion of the vadose zone in the vicinity of the RWMC. 


\section{INFILTRATION TEST}

\subsection{Overview}

During the summer of 1994, a large-scale aquifer pump test and vadose zone infiltration test was conducted approximately 1.3 miles south of the RWMC (Figure 1). Descriptions of these two tests can be found in Wylie et al. (1994) and Norrell et al. (1994). In the aquifer pump test, a largediameter well was pumped at a high rate (3,000 gallons per minute for 36 days). The test was conducted to determine hydraulic properties of the eastern Snake River Plain Aquifer in the vicinity of the RWMC. Results from the aquifer stress test are reported in Wylie et al. (1995).

The infiltration test was conducted to provide a basis to determine hydraulic and solute transport properties at a field-scale for an $\sim 180$-ft thick fractured basalt sequence within the vadose zone. Water from the aquifer pump test was ponded on the ground surface in a 600 -ft diameter circular basin (Figure 2). Six days after the start of the infiltration test, water in the basin was spiked with both conservative (Se-75) and reactive ( $\mathrm{Sr}-85$ and $\mathrm{Tb}-160)$ tracers. The concentration of the tracers in the basin was maintained by not adding any additional discharge water from the pump test for 11 days.

Changes in water content and movement of tracers in the subsurface were monitored. The monitoring wells were aligned on spokes emanating from the center of the basin. Wells were located at four rings spaced from the center of the basin. The A ring wells were within the basin, and the B, C, and E ring wells were 50,300, and $750 \mathrm{ft}$ from the edge of the basin, respectively. The well name nomenclature indicates which ring by the initial letter and the spoke by the first number. The second letter and number pair refer to depths at that location for nested monitoring wells. The infiltration test monitoring results and analyses of the results are reported in Starr and Rohe (1995), Burgess (1995), Dunnivant et al. (1994), Newman and Dunnivant (1995), Dunnivant and Newman (1995), Pfeifer and Andersen (1995), and Porro and Bishop (1995).

In general, the results of the infiltration test indicated that within the fractured basalts beneath the infiltration basin, there were no large-scale heterogeneities in the hydrologic properties that influenced water movement as it infiltrated downward through the 180 -ft thick fractured basalt sequence. On the scale of the infiltration test, the water moved essentially vertically within the downward projection of a cylinder defined at the land surface by the basin. Neutron probe moisture monitoring in the A ring wells indicated that the wetting front moved downward at an average velocity of $5 \mathrm{~m} /$ day ( $16 \mathrm{ft} /$ day) based on monitoring the advance in the A ring wells (Porro and Bishop, 1995). There were small-scale indications of lateral movement within the basalt beneath the basin (Porro and Bishop, 1995) but there was no certain detection of lateral movement of water out to the B ring wells $50 \mathrm{ft}$ outside the basin.

Once the infiltrating water reached the sedimentary interbed at a depth of approximately $180 \mathrm{ft}$, perched conditions developed as expected and water then began to move horizontally and was detected in the B, C, and E ring wells at several locations (Burgess, 1995). The development of perched water was facilitated by dense clay layers in the top portion of the interbed that were noted during drilling (Burgess, 1995). The spreading of perched water was in part controlled by the elevation of the interface between the fractured basalt and the sedimentary interbed. Perched water 


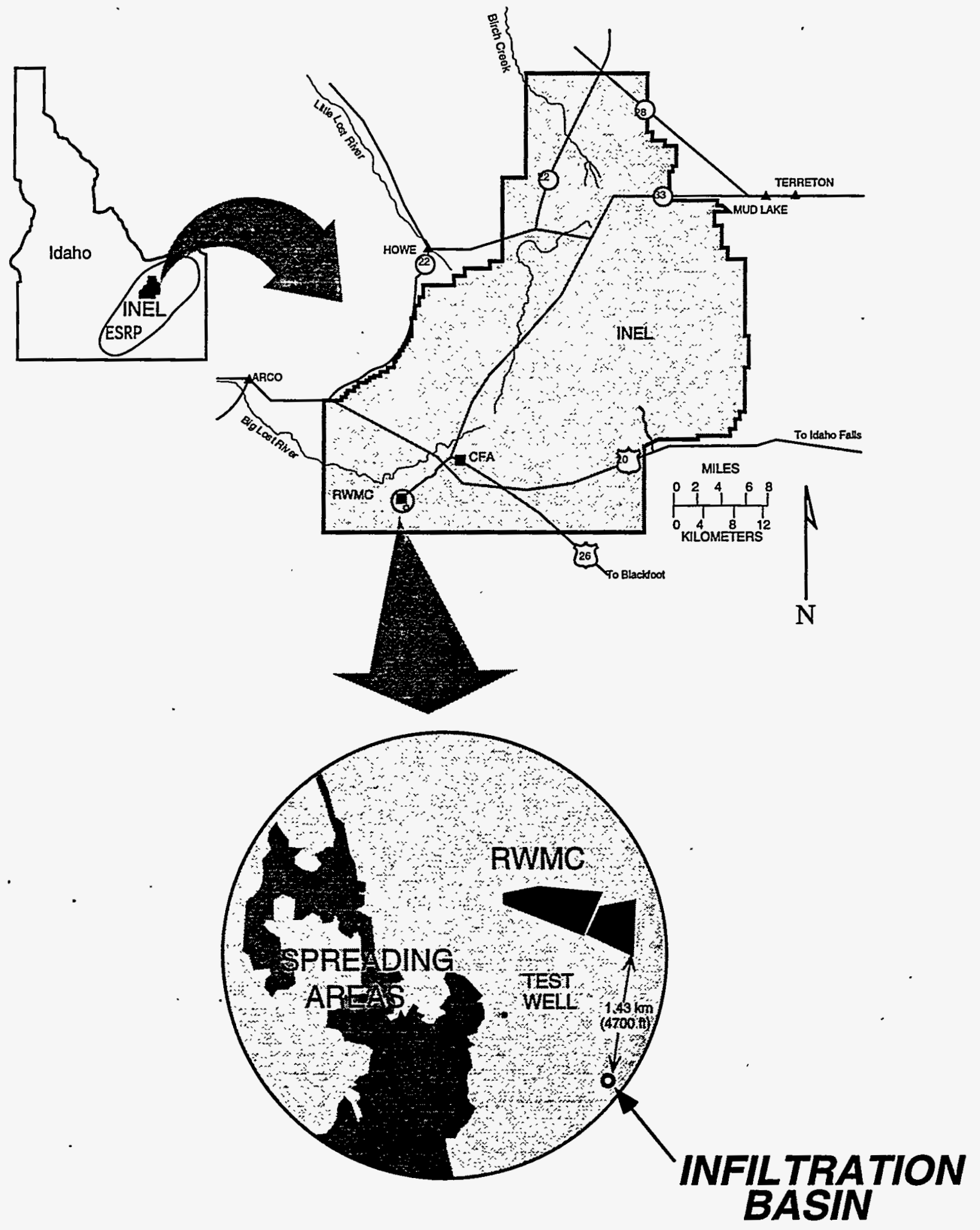

Figure 1. Location of the large-scale infiltration test. 


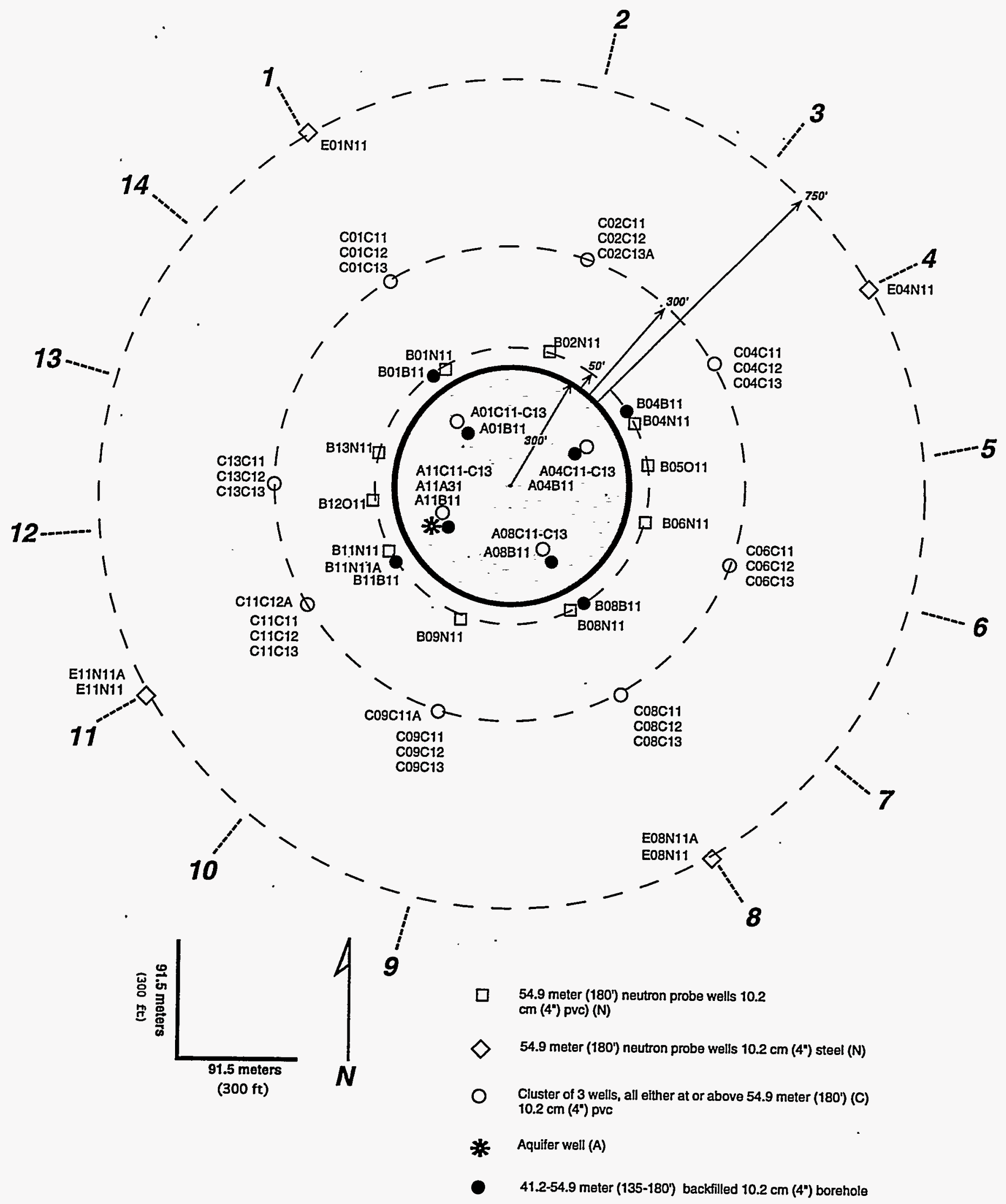

Figure 2. Large-scale infiltration basin showing monitoring well locations. 
was detected at 17 locations ( $3 \mathrm{~A}$ ring wells, $10 \mathrm{~B}$ ring wells, $3 \mathrm{C}$ ring wells, and $1 \mathrm{E}$ ring well). The timing of the water arrival varied as did the maximum elevation of perched water.

The elevation of the top of the B-C interbed ranges from 4888 to $4896.8 \mathrm{ft}$ amsl in the vicinity of the infiltration basin, considering all the monitoring wells drilled that intersected the interbed. The wells with basalt/interbed interface elevations above $4895 \mathrm{ft}$ amsl are shown in Table 1. Interbed elevations are from Burgess (1995).

Three of the \#11 spoke wells have interbed elevations above $4895 \mathrm{ft}$ amsl; therefore, it appears that there could be a ridge along the \#11 spoke. However, along this same spoke, wells A11C11, B11B11, and E11N11A have interbed elevations below $4893.0 \mathrm{ft}$ amsl. Based on the small scale of the interbed fluctuations, it is difficult to conclude that a significant ridge exists along the \#11 spoke.

There are 7 pairs of wells that are drilled within 5 to $40 \mathrm{ft}$ of each other. Table 2 shows the interbed surface elevations and elevation differences for each pair.

Table 1: Infiltration basin wells with interbed surface elevations above $4895 \mathrm{ft}$ amsl.

\begin{tabular}{|c|c|}
\hline Well & Interbed Surface Elevation (ft amsl) \\
\hline \hline B06N11 & 4895.9 \\
\hline B10N21 & 4895.8 \\
\hline A11A31 & 4896.8 \\
\hline B11N11 & 4896.7 \\
\hline E11N11 & 4895.9 \\
\hline
\end{tabular}

Table 2: Interbed surface elevations for close ( $<\mathbf{5 0} \mathbf{f t})$ well pairs.

\begin{tabular}{|c|c|c|c|c|}
\hline Well & $\begin{array}{c}\text { Interbed Surface } \\
\text { Elevation (ft amsl) }\end{array}$ & Well & $\begin{array}{c}\text { Interbed Surface } \\
\text { Elevation (ft amsl) }\end{array}$ & $\begin{array}{c}\text { Difference } \\
(\mathrm{ft})\end{array}$ \\
\hline \hline A04B11 & 4894.9 & A04C11 & 4891.7 & 3.2 \\
\hline A11A31 & 4896.8 & A11C11 & 4892.8 & 4.0 \\
\hline B04B11 & 4888.0 & B04N11 & 4891.7 & 3.7 \\
\hline B11N11 & 4896.7 & B11B11 & 4891.8 & 4.9 \\
\hline C09C11 & 4890.7 & C09C11A & 4889.9 & 0.8 \\
\hline E08N11 & 4888.4 & E08N11A & 4888.5 & 0.1 \\
\hline E11N11 & 4895.9 & E11N11A & 4892.8 & 3.1 \\
\hline
\end{tabular}


With the exception of the $\mathrm{C} 09$ and E08 well pairs, the interbed elevation differences at each location approach half of the total range of interbed elevations ( $8.8 \mathrm{ft}$ ) over all the wells in the study area. Therefore, it is very difficult to identify any statistically significant trends in the interbed top elevation. Through variogram analysis, Burgess (1995) estimated a correlation range of $50 \mathrm{ft}$ for the interbed surface elevation data and concluded that overall, the data were "noisy." Burgess (1995) nevertheless attempted contouring the interbed surface elevations and perched water thicknesses using three different methods. The contouring results generally showed lower interbed surface elevations to the southeast. However, the confirmed water spreading during the test was to the northeast where interbed elevations were generally similar to or slightly higher than those beneath the infiltration basin. Given the sparseness of the data and the observed variability, it is possible that the actual interbed elevations do not follow the patterns in the contour attempts and the interbed could be more or less flat at a large scale and only vary significantly at the smaller scale. Reliance on the latter interpretation is used below to help justify treating this material interface as if it were flat.

Tracer concentrations were monitored in lysimeters at various depths beneath the infiltration basin (A ring wells) and where perched water formed above the interbed in completed wells. Differing behavior of concentration breakthrough curves at different locations within the fractured basalt was observed, especially in the A ring lysimeter sampling locations (Newman and Dunnivant, 1995). Breakthrough curves for conservative tracers in the perched water in the B ring wells showed qualitatively better agreement. This is likely due to averaging that occurred as the spiked water transited more of the fractured basalt formation. Alternatively, the water present within the perched water likely represents more transport pathways through the fractured basalt than the lysimeter sampling locations higher up within the fractured basalt. Admittedly, the breakthrough curves still show some varying behavior between monitoring locations. Possible reasons for these differences are discussed in Newman and Dunnivant (1995). One possible explanation offered is the effect of dead-end fractures that initially are dry, fill up with water, and then contribute only minimally, if at all, to flow for the remainder of the test. No reactive tracers were detected in any of the monitoring locations.

\subsection{Calibration Targets}

Three specific calibration targets were chosen. They were the rate of advance of the wetting front down through the fractured basalt formation to the sedimentary interbed at a depth of $\sim 180 \mathrm{~m}$, the spreading and development of perched water above the sedimentary interbed at the $B$ and $C$ ring locations, and the observed concentration breakthrough history at the B ring wells. Each of these is discussed in turn.

\subsubsection{Advance of Wetting Front}

Table 3 shows the average rate of advance of the wetting front calculated for each individual well on the A ring. The $B$ ring wells yielded no information on the vertical advance of the wetting front since they did not detect water other than the lateral spreading of perched water above the sedimentary interbed at depth. As can be seen, there is variability between locations but the standard deviation is not overly large. The average rate of $5 \mathrm{~m} /$ day was considered reflective of general behavior. The calibration target in the simulation study then was to simulate the wetting front advance within one standard deviation of the observed average wetting front advance. This 
Table 3: Wetting front advance data (adapted from Porro and Bishop, 1995, their Table 2).

\begin{tabular}{|c|c|c|}
\hline Well & $\begin{array}{c}\text { Number of Moisture First } \\
\text { Arrival Detections per Well }\end{array}$ & $\begin{array}{c}\text { Average Rate of Wetting Front } \\
\text { Advance by Well (m/day) }\end{array}$ \\
\hline \hline $\mathrm{A} 01 \mathrm{C} 11$ & 3 & 5.93 \\
\hline $\mathrm{A} 01 \mathrm{C} 12$ & 4 & 4.53 \\
\hline $\mathrm{A} 01 \mathrm{C} 13$ & 1 & 4.70 \\
\hline $\mathrm{A} 04 \mathrm{C} 11$ & 3 & 4.93 \\
\hline $\mathrm{A} 04 \mathrm{C} 12$ & 4 & 7.90 \\
\hline $\mathrm{A} 04 \mathrm{C} 13$ & 2 & 3.75 \\
\hline $\mathrm{A} 08 \mathrm{C} 11$ & 3 & 4.90 \\
\hline $\mathrm{A} 08 \mathrm{C} 12$ & 5 & 5.38 \\
\hline $\mathrm{A} 08 \mathrm{C} 13$ & 3 & 4.27 \\
\hline $\mathrm{A} 11 \mathrm{C} 11$ & 2 & 4.10 \\
\hline $\mathrm{A} 11 \mathrm{C} 12$ & 3 & 6.97 \\
\hline $\mathrm{A} 11 \mathrm{C} 13$ & 5 & 2.14 \\
\hline & \multicolumn{2}{|c|}{ Average: $4.96 \mathrm{~m} /$ day } \\
\hline \multicolumn{2}{|c|}{ Standard Deviation: $1.50 \mathrm{~m} /$ day } \\
\hline
\end{tabular}

would correspond to an arrival of the wetting front at the basalt/interbed interface between 8.3 and 15.4 days.

\subsubsection{B and C Ring Perched Water Hydrographs}

Perched water elevations were measured at 17 locations (see Figure 3). The hydrographs in Figure 3 are the same as those presented in Burgess (1995) but are plotted as a function of time since the water was added to the infiltration basin rather than on the corresponding date the measurements were taken. On average, water level measurements were taken daily when water was detected. It is important to note that absence of detected water does not necessarily mean that perched water did not develop in a region due to well completions sometimes being above the interface between the fractured basalt and the sedimentary interbed. Also, wells B09G11 and B10G11 were drilled with water during the infiltration test. The use of drilling water at best complicates and at worst negates the use of these two wells in further analysis. Although the timing when saturation first occurred and the extent of rise in individual hydrographs vary, there is still some general agreement in the shapes of the hydrographs.

Since water was detected at only three of the $C$ ring wells, the possible selections to use for calibration were limited. Because a two-dimensional vertically axi-symmetric simulation domain 

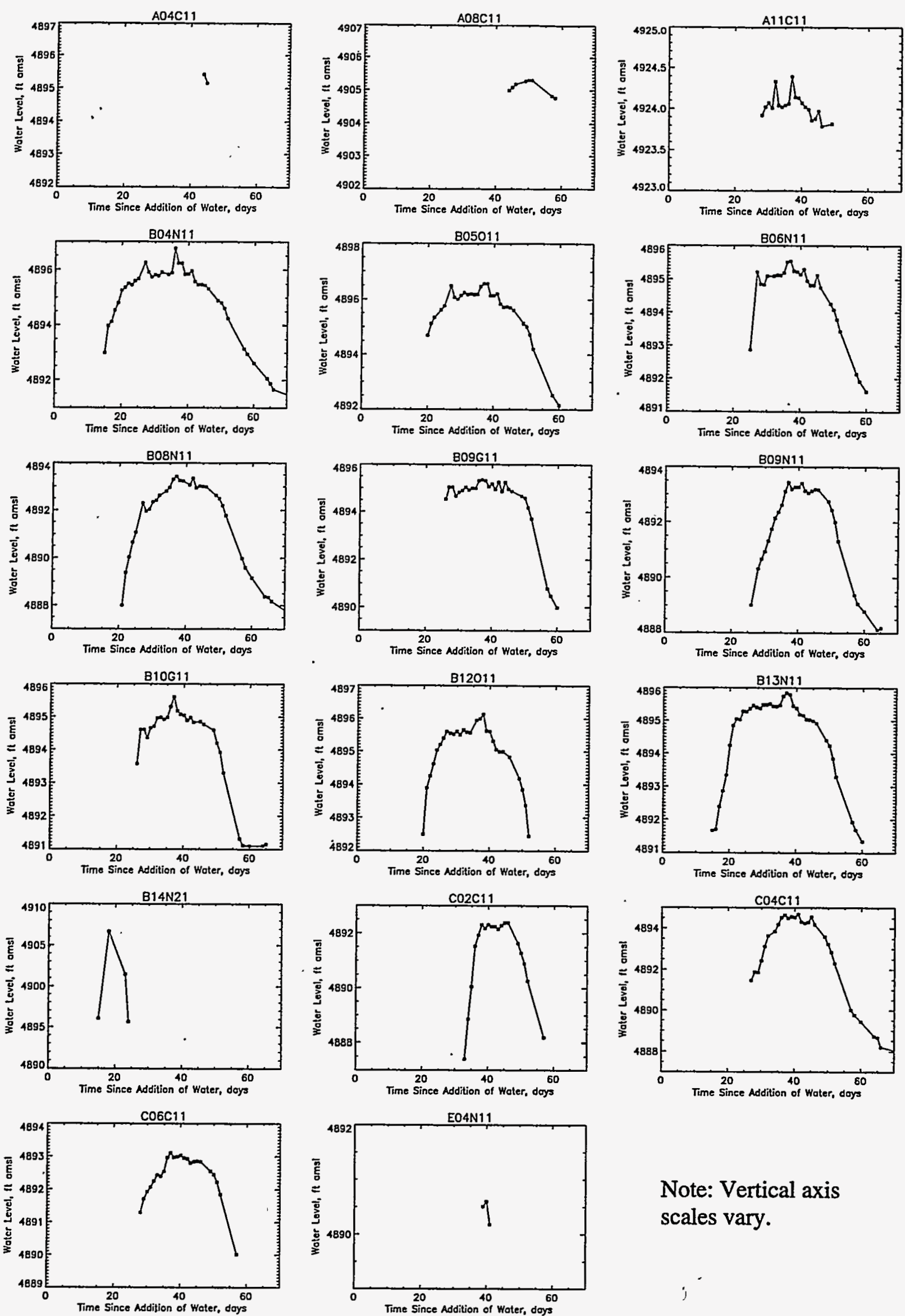

Note: Vertical axis scales vary.

Figure 3. Perched water hydrographs from large-scale infiltration test. 

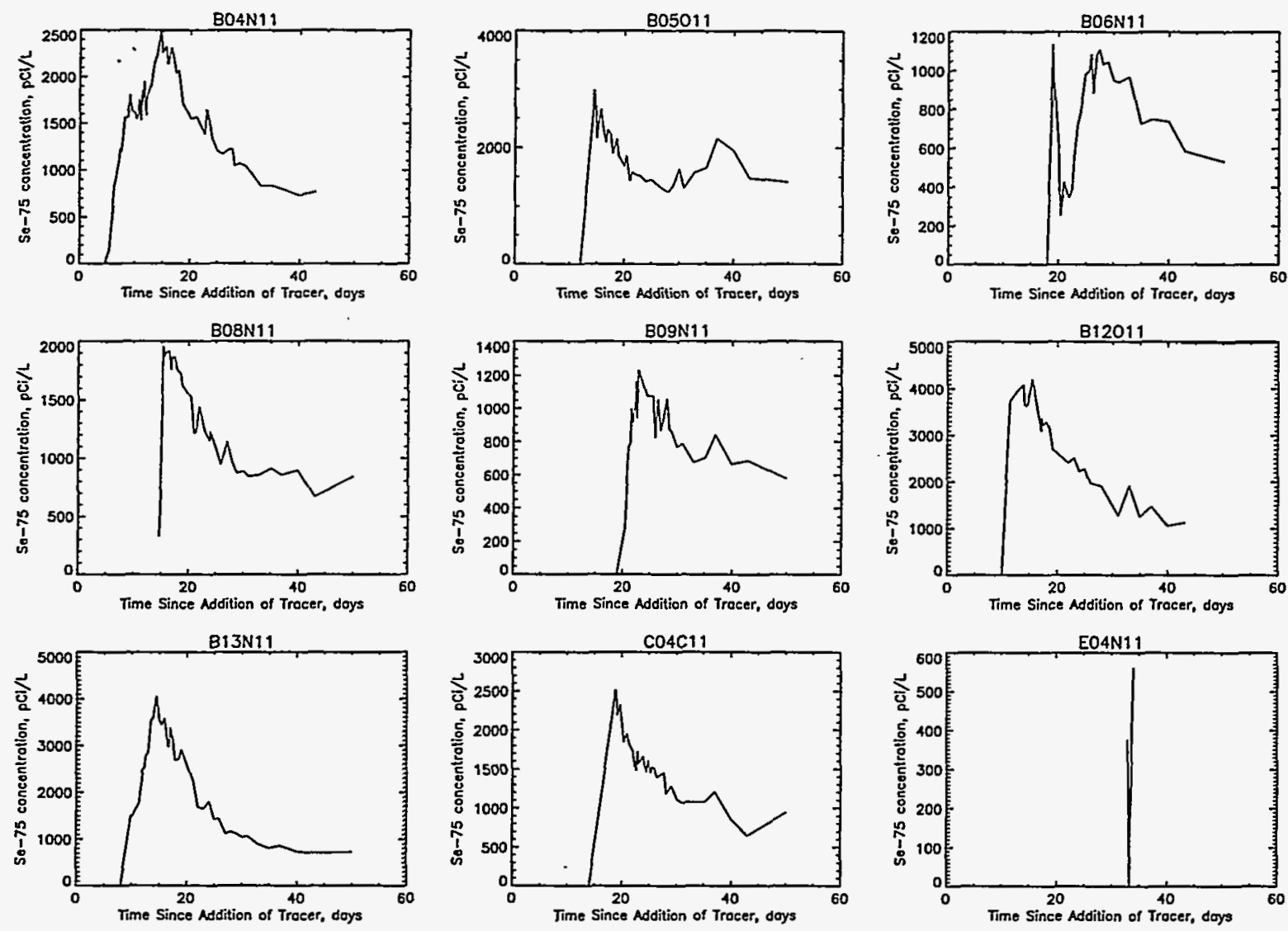

Figure 4. Conservative tracer breakthrough curves for B ring wells.

was used (discussed later), it was desirable to pick a spoke on which water was detected at both the $\mathrm{B}$ and $\mathrm{C}$ locations. For purposes of inverse modeling, the \#4 spoke (B04N11 and C04C11) wells were chosen for calibration. This spoke has the advantage of being in a direction where the elevation of the basalt/interbed interface is interpreted to be relatively constant. This pair also shows a good lag between water arrival at each location and better development of the rising limb of the hydrograph. The other two potential $\mathrm{C}$ ring locations where perched water was detected were not used because at one of the corresponding B ring locations (B02N11), perched water did not develop, and at the other corresponding B ring location (B06N11), the shape of the rising limb of the hydrograph was too steep and not reflective of most of the other locations.

\subsubsection{B Ring Conservative Tracer Concentration History}

Nineteen monitoring locations provided sufficient data to produce concentration breakthrough curves (BTCs) for the conservative Se-75 tracer (Newman and Dunnivant, 1995). The BTCs for the locations other than in the A ring are shown in Figure 4 and are replicates from Appendix D of Newman and Dunnivant (1995). The A ring wells showed even more varied behavior and are not considered for calibration purposes. Although the B ring wells vary in behavior, they still show a general trend of steeply rising concentrations after some period of time followed by tailing. Newman and Dunnivant (1995) divide the B ring BTCs into three types: near-symmetric, nonsymmetric, and bimodal. 
For calibration purposes, the near-symmetric BTCs were chosen. These were the BTCs for wells B04N11, B12011, and B13N11. Because the BTC results were still quite variable, three curves were chosen and all three curves were superimposed on the simulation results simultaneously. It was evident from the BTCs that the maximum concentrations varied between locations, and none of the maximum concentrations were close to the basin concentration of $19,000-20,000 \mathrm{pCi} / \mathrm{L}$ (Newman and Dunnivant, 1995). There is some evidence that some of the Se-75 was bound up in sedimentary material, contrary to expectations of an ideal conservative tracer. This irreversible loss of tracer is not, however, thought to result in a retardation value greater than 1 for Se-75, but does result in lower effective input concentrations (Dunnivant and Newman, 1995). Because of the observed variability, the three near-symmetric individual BTCs are normalized by their observed maximum value for purposes of comparison to simulation results. 


\section{MODEL DESCRIPTION}

This section describes the simulation code used in the study; the adaptation of a simulation grid to the lithology of the infiltration basin; the constitutive relationships used in the simulation for describing the interaction of capillary pressure, saturation, and relative permeability; the implementation of boundary conditions; the calibration methodology including lists of those parameters considered fixed and those parameters used for calibration in the modeling exercise; and lastly, how the initial conditions were obtained for each simulation.

\subsection{Simulation Code}

The TETRAD code (Vinsome and Shook, 1993) was used to simulate the infiltration basin for both the single-porosity and dual-porosity representations of the fractured basalt portion of the vadose zone. This code is relatively new to the environmental arena (Shook, 1995), but has been validated and used extensively in the petroleum and geothermal industries. It has complete multi-phase, multi-component capabilities. Both liquid and air phases were considered mobile in this simulation exercise for the infiltration basin experiment. The code uses a block-centered finite difference approach and has capabilities for local grid refinement. Dual porosity is incorporated into the code as an optional simulation feature.

\subsection{Lithology and Simulation Grid}

The simulations were done using a two-dimensional (2-D) vertical axi-symmetric representation of the vadose zone beneath the infiltration basin (Figure 5). While there were certainly variations in perched water development and arrival at B ring locations around the basin, there was still a general behavior between locations that was similar. For mimicking general behavior, a 2-D domain is adequate. This representation also takes advantage of radial symmetry to only simulate a 2-D slice of the infiltration basin rather than simulating the entire system. The interface between the surficial sediments (most of which were removed for the test) and the underlying fractured

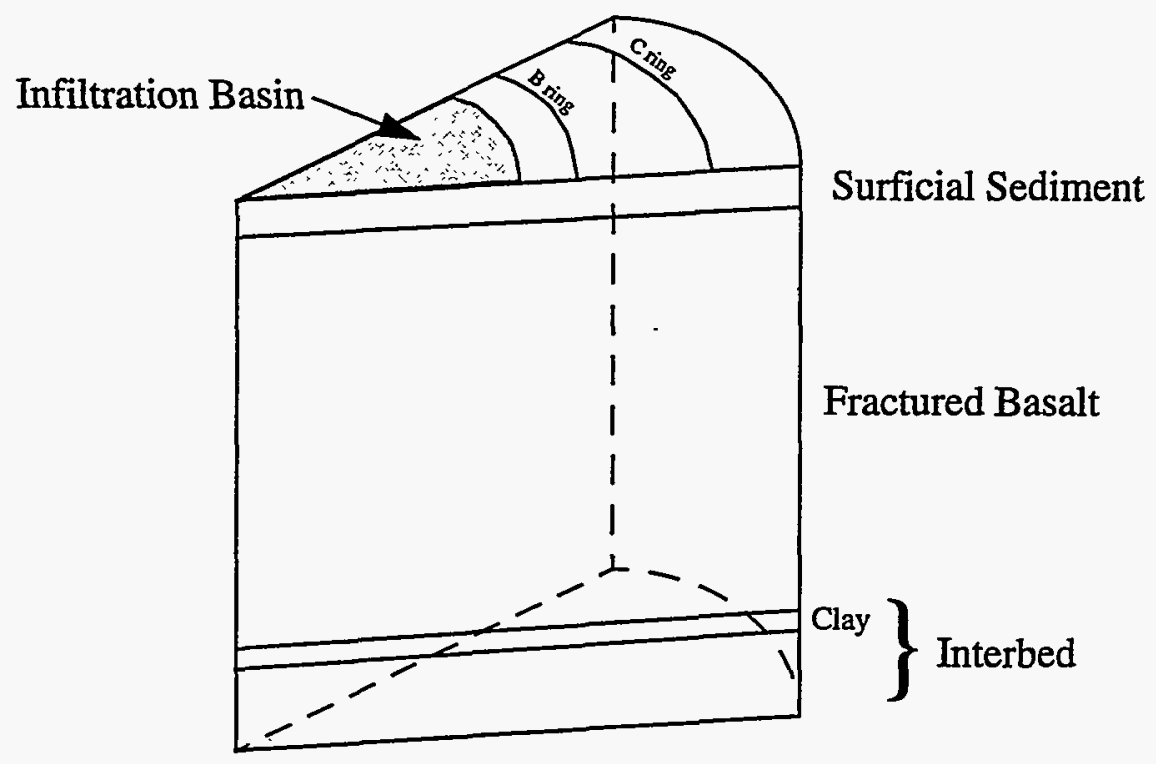

Figure 5. Axi-symmetric simulation domain showing lithology. 
basalt formation was treated as if it were horizontal and was uniformly $1.5 \mathrm{~m}$ thick. The thickness estimate was based on information presented in Starr and Rohe (1995). For the purposes of this modeling study, it was assumed that the basalt/interbed interface was also horizontal. As discussed previously, statistical analysis of the elevation of the basalt/interbed interface showed a short $(\sim 50-\mathrm{ft})$ correlation with distance and inconclusive results from several different contouring efforts based on the available sparse data. For purposes of this simulation study, the assumption of flat interfaces between the surficial sediments, basalt, and sedimentary interbeds is adequate.

The fractured basalt portion of the simulation domain was $52.5 \mathrm{~m}$ thick. This thickness was assigned based on the difference between the average ground surface and interbed surface elevations for the B ring wells (accounting for the 1.5-m surficial sediment thickness as well). The fractured basalt was underlain by a sedimentary interbed that was $25 \mathrm{~m}$ thick. This interbed thickness was slightly greater than the known interbed thickness beneath the infiltration basin of $\sim 21 \mathrm{~m}(70 \mathrm{ft})$ at one location. Using the exact interbed thickness is not important to the modeling study. What is important is to include enough of the interbed to simulate the interaction between the fractured basalt and the interbed and to move the bottom boundary of the simulation domain far enough away so that it does not influence the zone of interest during the simulation, namely the fractured basalt formation extending from below the surficial sediments down to the sedimentary interbed.

A thin $(0.25-\mathrm{m})$ clay layer was included in the simulations at the top of the interbed. The presence of this clay was mentioned in Burgess (1995) without specification as to the lateral extent or thickness. Low permeability clay layers are also found within the equivalent sedimentary interbeds beneath the SDA (McElroy and Hubbell, 1990). The modeling results (discussed later) also indicated the need for a low permeability layer at the basalt/interbed interface.

The radial extent of the infiltration basin in the simulation was $91.5 \mathrm{~m}$ ( $300 \mathrm{ft}$ ). The simulation domain had to extend further to allow for spreading of perched water at the interface between the basalt and the interbed at depth. Along one monitoring spoke of the infiltration test, perched water was observed in an E ring well, which was $230 \mathrm{~m}(750 \mathrm{ft})$ from the edge of the basin. The simulation domain extended radially to $400 \mathrm{~m}$ to encompass the spreading observed at the $\mathrm{E}$ ring well.

The computational grid used in the simulations is shown in Figure 6. Both the base grid and a locally refined region are shown. There were 22 horizontal and 39 vertical grid blocks for a total of 858 grid blocks in the base simulation grid. The refined area consisted of 12 horizontal and 9 vertical base grid blocks that were subdivided so each of the horizontal base grids now consisted of three equal-sized refined grid blocks. The locally refined area resulted in net gain of 216 computational grid blocks since the corresponding base grid blocks are treated as null blocks. The locally refined grid was used to improve the agreement between the hydrograph measurement locations and the corresponding block-centered locations in the model.

As discussed previously, lateral movement of water was not observed within the fractured basalt portion of the domain due to either horizontal capillary gradients or heterogeneity. However, the base simulation grid still included lateral refinement at the edge of the infiltration basin. The horizontal grid spacing beneath the infiltration basin was $13 \mathrm{~m}$ and was gradually scaled down to 


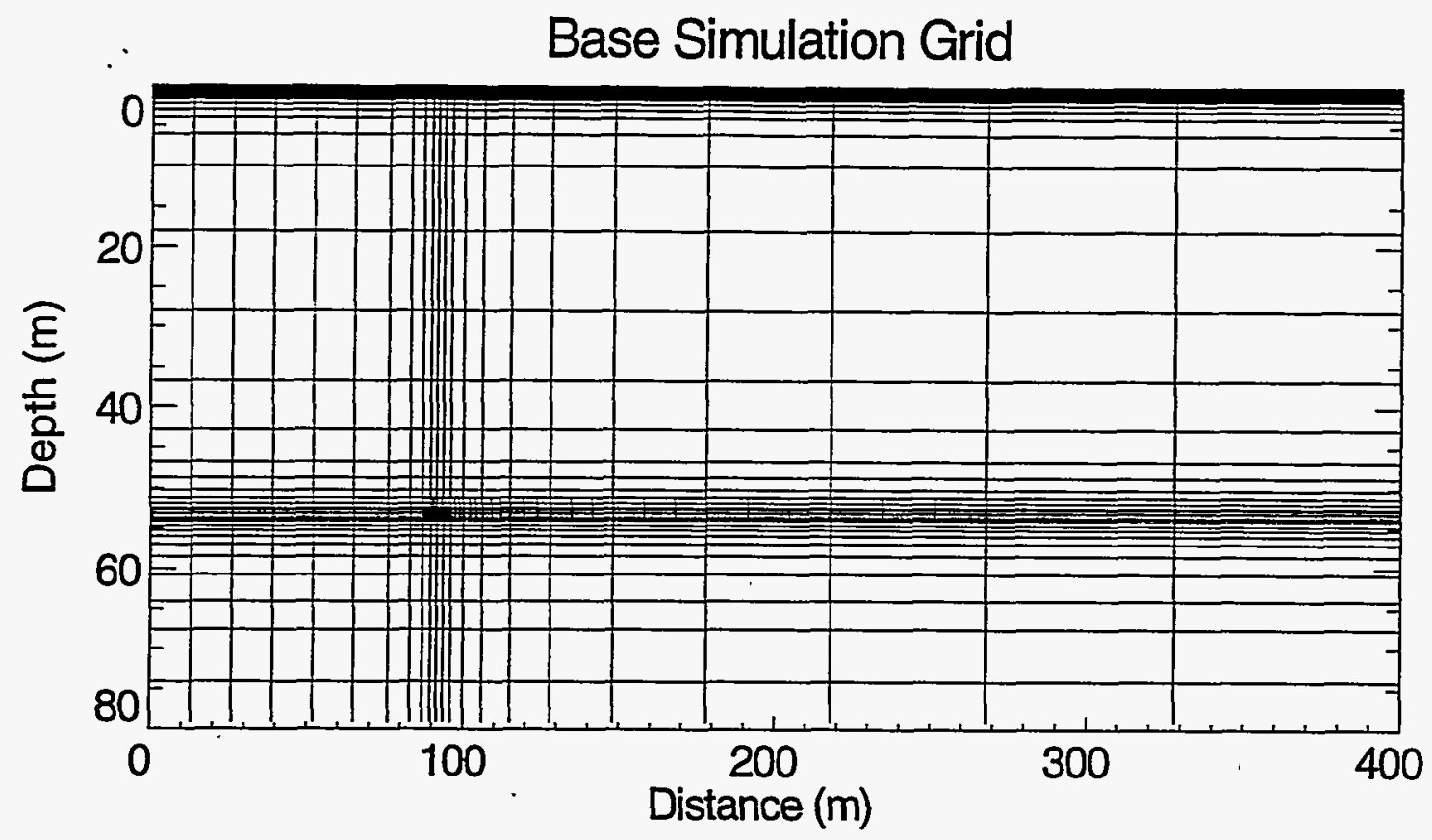

Locally Refined Grid

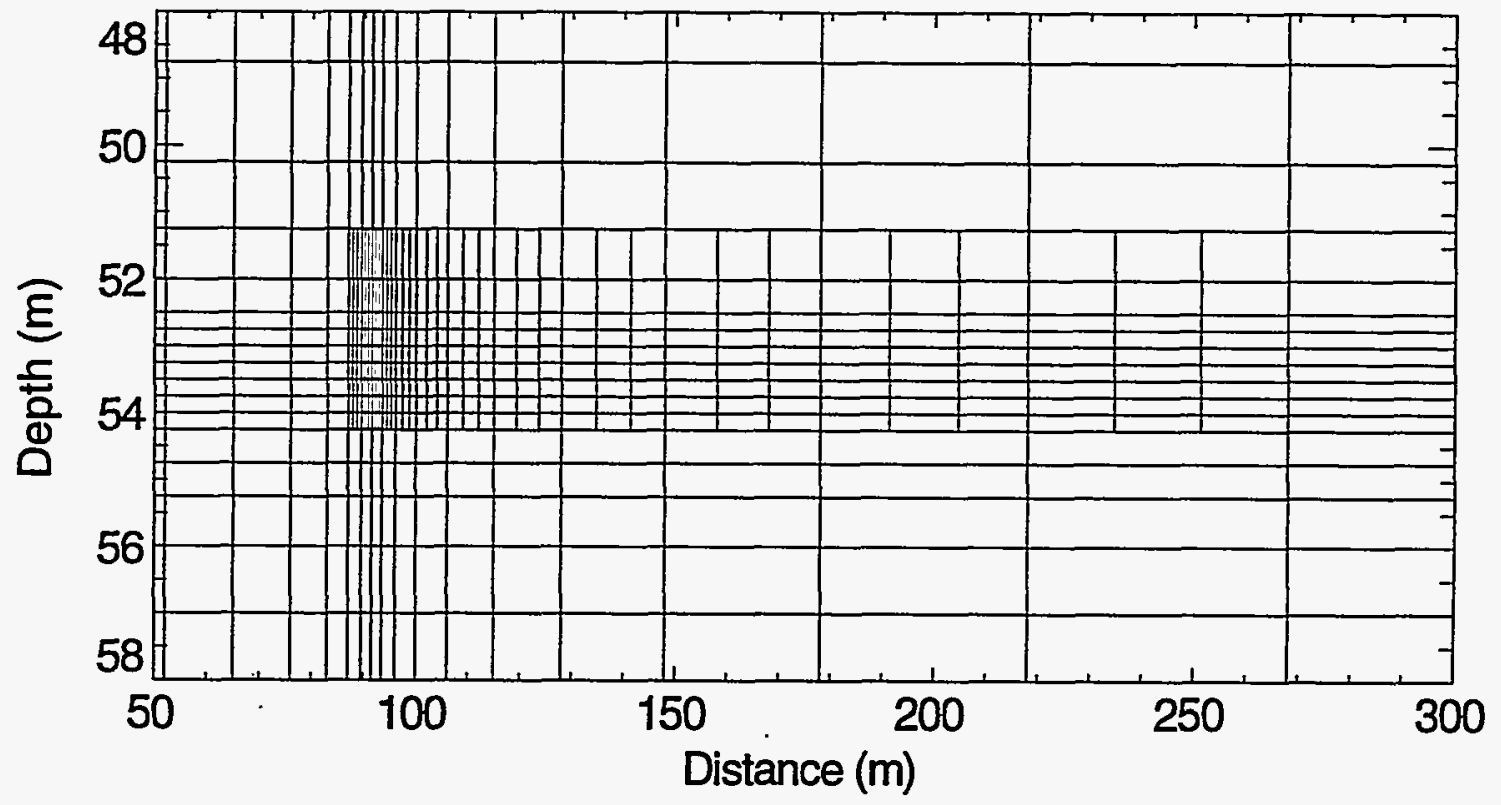

Figure 6. TETRAD computational grid for infiltration basin simulation.

$2 \mathrm{~m}$ grid blocks at the edge of the infiltration basin. Beyond the edge of the infiltration basin, the grid block sizes was scaled up to a maximum of $72 \mathrm{~m}$ at the outer edge of the simulation domain.

The vertical discretization consisted of 0.25 -m grid blocks within the surficial sediments, and at the interfaces between the surficial sediment, basalt, and interbed. Grid refinement is typically useful in areas containing large hydraulic discontinuities, such as at these interfaces. Such refinement also improves accurate simulation of the development of perched water bodies. The 
0.25-m resolution was required above the basalt/interbed interface in order to be able to see the rise in perched water in the simulation results. Within the basalt portion of the simulation domain, the maximum grid block size was $10 \mathrm{~m}$. Limited optimization was performed to see what size grid block could be used and still provide stable solutions. While $10 \mathrm{~m}$ was not the largest grid size that was successful in this regard, it was the largest grid size that could be used and still allow for reasonable transitions in size down to the $0.25-\mathrm{m}$ grid blocks at the interfaces. If more vertically extensive regions of basalt were to be simulated, it is likely that larger grid block sizes could be used. The maximum grid block size within the interbed was $5 \mathrm{~m}$.

For the dual-porosity formulation, a complete fracture domain was required throughout the simulation domain. This implies that fractures are present in the interbed and surficial sediments. These portions of the fracture domain were assigned the same hydraulic properties as the sediments, making them mathematically equal to the sediments. The dual-porosity approach results in twice the number of computational grid blocks as the single porosity simulations since there are two continua (Warren and Root, 1963).

The simulations were run for 60 days following the onset of ponding. This covered the bulk of the period when sampling occurred.

\subsection{Constitutive Relationships}

Relationships are required to describe the interaction between capillary pressure, saturation, and relative permeability for each material type used in the simulation domain. For the sediments and for the basalt matrix, van Genuchten (1980) equations from the soil physics literature were the basis for the constitutive relationships. The two-phase van Genuchten constitutive equations as adapted by Parker et al. (1987) with slight modifications to the normalized saturations terms were used. The resulting constitutive relation equations used in this simulation study are:

$$
\begin{gathered}
\bar{S}_{w}=\frac{S_{w}-S_{w r}}{1-S_{w r}} ; \quad \bar{S}_{a}=\frac{S_{a}-S_{a r}}{1-S_{a r}} \\
P_{c a w}=\frac{\rho_{f w} g}{\alpha}\left[\left(1-\bar{S}_{a}\right)^{1 / \gamma}-1\right]^{1 / \beta} \Leftrightarrow \bar{S}_{a}=1-\left[1+\left(\frac{\alpha P_{c a w}}{\rho_{f w} g}\right)^{\beta}\right]^{-\gamma} \\
k_{r w}=\left(\bar{S}_{w}\right)^{1 / 2}\left[1-\left[1-\left(\bar{S}_{w}\right)^{1 / \gamma}\right]^{\gamma}\right]^{2} . \\
k_{r a}=\left(\bar{S}_{a}\right)^{1 / 2}\left[1-\left(1-\bar{S}_{a}\right)^{1 / \gamma}\right]^{2 \gamma}
\end{gathered}
$$

where

$S_{w}$ and $S_{a}=$ water and air saturations,

$S_{w r}$ and $S_{a r}=$ residual water and air saturations,

$P_{c \text { aw }}=$ capillary pressure between air and water $(\mathrm{kPa})$, 
$\alpha=$ curve fitting parameter $\left(\mathrm{m}^{-1}\right.$ of water) inversely related to the air entry potential, $\beta=$ curve fitting parameter, affects nonlinearity of characteristic curve (dimensionless),

$\gamma=1-1 / \beta$,

$\rho_{f w}=$ fresh water density $\left(\mathrm{kg} / \mathrm{m}^{3}\right)$,

$g=$ gravitational acceleration $\left(\mathrm{m} / \mathrm{s}^{2}\right)$, and

$k_{r w}$ and $k_{r a}=$ water and air relative permeability.

These constitutive relations are implemented in the simulation study through the use of tabular input functions. An external numerical code was written that generated the tabular input and required as input the porosity, the residual saturation, and the van Genuchten parameters ( $\alpha$ and $\beta$ ). These constitutive relation equations have also been extended to three-phase simulations by Parker et al. (1987) through use of scaling relationships based on interfacial tensions. Adapting the hydraulic descriptions obtained in this study to three-phase constitutive relationships requires finding the correct interfacial tensions from the literature.

Determining constitutive relationships for fractures continues to be an active research area. A Brooks-Corey (1966) analytical formulation was used to describe the constitutive relationships for the fractures. The general Brooks-Corey formulas implemented in TETRAD are

$$
\begin{gathered}
P_{c a w}=A_{a w}\left(1-S_{w}\right)^{B_{a w}} \\
k_{r i}=A_{i}\left(\left(S_{i}-S_{i r}\right) /\left(1-S_{i r}\right)\right)^{B_{i}}
\end{gathered}
$$

where

$P_{c \text { aw }}=$ capillary pressure between air and water $(\mathrm{kPa})$,

$k_{r i}=$ relative permeability of any phase $i$,

$S_{i}$ and $S_{i r}=$ saturation and residual saturation of any phase $i$, and

$A_{a w}, B_{a w}, A_{i}, B_{i}$, are fitting parameters for the various curves.

The capillary pressure curve for clay was obtained through use of Leverett-j scaling relationships (Leverett, 1941) applied to the sediment capillary pressure curves.

This section presented only the form of the equations for the constitutive relationships. The parameterization of the equations is discussed below in the methodology and parameterization section.

\subsection{Boundary Conditions}

Boundary conditions are necessary at all the exterior surfaces of the simulation domain. The inner boundary was treated as a no-flux boundary due to symmetry. Likewise, the outer radial boundary was also treated as a no-flux boundary because water movement at this boundary was strictly 
vertical. The bottom boundary was essentially a prescribed moisture content/capillary pressure boundary. The effective volume of the bottom row of grid blocks was increased by a factor of 10000 to provide almost infinite storage. In this fashion, whatever was specified in the bottom row of grid blocks as the initial conditions for saturation was maintained throughout the simulation. The upper boundary condition consisted of prescribing atmospheric pressure on the top surface of the simulation domain and no-flux everywhere else. This allowed air to exit the simulation domain as the infiltrating water pushed the air ahead of the wetting front.

Infiltration was treated as an internal source adjacent to the upper boundary. The rate of infiltration was varied to simulate the effect of ponding within the basin. The background infiltration rate prior to ponding was assigned a value of $0.01 \mathrm{~m} / \mathrm{yr}$. This was within the range of infiltration rates for undisturbed sediments at the INEL estimated by Cecil et al. (1992).

Infiltration rates during the experiment were estimated to range from $1.42 \times 10^{-3}$ to $2.35 \times 10^{-3}$ $\mathrm{gal} / \mathrm{min} / \mathrm{ft}^{2}$ with a time-weighted average infiltration rate during ponding estimated to be $1.99 \times 10^{-3} \mathrm{gal} / \mathrm{min} / \mathrm{ft}^{2}$ (Starr and Rohe, 1995). This rate was not actually constant due to time periods when water was not supplied to the basin; however, it serves the purpose for this study. This average rate is equivalent to 0.12 meters of water per day. This rate was applied from time 0.0 days to 35.5 days, the approximate time the pond went dry and excess water stopped infiltrating. After 35.5 days, the simulated infiltration rate within the basin reverted to the background infiltration rate of $0.01 \mathrm{~m} / \mathrm{yr}$ for the duration of the 60 day simulation. The infiltration rate outside the basin was always left constant at the background infiltration rate.

Evaluation of conservative tracer transport was included by keeping track of the types of water infiltrating in the simulation. A "clean" water infiltrated from day 0 through day 5 . Then a different "tagged" water infiltrated from day 6 through 16, inclusive. Then "clean" water again infiltrated from day 17 through 35.5. In the simulation, the liquid phase mass or mole fractions of tagged water represented the tracer concentration normalized to the initial tracer concentration at any location. This simulated tracer concentration was compared to the observed BTC results for the B ring monitoring locations.

\subsection{Methodology and Parameterization}

Calibration was performed in this simulation study by the direct trial-and-error method. That is, the model was parameterized as best possible, and run to mimic the infiltration experiment. Simulation results were then compared against the observed calibration targets, and certain parameters were varied using judgement, and then the process was repeated. The comparisons were graphical in nature, which allowed for a certain degree of subjectivity. Automated inverse modeling simulation codes exist, but these are primarily for saturated flow and transport. Given the number of parameters that would have to be varied, it was not deemed practical to attempt use of the automated methods for variably saturated flow. Another benefit of using the direct trial-and-error approach is that it allowed experience to be gained as to which were the most sensitive parameters as part of the calibration process.

It is important to keep in mind that inverse modeling in general does not yield unique solutions. This was the case in this simulation study. The method used in this study was to first calibrate 
model parameters in order to match the $\mathrm{B}$ and $\mathrm{C}$ ring hydrographs. It was found that there were multiple combinations of parameters that would yield reasonable matches to the observed perched water hydrographs. Then the evaluation of the tracer BTCs was included, and the number of possible combinations was reduced.

The overall guiding principle used in this modeling study was to obtain a simulation that matched the general character of the field test results while modifying a minimum number of parameters. For this reason not all parameters were treated as variable in order to improve the simulation agreement. The following two sections discuss those parameters that were fixed, why they were treated as constant, and either the information source upon which the parameters were based or how the values were assumed. Following that, the parameters that were varied during the simulation process are discussed along with the sources for the initial estimates.

\subsubsection{Constant Parameters}

Since the focus of this simulation study was to determine hydrologic descriptions for the fractured basalts, the hydrologic properties of the surficial sediments and the sedimentary interbed were generally kept constant. As part of the calibration process, it became obvious that a low permeability layer was necessary at the basalt/interbed interface for the simulations to result in the observed spreading of perched water.

Table 4 contains the hydrologic parameters that were treated as constant in the simulation study, the values used, and the source for the value. The surficial and interbed sediment hydrologic parameters were assigned default values from the GWSCREEN manual (Rood, 1994). This was appropriate since they were not the focus of either the field test or simulation study. For purposes of this study, the surficial sediments were only important for conveying the right amount of water into the fractured basalt portion of the simulation domain in a timely manner. The GWSCREEN default hydrologic description was sufficient for this purpose.

Although there are no universally accepted constitutive relationships for fractures, it is obvious that fractures conduct more water when they are wet than when they are dry. In other words, the relative permeability to water approaches 1.0 when the saturation approaches 1.0 . Likewise, the relative permeability to water approaches 0.0 as the water saturation approaches 0.0 . The shape of the relative permeability curve between these two endpoints is unknown. For purposes of this study, it was assumed to be linear for water.

The capillary pressure curve assigned actually only results in only slight capillary forces within the fracture. Gravity dominates by comparison. Vertical one-dimensional simulations (not presented in this report) were performed with just the fracture domain alone to obtain a reasonable advance of a wetting front under ponding conditions. In these simulations, it was found that if the capillary pressure curve was defined such that capillary forces were significant, too much water was "wicked" down the fractures and the wetting front always advanced too fast. Additionally, it was found that the capillary pressure cutoff term $\left(A_{\text {ow }}\right)$ being set to $32 \mathrm{kPa}$ resulted in the least number of computational steps to reach an initial steady-state solution.

Multiphase simulators such as TETRAD also require input for component densities in each of the phases present (gaseous and aqueous in this case). Default values were utilized for these 
Table 4: Hydrologic parameters treated as constant.

\begin{tabular}{|c|c|c|}
\hline Parameter & Value & Source \\
\hline \multicolumn{3}{|c|}{ Surficial and Interbed Sediments } \\
\hline$k_{s}$ & $\begin{array}{l}78 \text { milliDarcy } \\
(\mathrm{mD}), \text { isotropic }\end{array}$ & GWSCREEN sediment default (Baca et al., 1992) \\
\hline$\theta$ & $0.487 \mathrm{~cm}^{3} / \mathrm{cm}^{3}$ & GWSCREEN sediment default \\
\hline$S_{w r}$ & 0.292 & GWSCREEN sediment default \\
\hline$S_{a r}$ & 0.0 & assumed \\
\hline$\alpha$ & $1.066 \mathrm{~m}^{-1}$ & GWSCREEN sediment default \\
\hline$\beta$ & 1.523 & GWSCREEN sediment default \\
\hline \multicolumn{3}{|l|}{ Basalt Matrix } \\
\hline$\theta$ & $0.228 \mathrm{~cm}^{3} / \mathrm{cm}^{3}$ & GWSCREEN basalt default (Bishop, 1991) \\
\hline$S_{w r}$ & 0.066 & GWSCREEN basalt default \\
\hline$S_{a r}$ & 0.0 & assumed \\
\hline$\alpha$ & $3.840 \mathrm{~m}^{-1}$ & GWSCREEN basalt default \\
\hline$\beta$ & 1.474 & GWSCREEN basalt default \\
\hline \multicolumn{3}{|l|}{ Basalt Fractures } \\
\hline$A_{a w}$ & $32 \mathrm{kPa}$ & assumed \\
\hline$B_{a w}$ & 1.5 & assumed \\
\hline$A_{w}$ & 1.0 & assumed \\
\hline$B_{w}$ & 1.0 & assumed to be a linear function \\
\hline$S_{w r}$ & 0.0 & assumed, allows complete drying \\
\hline$A_{o}$ & 0.0 & assumed, no oil present \\
\hline$B_{o}$ & 1.1 & assumed, no oil present \\
\hline$S_{\text {or }}$ & 0.0 & assumed, no oil present \\
\hline
\end{tabular}


Table 4: Hydrologic parameters treated as constant.

\begin{tabular}{|c|c|c|}
\hline Parameter & Value & Source \\
\hline$A_{a}$ & 1.0 & assumed \\
\hline$B_{a}$ & 1.2 & assumed to be slightly nonlinear \\
\hline$S_{a r}$ & 0.0 & assumed, allows complete wetting \\
\hline \multicolumn{3}{|l|}{ Other } \\
\hline$\rho_{f w}$ & $1000 \mathrm{~kg} / \mathrm{m}^{3}$ & literature value \\
\hline $\begin{array}{l}\text { characteristic } \\
\text { matrix block length }\end{array}$ & $2 \mathrm{~m}$ & Knutson et al. (1992) \\
\hline
\end{tabular}

parameters. The water component was allowed to partition into the gaseous phase according to default relationships. Compressibility within phases is calculated internally from an equation of state. Since the viscosity for air in the gaseous phase is low compared to water in the liquid phase, the implication is that any air present in the gaseous phase would be able to easily move ahead of the wetting front in order for water to be able to occupy the region.

The basalt matrix hydrologic description is also taken from the GWSCREEN default parameters for basalt. This default description was based on an analysis of vesicular basalt cores (Bishop, 1991). The GWSCREEN default basalt permeability was not used. This parameter was treated as a variable in those simulations that used a dual porosity conceptual model.

In a dual porosity model, two separate mathematical continua representing the matrix and the fracture domains are treated as if they coexist in the same physical domain (Warren and Root, 1963). A matrix-fracture interaction term describes the ability of fluids to move between the continua. The magnitude of the interaction term, which is comprised of physical and numerical components, dictates the relative degree of interaction between the continua. Physical parameters affecting the interaction term are the average or characteristic matrix block length, which is the distance between fractures, the characteristic fracture aperture, and matrix-matrix interaction. The characteristic block length was assigned an intermediate value from a range of fracture spacings reported in Knutson et al. (1992).The fracture aperture is used in calculating a harmonic effective permeability between the fracture and matrix domains. The characteristic fracture aperture was set to zero which implied the matrix permeability alone controlled water movement into the matrix. Matrix-matrix interaction across fractures was set to 0.5 for each orthogonal direction which allowed partial contact between matrix blocks.

The effective area through which water and tracer could move was treated as variable by modifying the effective porosity of the fracture continua. It is also useful to note that even though this is an axi-symmetric simulation, the use of a constant matrix block length does not mean that the model is solving for flow and transport in a series of concentric fractures away from the infiltration basin. The characteristic block length is used in the context of orthogonal fracture planes for determining 
Table 5: Hydrologic parameters treated as variable.

\begin{tabular}{|c|c|c|}
\hline Parameter & Value & Source \\
\hline \multicolumn{3}{|l|}{ Basalt Fractures } \\
\hline$\theta_{b}$ & 0.01 to 0.05 & Porro and Bishop, 1995 \\
\hline$k_{v, b}($ vertical $)$ & anything & assumed \\
\hline$k_{h, b}$ (horizontal) & anything & assumed \\
\hline \multicolumn{3}{|l|}{ Basalt Matrix } \\
\hline$k_{b m}$ (isotropic) & 0.1 to $10 \mathrm{mD}$ & Knutson et al., 1992 \\
\hline \multicolumn{3}{|l|}{ Clay } \\
\hline$k_{c}$ & 0.1 to $1 \mathrm{mD}$ & $\begin{array}{l}\text { upper bound of clay permeability (Freeze and } \\
\text { Cherry, 1979) }\end{array}$ \\
\hline
\end{tabular}

effective degree of interaction.

\subsubsection{Variable Parameters}

The primary parameters adjusted as part of the calibration process were the permeability and the porosity of the basalt fractures. The fracture permeability was allowed to be anisotropic $\left(k_{v, b}\right.$ and $\left.k_{h, b}\right)$. Keep in mind that the fractures were treated as if they were a continuum and not discrete fractures. The fracture porosity $\left(\theta_{b}\right)$ refers to the portion of the continuum that acts as fractures. This value was allowed to range from 0.01 to 0.05 . This range was assigned in part based on an estimated "wetted volume fraction"'or porosity for the fractured basalts of 0.02 (Porro and Bishop, 1995). The basalt matrix permeability $\left(k_{b m}\right)$ was sometimes treated as a variable when dual porosity simulations were performed. The values assigned ranged from 0.1 to $10 \mathrm{mD}$. This is well within the range of reported basalt matrix permeabilities (Bishop, 1991: Knutson et al., 1992).

Lastly, as referred to earlier, it was necessary to include a low permeability clay layer $\left(k_{c}\right)$ at the top of the sedimentary interbed. The permeability of this clay was used to refine the agreement of the simulation results to the perched water hydrographs at the $\mathrm{B}$ and $\mathrm{C}$ ring locations. Table 5 summarizes the parameters treated as variable in the calibration exercise as well as the range of values over which the parameter might reasonably be expected to vary.

\subsection{Initial Conditions}

Once all the parameters were defined for a particular calibration attempt, initial conditions had to be obtained. Initial conditions in this sense apply to just before ponding began in the infiltration test and refer primarily to the water saturations at each grid block in the simulation domain. This time is referred to as time 0 days for the duration of this report. Determining initial conditions was actually a two-stage process. In general, a vertical one-dimensional simulation representing a single column of computational grids from the two-dimensional simulation was used. The 
hydraulic properties were assigned as they were going to be assigned for the two-dimensional simulation. Then the one-dimensional simulation was run to steady-state conditions with the background infiltration rate of $0.01 \mathrm{~m} / \mathrm{yr}$. This resulted in a saturation profile that was in equilibrium with the background infiltration rate. The saturation in each of the individual grid blocks from the one-dimensional simulation was then used over the entire corresponding layer in the two-dimensional simulation.

Pressures were initialized for each simulation assuming vapor-static equilibrium. The top surface of the domain was set to atmospheric pressure, and the pressure field was assigned from the density of air. 


\section{CALIBRATION RESULTS}

The calibration results are discussed in two sections. The order of discussion approximately follows the order in which the calibrations were performed. First, comparisons to the observed advance of the wetting front and to the perched water hydrographs for the B and C ring wells are discussed followed by the comparison to the observed B ring concentration BTCs.

\subsection{Wetting Front Advance and Hydrograph Comparison.}

Initially, it was thought that the wetted porosity of 0.02 for the fractured basalt estimated by Porro and Bishop (1995) was too low. This number was considerably less than traditional estimates of basalt formation porosities which range from 0.05 to 0.15 (Robertson, 1974; Rood et al., 1989; McCarthy and Neupauer, 1993). So the low end from the traditional range (0.05) was used as the effective porosity for the fractured basalt portion of the domain in a single porosity simulation. A series of runs were made in which first the fracture vertical permeability $\left(k_{v, b}\right)$ was adjusted to match the observed advance of the wetting front. Using $k_{v, b}=250 \mathrm{mD}$ provided the best agreement to the first arrival of the wetting front. However, as part of the calibration to the hydrographs, it was found that using a higher fracture vertical permeability $\left(k_{v, b}=300 \mathrm{mD}\right)$ improved the agreement in perched water arrival at the B ring location. Figure 7 shows the simulated water saturation history just above the basalt/interbed interface at the first radial grid block using $k_{v, b}=300 \mathrm{mD}$. This wetting curve indicates the advance of the simulated wetting front to the interbed. While the first arrival of water at the interbed is not exactly within the range of $+/$ - one standard deviation of the calibration target, it is close.

The fracture horizontal permeability $\left(k_{h, b}\right)$ was then adjusted in order to match the observed hydrographs at the $B$ and $C$ ring locations. It was during this series of runs that it became necessary

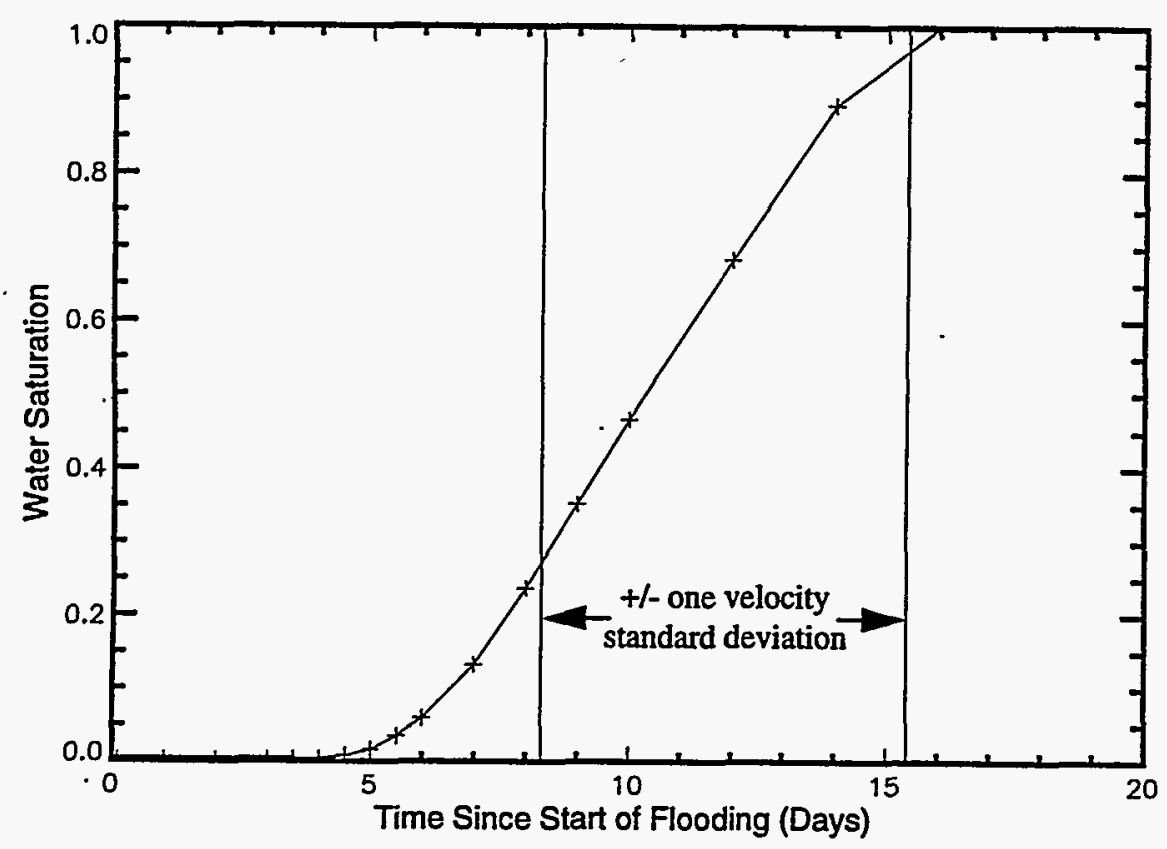

Figure 7. Wetting history at interbed for $\theta_{b}=0.05$ 
to assign a comparatively low permeability layer $(1 \mathrm{mD})$ at the top of the interbed in order to allow perched water to spread laterally to the $C$ ring location. Without this layer, perched water would form beneath the basin but would not spread to the $C$ ring location. It was necessary to increase the fracture horizontal permeability $\left(k_{h, b}\right)$ to $90,000 \mathrm{mD}$ in order to mimic the observed hydrograph at the $\mathrm{C}$ ring well location. Figure 8 shows the comparison between the observed and simulated perched water hydrographs for both the single and dual porosity conceptual models for an effective basalt fracture porosity of 0.05 . The dashed line indicates the interface between fractured basalt and the interbed. The elevation of perched water in the simulation results was considered to be a point with water saturation above 0.98 . The 0.98 level was chosen in part because the simulation results became slightly "noisy" as saturations approached 1.0. In the dual porosity model, the permeability of the basalt matrix was adjusted to improve the fit. The resulting basalt matrix permeability $\left(k_{b m}\right)$ was $0.5 \mathrm{mD}$. The simulated locations are at the centers of grid blocks and do not exactly correspond to the radial distances in the field. The simulated $\mathrm{B}$ and $\mathrm{C}$ ring locations are 107.5 and $184.6 \mathrm{~m}$ from the center of the basin, while the actual locations are more on the order of 107 and $183 \mathrm{~m}$, respectively. Given the objective of mimicking general behavior, these slight differences in location are minor.

While the agreement between the simulated and observed hydrographs in Figure 8 appears quite good, it should be recognized that the set of model parameters that resulted in this fit is only one of several possible combinations. Non-uniqueness is a problem inherent to inverse modeling. To illustrate this nonuniqueness, a series of calibration runs was performed using effective fracture domain porosities of 0.03 and 0.01 . Figures 9 and 10 illustrate the optimized fits for both single and dual porosity conceptual models for the effective fracture porosities of 0.03 and 0.01 , respectively.

Although the agreement for each of these optimized fits is subjective, it can be said that in each case, the models mimic the general behavior. In each simulation, the arrival of perched water at the $B$ ring location is very close (within $\sim 1$ day). The simulated arrival at the $C$ ring locations is always faster than the observed. This is undoubtedly in part due to variations in the elevation of the basalt/ interbed interface and actual hydrologic properties, which the model does not capture. Also, in each case the simulated hydrograph at the B ring location drops off quicker than the observed hydrograph. Even so, it can be concluded that the general behavior is represented.

Table 6 summarizes the optimized hydraulic properties for each of the simulations. The order in which the runs were performed can be seen by the changes that occur in fitted parameters. Only the vertical fracture permeability, $k_{v, b}$, was changed in the $\theta_{b}=0.03$ simulations. For the $\theta_{b}=0.01$ simulations, every parameter had to be changed to mimic the observed hydrographs. Reducing the basalt fracture effective porosity reduced the area through which water moves. Accordingly, the fracture vertical permeability had to be reduced to keep the advance of the wetting front to the interbed the same between simulations. For the $\theta_{b}=0.01$ simulation, the need to decrease the permeability of the clay layer and the fracture horizontal permeability illustrates the importance of the hydrologic interaction between the fractured basalt and the interbed. Monitoring emphasis during the field experiment was on water and tracer movement within the fractured basalt at the expense of obtaining information of the movement of water across the interface. In retrospect, this would also have been valuable information to collect. 
a)

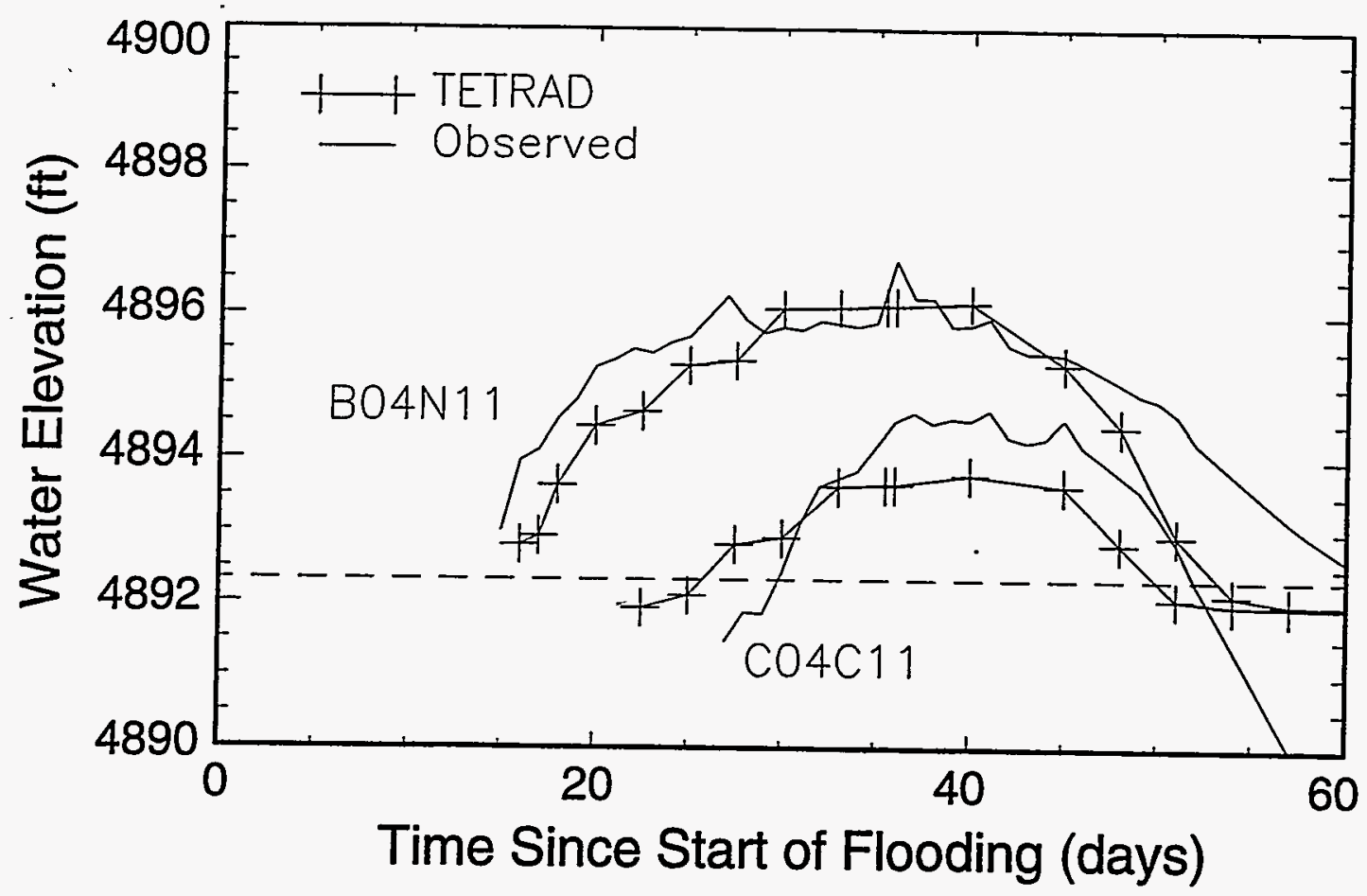

b)

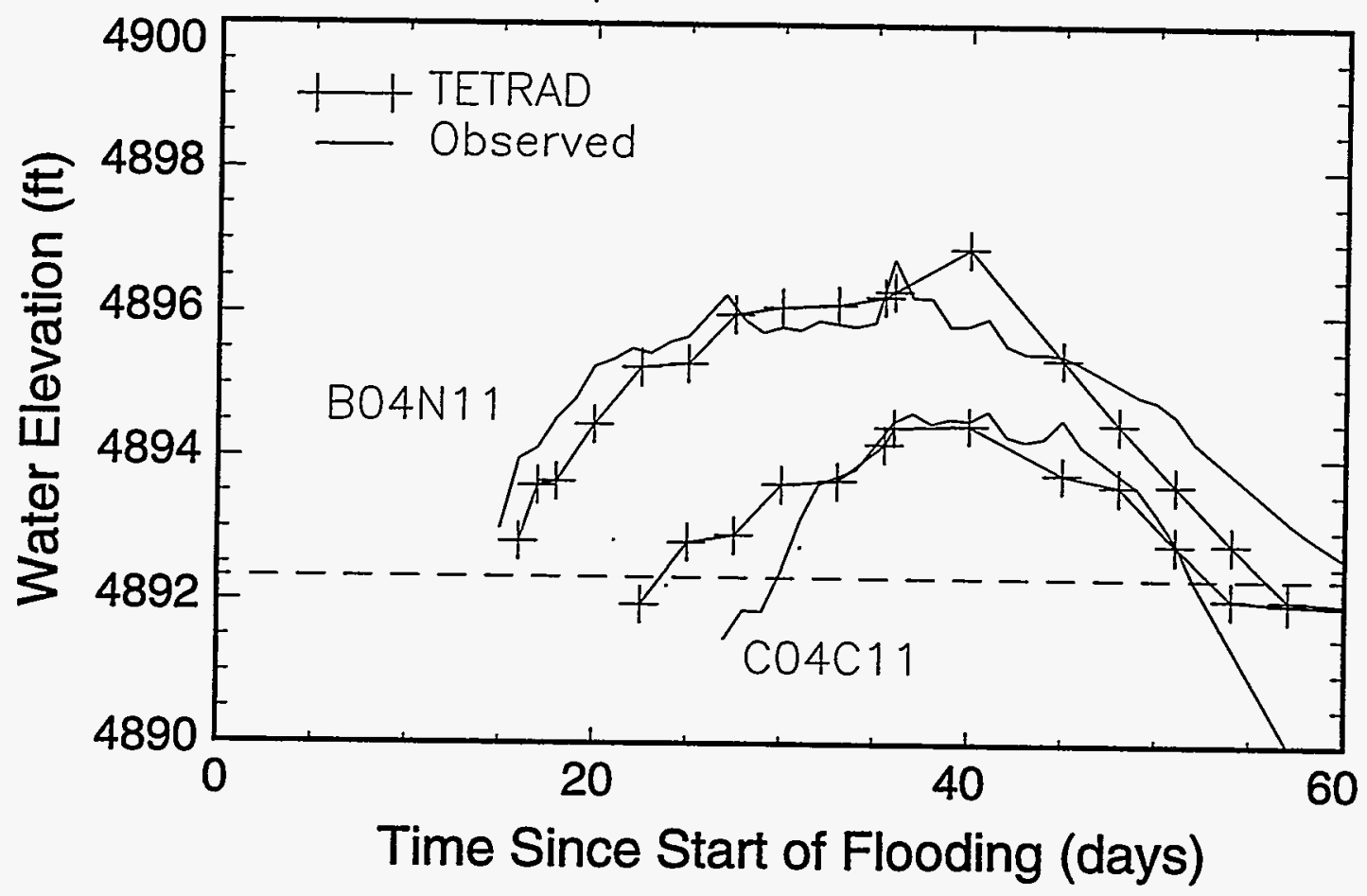

Figure 8. Comparison of simulated and observed hydrographs for $B$ and $C$ ring locations for $\theta_{b}=0.05:$ a) single porosity, b) dual porosity. 
a)

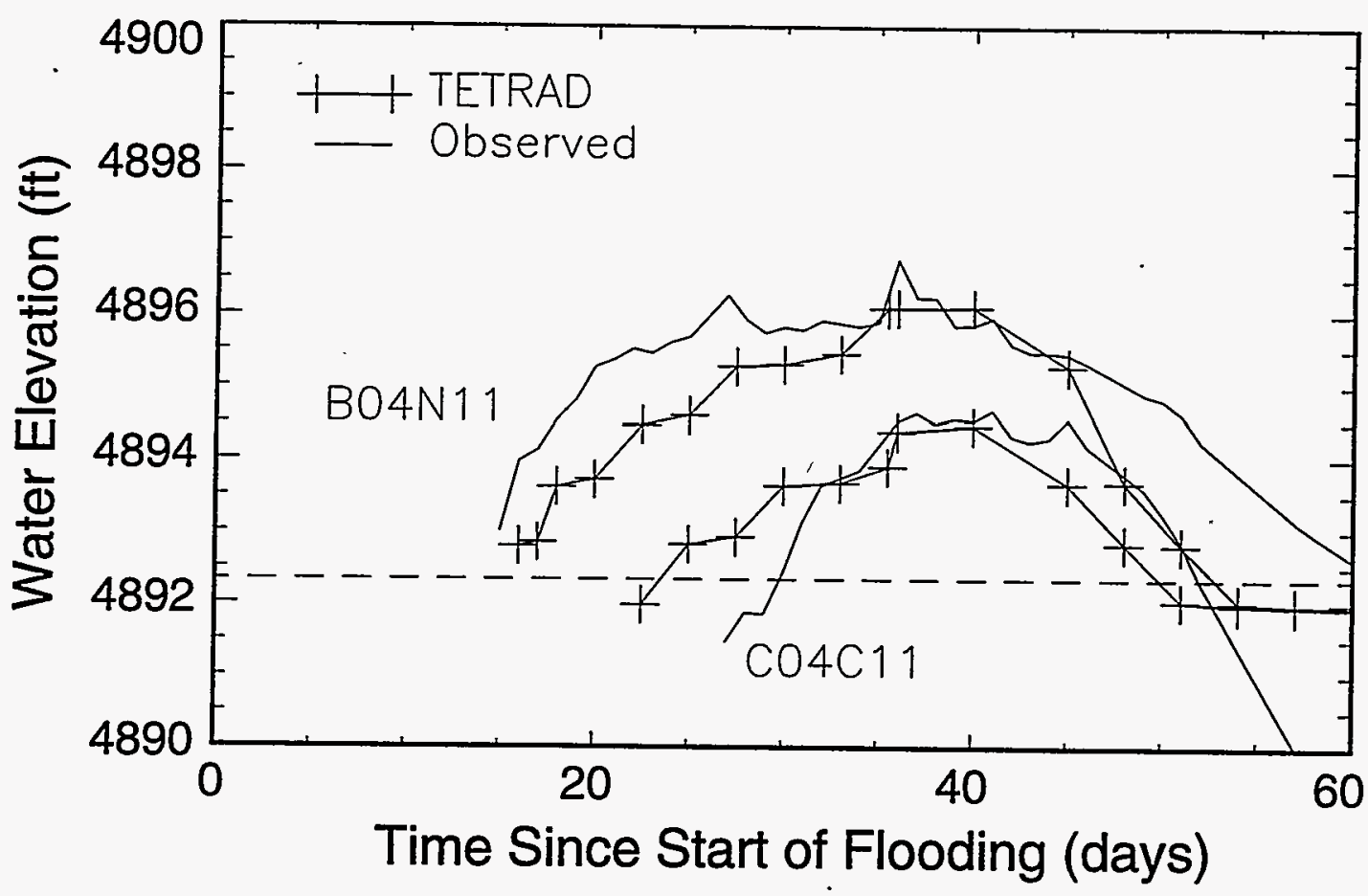

b)

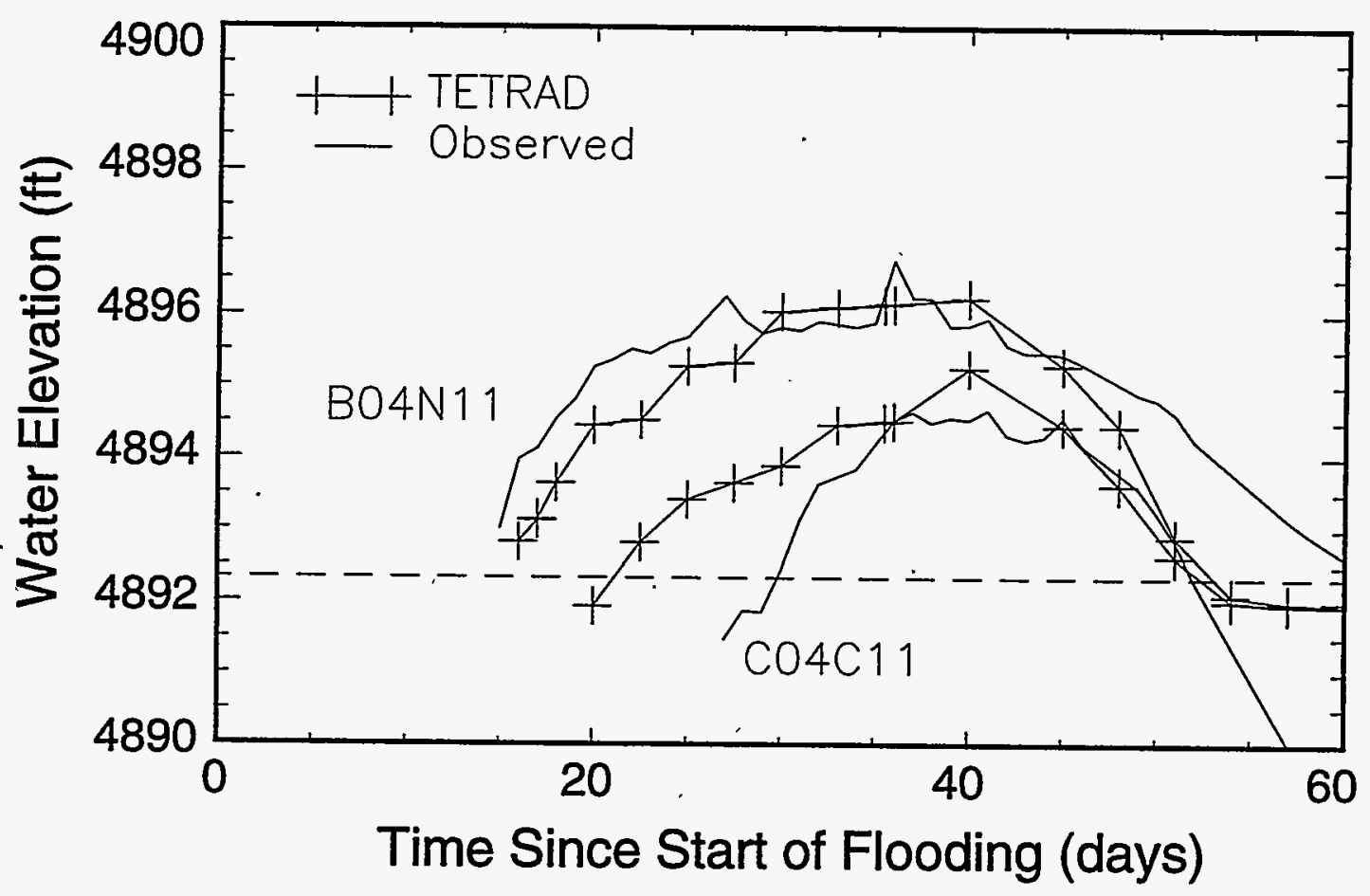

Figure 9. Comparison of simulated and observed hydrographs for $B$ and $C$ ring locations for $\theta_{b}=0.03$ : a) single porosity, b) dual porosity. 
a)

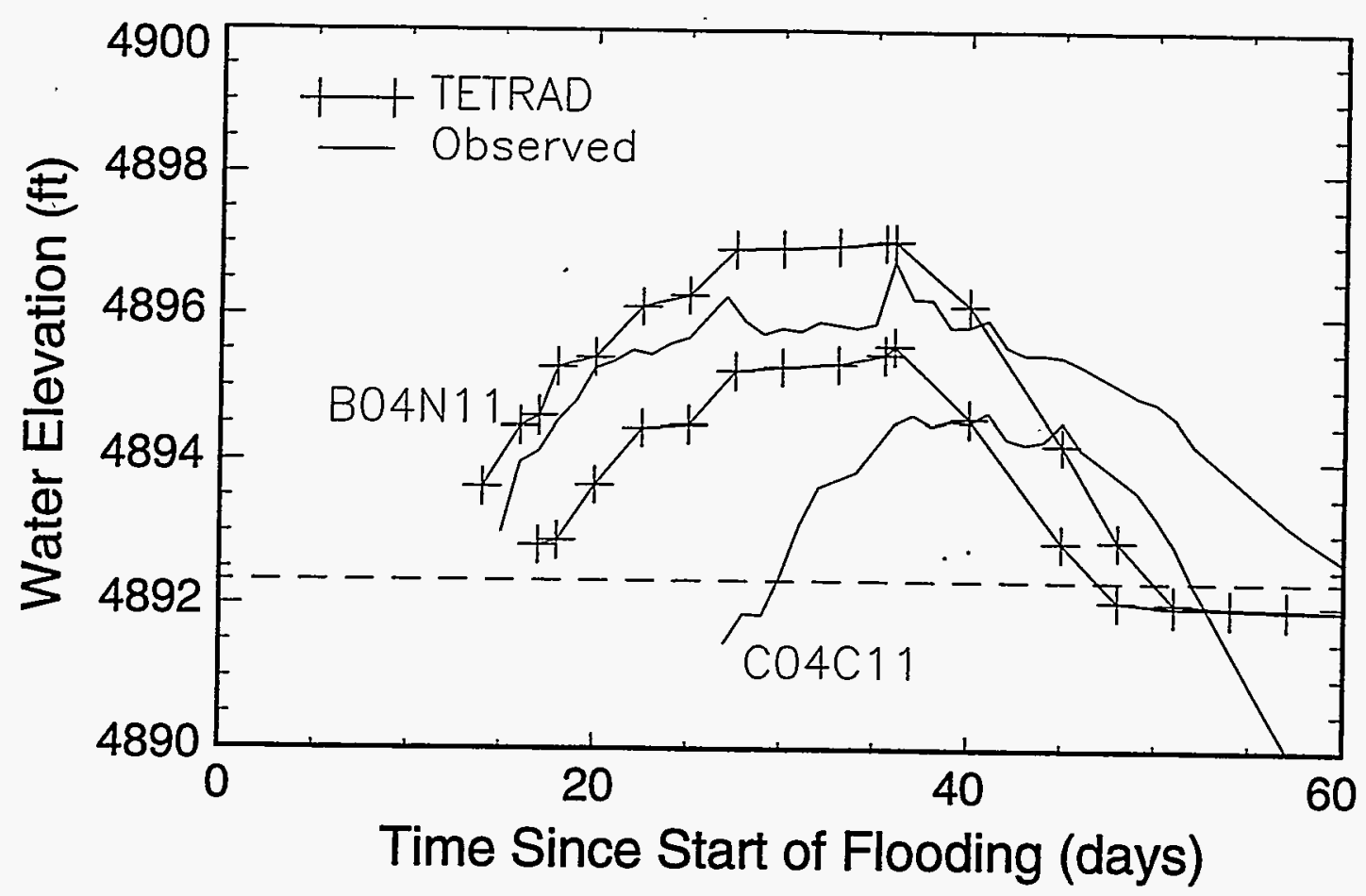

b)

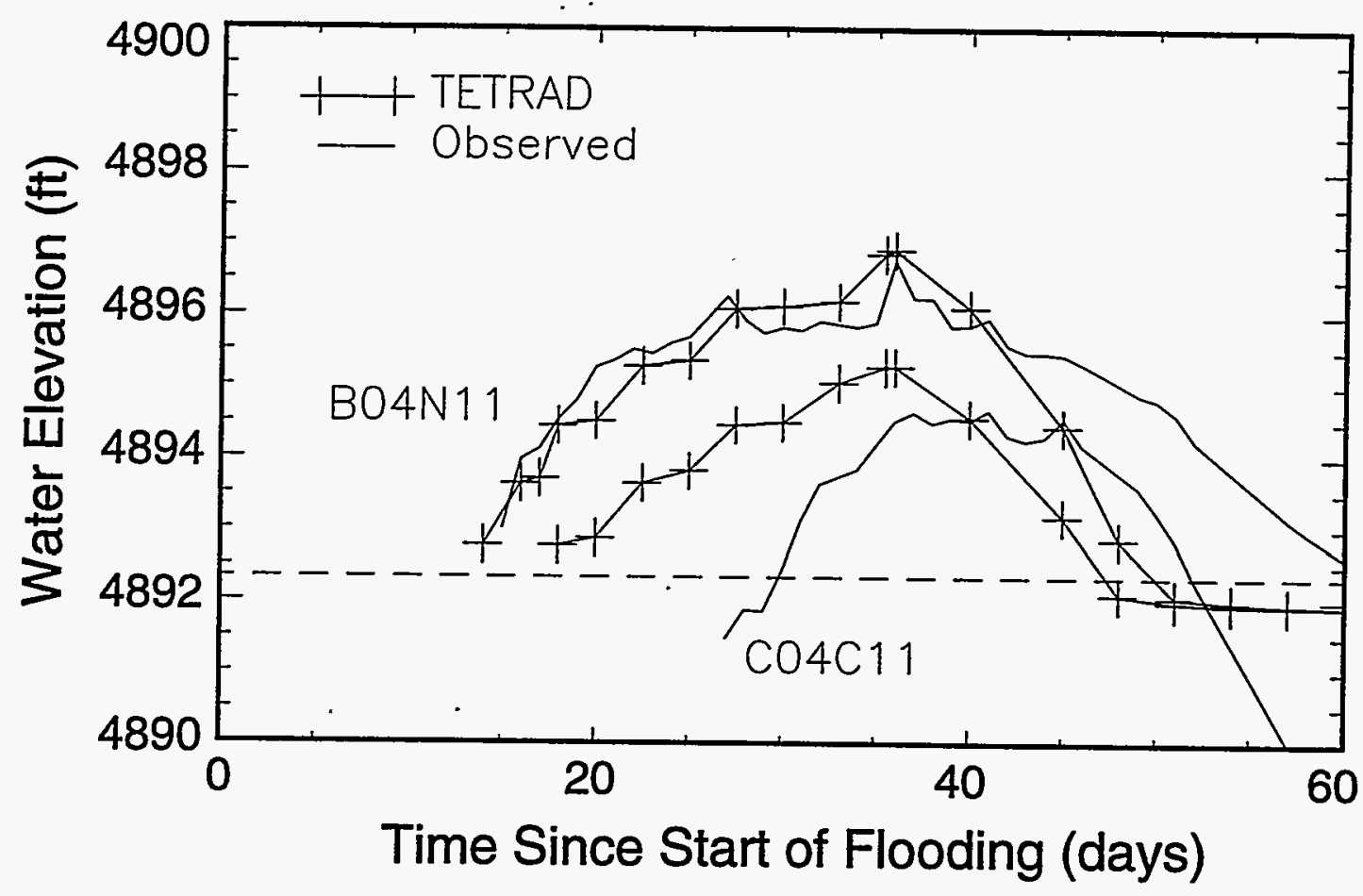

Figure 10. Comparison of simulated and observed hydrographs for $B$ and $C$ ring locations for $\theta_{b}=0.01$ : a) single porosity, b) dual porosity. 
Table 6: Calibration results for variable basalt fracture effective porosity.

\begin{tabular}{|l|l|l|l|}
\hline & \multicolumn{3}{|c|}{$\begin{array}{c}\text { Primary Parameter, Basalt Fracture } \\
\text { Effective Porosity }\end{array}$} \\
\hline \multicolumn{1}{|c|}{ Secondary Parameter } & $\theta_{b}=0.05$ & $\theta_{b}=0.03$ & $\theta_{b}=0.01$ \\
\hline \hline Fracture vertical permeability, $k_{v, b}$ & $300 \mathrm{mD}$ & $175 \mathrm{mD}$ & $50 \mathrm{mD}$ \\
\hline Fracture horizontal permeability, $k_{h, b}$ & $90000 \mathrm{mD}$ & $90000 \mathrm{mD}$ & $40000 \mathrm{mD}$ \\
\hline Clay permeability, $k_{c}$ & $1.0 \mathrm{mD}$ & $1.0 \mathrm{mD}$ & $0.85 \mathrm{mD}$ \\
\hline Basalt matrix permeability (dual porosity), $k_{b m}$ & 0.05 & 0.05 & $0.03 \mathrm{mD}$ \\
\hline
\end{tabular}

In each pair of single and dual porosity simulations, the dual porosity results show a slightly better match to the observed hydrographs. Whether dual porosity should be included in risk and performance assessments is partly a matter of necessity and expedience. The computational burden of including dual porosity is considerable. Average run times on HP700 series workstations were 1.5 hours for the single porosity simulations and 6 hours for the dual porosity simulations. This additional burden does not seem warranted for problems where only contaminants dissolved in water are being considered. The improvement in agreement between single and dual porosity simulations is not that significant. But if volatile organics are being assessed, then dual porosity is potentially of interest, given the ability of vapors to diffuse into and out of the basalt matrix.

Only the four parameters in Table 6 were varied to obtain the match between simulation and observed hydrograph results. It was a matter of judgement that these four parameters were selected to vary in the first place. It was a further judgement that other parameters were not also varied. The use of these hydraulic descriptions in risk assessments at the Subsurface Disposal Area, for example, should be further compared to observed hydrologic behavior observed in the subsurface under ambient flow regimes before decisions regarding disposed waste are finalized.

The use of large horizontal to vertical permeability anisotropy ratios (500:1) in the permeability of the fractured basalt portion domain was necessary in order to mimic the observed results of the infiltration test. Anisotropy ratios close to this order of magnitude are not without precedent for the INEL. Schmalz (1969) presented an analysis of a gas tracer injection test near Test Area North, which was analyzed and required a horizontal to vertical anisotropy ration of 75:1 to match observed results. The observed horizontally-oriented rubble zones beneath the infiltration basin (and the SDA) make anisotropy ratios on the order of those required for this simulation study appropriate.

Given the demonstrated non-uniqueness of the inverse modeling results, it was difficult to determine at this point in the simulation study which set of parameters was best overall at describing the results of the infiltration test. In the next section, the observed conservative tracer BTCs were used to further refine the choice. 


\subsection{B Ring Breakthrough Curve Comparison}

As discussed previously, the history of tracer concentrations at the B ring was the remaining calibration target. The simulated BTCs were obtained in a normalized sense using the mole fractions of tagged (tracer-containing) water. Figure 11 shows six normalized simulated BTCs for . the single and dual porosity simulations with fracture effective porosities of $0.05,0.03$, and 0.01 . Each of these simulations was performed with a longitudinal dispersivity set to $5.0 \mathrm{~m}$ and a transverse dispersivity set to $0.0 \mathrm{~m}$. (The longitudinal dispersivity effects primarily vertical transport in this case.) Shown for comparison as dotted lines are the three nearly-symmetric B ring location BTCs after each was normalized to its own maximum value. As discussed previously, there was some evidence that a portion of the "conservative" tracer precipitated out of solution as it passed through the surficial sediments during the infiltration test. This prevents comparisons to measured concentrations since the total tracer mass was not transported.

The simulation results indicate that the lower the effective basalt fracture porosity, the better the agreement with the general character of the B ring location BTCs. The difference resulted mainly from faster velocities both during vertical movement through the fractured basalt and within the perched water. This faster velocity resulted because, although the advance of the wetting front down to the interbed was kept the same, once near-equilibrium conditions were obtained during ponding, the same prescribed amount of water was moving through a smaller effective area. The faster velocity also resulted in water arriving at the $\mathrm{C}$ ring sooner than was observed. There is a trade-off in the simulations between matching the hydrograph at the $\mathrm{C}$ ring location and the concentration BTCs at the B ring location. Improving the match to the B ring BTCs makes the hydrograph match at the $\mathrm{C}$ ring worse.

There are several possible explanations for this trade-off. First, there are undoubtedly variations in the topography of the basalt/interbed interface and in the hydrologic properties of both the fractured basalt and the interbed that affect the spreading of perched water. None of these features are represented in the model. A second possibility is the previously mentioned hypothesis of Newman and Dunnivant (1995) regarding dead-end fractures. The simulation results of this study tend to support their hypothesis since the simulated breakthrough of water always occurs after the observed breakthrough, indicating that the actual breakthrough resulted from a faster velocity than that for the initial wetting front. While the question of why the C ring hydrograph and B ring BTCs need two different velocities cannot be answered, the solution for this simulation study was to recommend the median result $\left(\theta_{b}=0.03\right)$ with the fracture anisotropy of $k_{v, b}=175 \mathrm{mD}$ and $k_{h, b}=$ $90,000 \mathrm{mD}$ as most appropriate and thereby split the difference between the two calibration targets. Appendix A contains the complete TETRAD input decks for both the single and dual porosity simulations with $\theta_{b}=0.03$.

\subsection{Sensitivity to Calibrated Parameters}

Each of the simulations to this point in the report were performed using a longitudinal dispersivity $\left(\alpha_{l}\right)$ equal to $5 \mathrm{~m}$ and a transverse dispersivity $\left(\alpha_{t}\right)$ equal to $0 \mathrm{~m}$. The longitudinal dispersivity estimate is within a range of 0.1 to $45 \mathrm{~m}$ determined in Dunnivant and Newman (1995) in which dispersivities were estimated based on observed BTCs for each B ring sampling location. The $\alpha_{l}=5 \mathrm{~m}$ value was selected by using the simulated set of properties that best matched the observed $B$ ring hydrograph, varying the dispersivities, and selecting those that resulted in the best overall 
a)

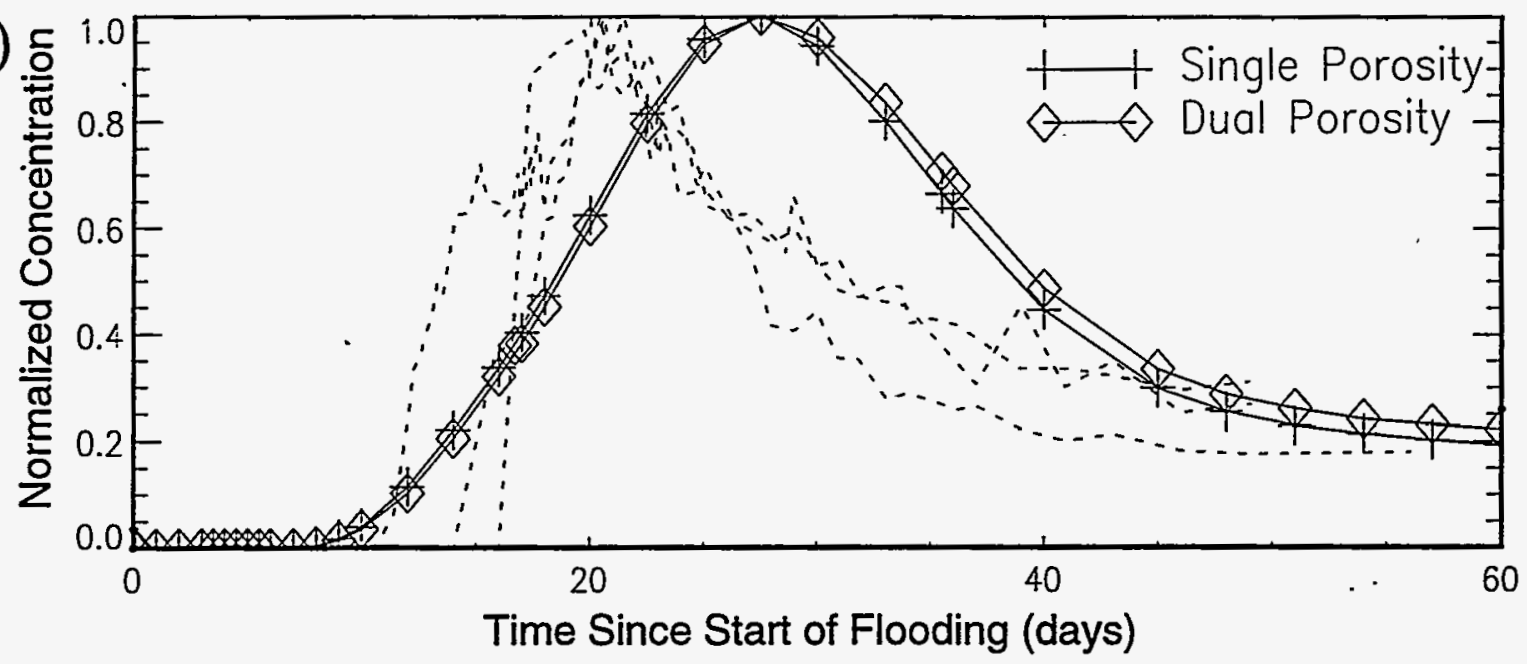

b)

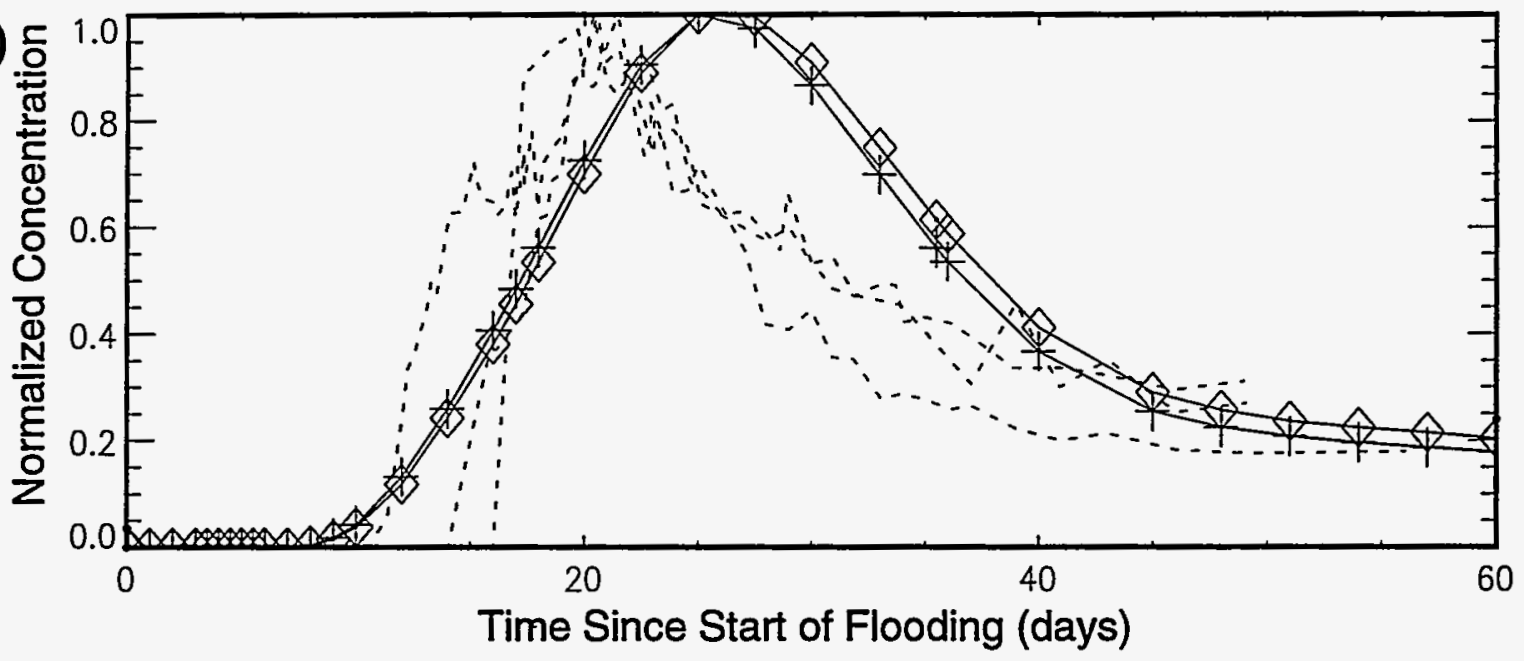

c)

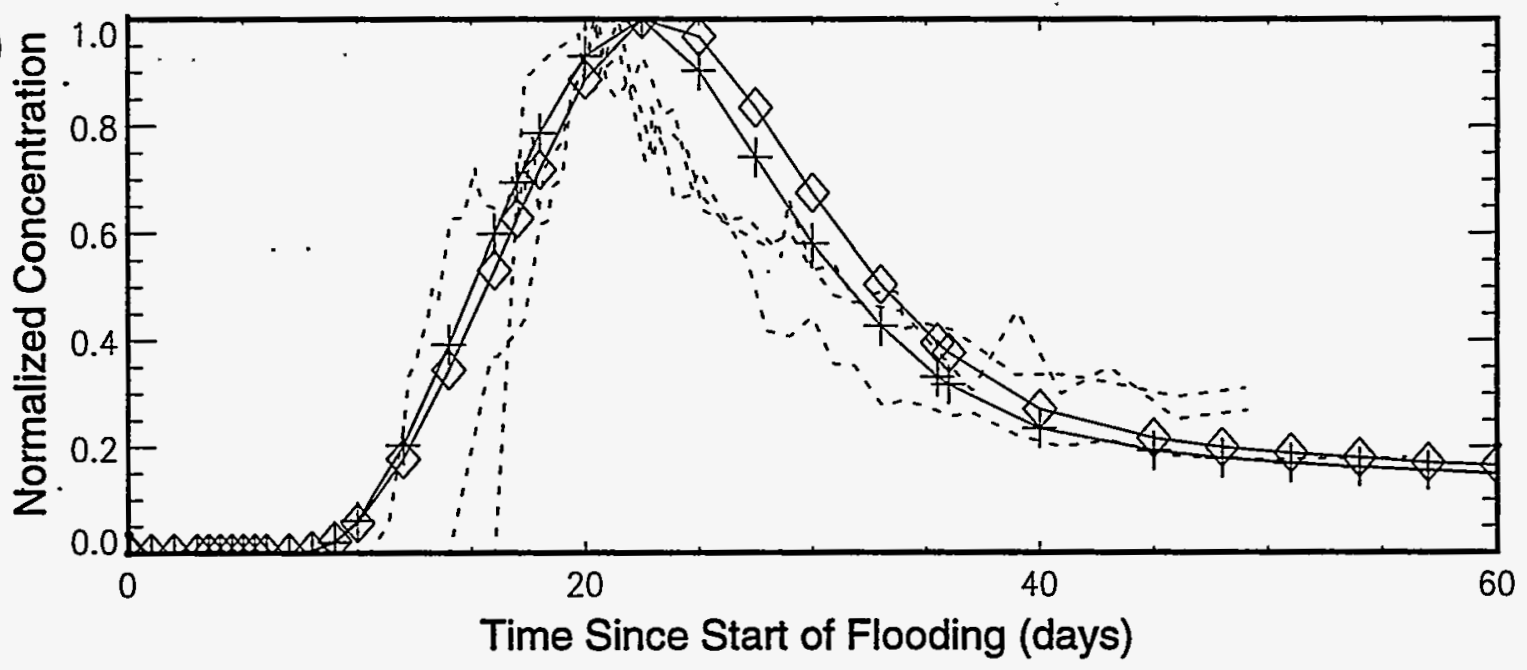

Figure 11. Comparison of simulation BTCs to nearly-symmetric B ring well BTCs (dashed lines) for single and dual porosity models: a) $\theta_{b}=0.05$ b) $\theta_{b}=0.03$, and c) $\theta_{b}=0.01$. 
agreement to the shape of the observed BTCs.

The simulation with the best B ring hydrograph match was judged to be the dual porosity simulation with an effective fracture porosity of 0.05 (see Figure 8). The results of varying the longitudinal and transverse dispersivities from this simulation are shown graphically in Figure 12. Both the normalized ( $a \& c$ ) and non-normalized tracer mole fractions (b \& d) are shown. The top two plots show the effect of varying only longitudinal dispersivity. As can be seen more plainly in the actual tracer mole fractions (which could be converted to concentrations), the classical result of increased dispersion causing a lower peak concentration and increased tailing occurs. In the normalized (a) concentrations, the $\alpha_{l}=1 \mathrm{~m}$ probably matches the general shape of the observed BTCs the best, but it underestimates the degree of tailing. The $\alpha_{l}=5 \mathrm{~m}$ simulation does a better job of mimicking the tailing of the BTCs, and was selected as the more representative value. This selection was in part due to the scale of the measurement location relative to the ground surface in the infiltration basin being greater than $50 \mathrm{~m}$.

The effects of including transverse dispersion in the simulation.are shown in the bottom half of Figure 12 (c \& d). As stated previously, the simulations in this study were vertical two-dimensional axi-symmetric. Including transverse dispersion does not allow mass to disperse in the axial direction. Rather, it could only disperse within the plane of the simulation. Since infiltrating water was not observed outside the confines of a cylinder projected downward from the basin to the
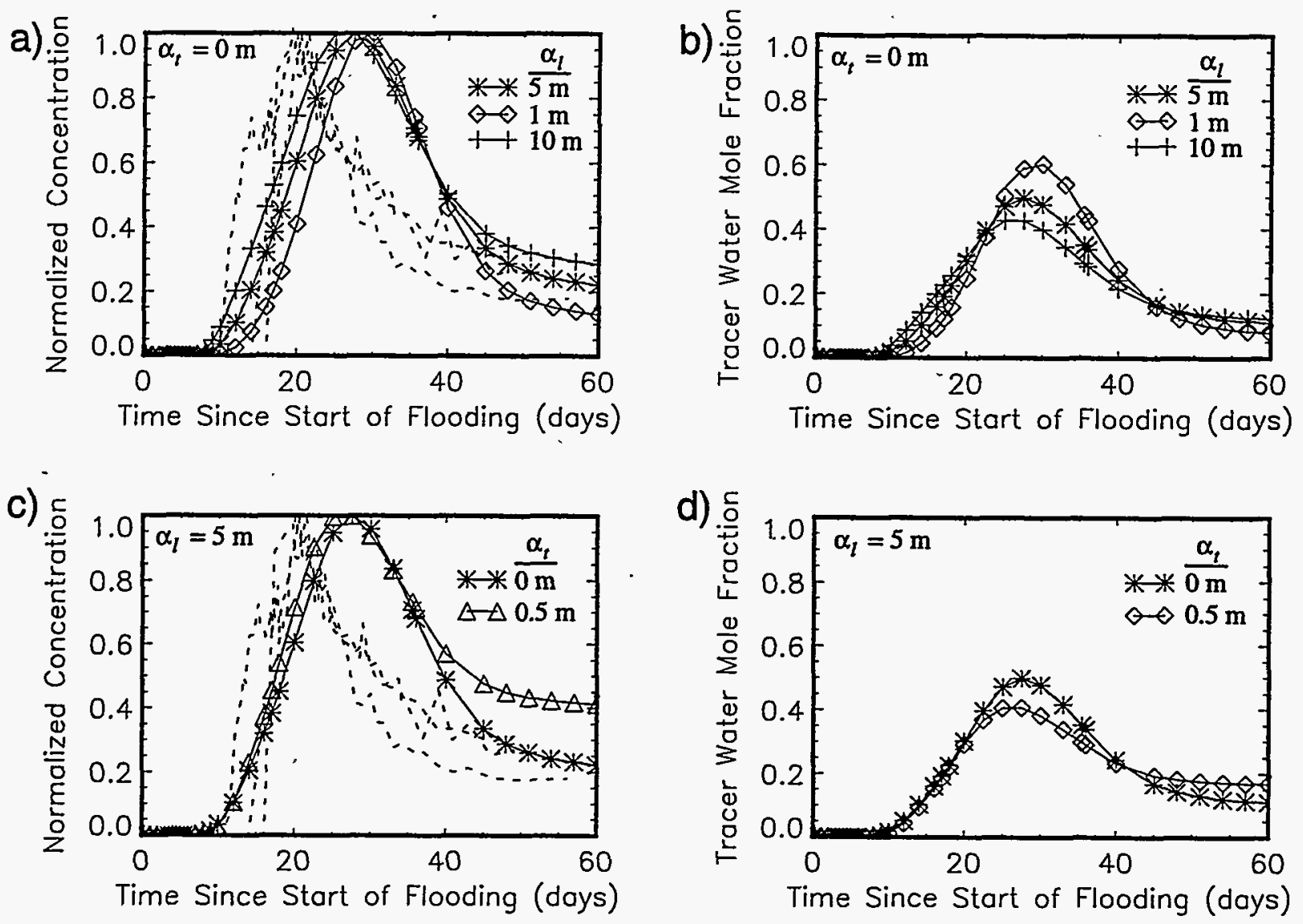

Figure 12. Sensitivity to longitudinal ( $a$ and $b$ ) and transverse ( $c$ and d) dispersivity. 
interbed, it is not surprising that the simulation without transverse dispersivity did a better job mimicking both the shape and tailing in the observed BTCs. While the infiltration test was not really configured to detect transverse dispersion, the indication from the test is that transverse dispersion within the aqueous phase is small compared to longitudinal dispersion.

Another calibration parameter for which the sensitivity was tested was the basalt fracture horizontal permeability. A series of simulations was run using a basalt fracture effective porosity of 0.03 as the base run. The basalt fracture horizontal permeability in this run was $90,000 \mathrm{mD}(90$ D). This permeability was arbitrarily set to $50 \%(45 \mathrm{D})$ and $150 \%(135 \mathrm{D})$ of the base value. The resulting simulated $B$ ring $B T C$ and $B$ and $C$ ring hydrographs are shown in Figure 13 . Also shown, for consistency with previous figures, are the calibration targets. As can be seen, there is a substantial effect on the hydrographs. Reducing the horizontal fracture permeability results in perched water rising higher. The converse holds true for increasing the horizontal fracture permeability where the perched water rise is less. In contrast to the changes in the simulated hydrographs, the resulting sensitivity in the simulated BTC was very slight.

Although it appears in Figure 13 that perched water arrives earlier at the B ring location, it actually does not. It is an unfortunate artifact of slight "noise" in the results as the saturation approaches 1.0. If a lower saturation level of 0.96 was used to create simulation hydrographs, the first arrival would be the same for each simulation.

The last calibration parameter for which a series of sensitivity results are presented is the permeability of the clay layer at the top of the interbed. For the $\theta_{b}=0.05$ and $\theta_{b}=0.03$ simulations, the permeability of the clay layer was $1.0 \mathrm{mD}$. It was only for the $\theta_{b}=0.01$ simulation that the clay permeability had to be changed to $0.85 \mathrm{mD}$ in order to achieve a reasonable match to the observed hydrographs. For this reason, the $\theta_{b}=0.01$ single porosity simulation is used as the base run in order to demonstrate the sensitivity to the clay permeability in the simulated BTC and hydrograph results. The clay permeability was assigned values of 0.5 and $1.2 \mathrm{mD}$. The resulting simulated $\mathrm{B}$ ring BTC and B and C ring hydrographs are shown in Figure 14. Similar to the previous figure, the calibration targets are also shown. The response is predictable. As the clay permeability increases, the development and spread of perched water decreases since the infiltrating water more easily contimues down into and through the clay layer. The converse also occurs as the clay permeability decreases. It was actually quite easy to create "bathtub" conditions where the simulated perched water rose much higher (above the upper plot axis extent due to increasing grid size) than the observed hydrographs due to an inability to infiltrate into a clay with a lowered permeability. Therefore, results are quite sensitive to this parameter.

\subsection{Sensitivity to Fracture Relative Permeability Curvature}

As discussed previously, some parameters were assumed to be constant for the purpose of this calibration study. Reasonable matches to the observed BTCs and hydrographs were obtained using only a small set of parameters for calibration. One important parameter that was assumed to be constant was the exponent that controlled the shape of the basalt fracture relative permeability curve ( $B_{w}$ in Table 4). Due to possible interest in the effect of this assumption, a series of simulations was made to demonstrate the effect of this assumption. The single porosity $\theta_{b}=0.03$ simulation was used as the base run. Figure 15 shows the three water relative permeability curves 

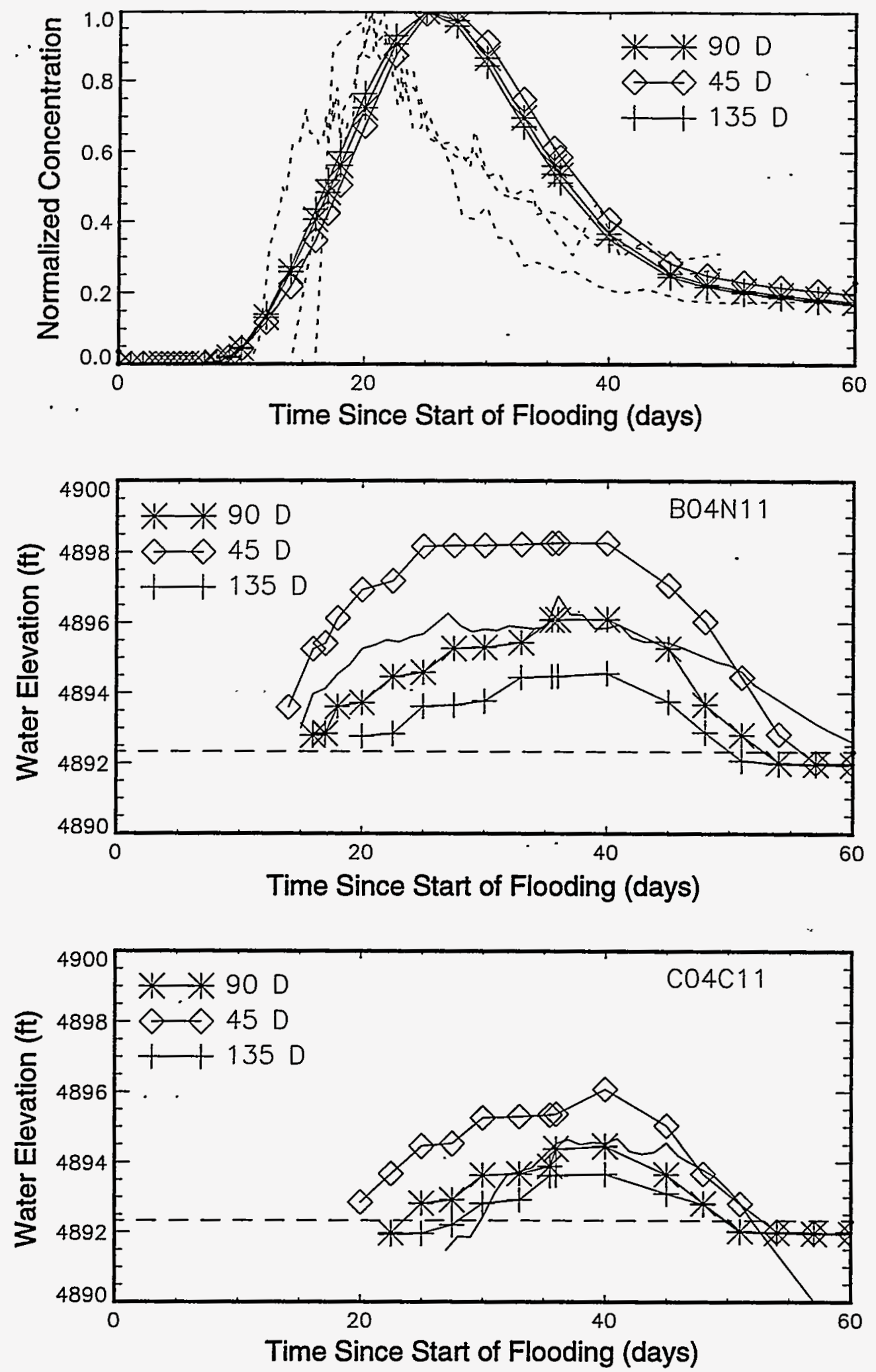

Figure 13. Sensitivity to basalt fracture horizontal permeability $\left(k_{h, b}\right)$. 

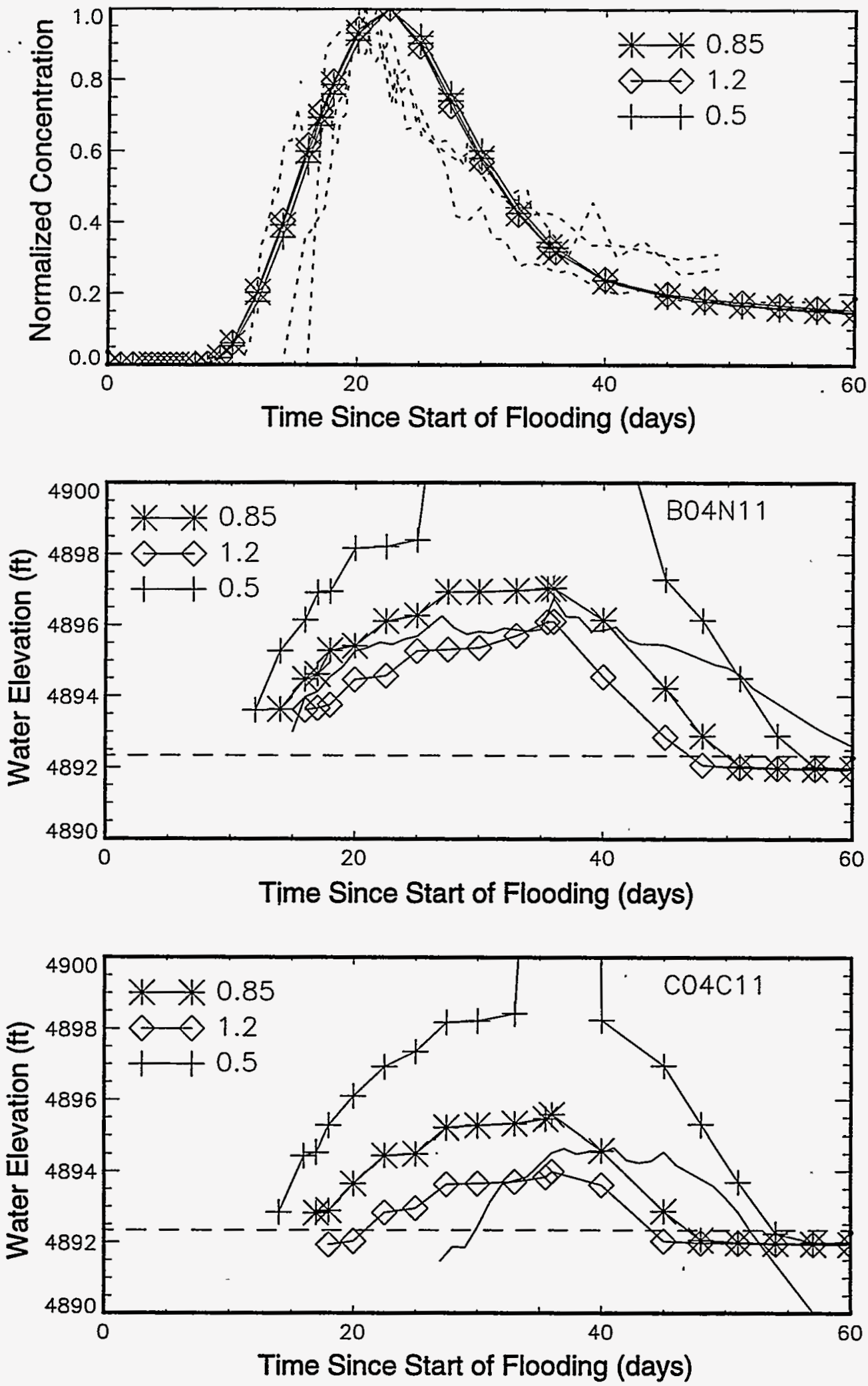

Figure 14. Sensitivity to clay permeability $\left(k_{c}\right)$. 


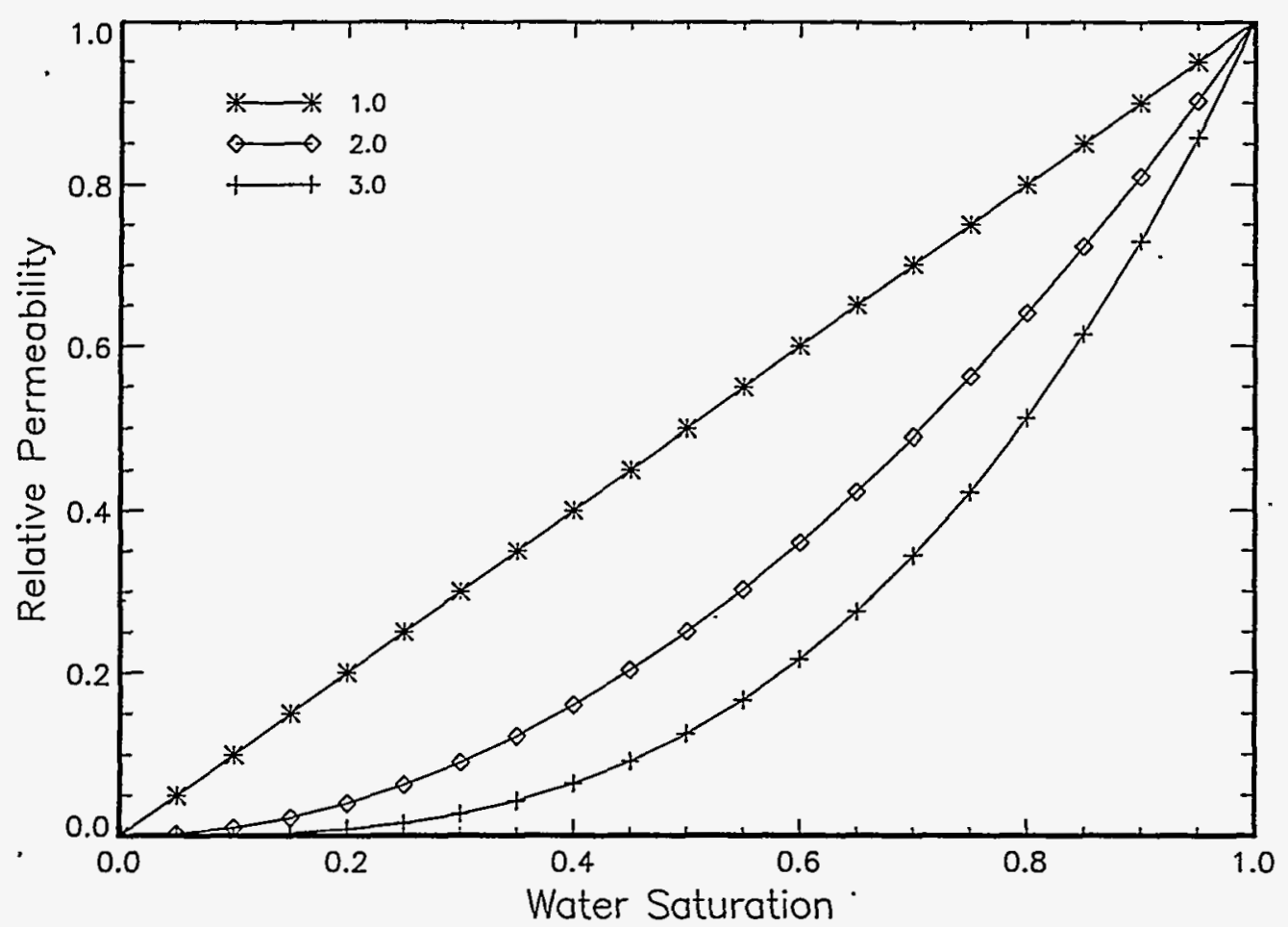

Figure 15. Effect of curvature exponent $\left(B_{w}\right)$ for basalt fracture relative permeability.

that were used in this sensitivity analysis, which had values of $B_{w}$ equal to 1.0 (base run), 2.0 and 3.0.

Figure 16 shows the simulated BTC and hydrographs that resulted from varying the curvature of the fracture relative permeability curve. As can be seen in the figure, the effect of including any curvature in the fracture relative permeability curve is to reduce the permeability as the fracture is wetting up. This has a similar effect on the hydrographs of reducing the overall horizontal fracture permeability. It causes the simulated hydrographs to show increased thicknesses of perched water. In the case of the $\mathrm{B}$ ring hydrograph, the $B_{w}=2.0$ simulation actually improves the match, both for the rising and falling limbs of the hydrograph. But reducing the permeability also delays breakthrough, as can be seen by the increasingly poorer comparison to the observed B ring BTCs as the $B_{w}$ parameter is increased from 1.0 to 2.0 and 3.0.

While there is an effect from changing the shape of the fracture relative permeability curve, it appears to be more a case of refining the calibration match once the other parameters were varied to obtain a reasonably close match in the first place. The conclusion to be drawn in this study is that the shape of the fracture relative permeability is less important than the absolute permeability. This is likely due in part since flooding conditions were artificially generated for the test. In the case of ambient infiltration pulses inside the SDA, the shape of this curve may be more sensitive. It should be reasonably straight-forward, once a model is constructed for the purpose of assessing risk at the SDA, to vary this parameter and see its effect when a realistic description of infiltration is used. 

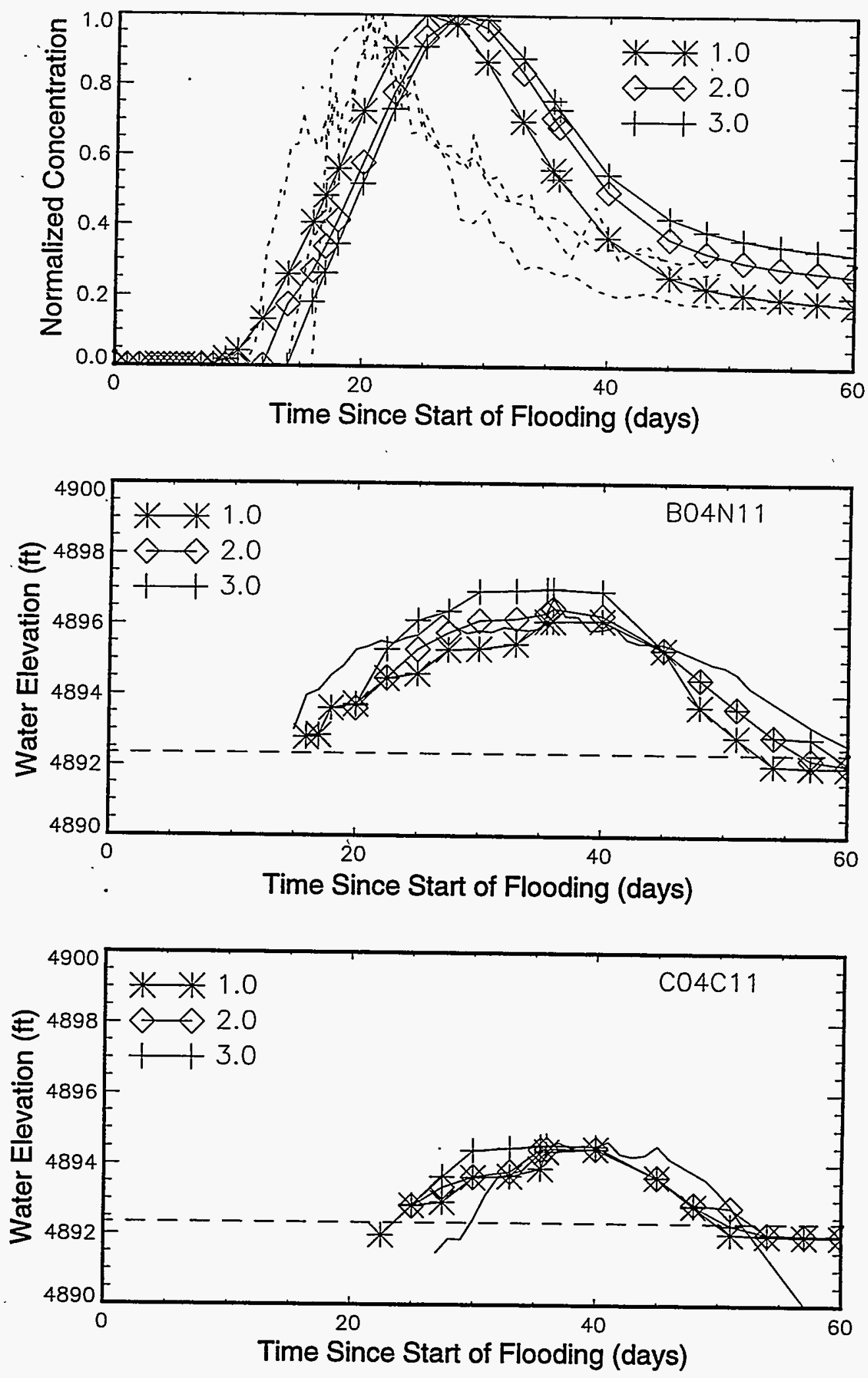

Figure 16. Sensitivity to degree of curvature of basalt fracture relative permeability $\left(B_{w}\right)$. 


\section{CONCLUSIONS}

An inverse modeling study was conducted to obtain a representative description of flow and transport through vadose zone fractured basalts for use in field-scale modeling studies, in particular for risk assessments performed at the SDA. An equivalent porous media model using either single or dual porosity was used to obtain reasonable matches to calibration targets selected from observed hydrographs and conservative tracer breakthrough curves. Due to non-ideal behavior in the field results (which was to be expected), subjective judgement was used both in selecting the particular calibration targets and in determining the adequacy of the match between the simulated and observed results. The main observations suggested by the simulation results are:

- The calibration process resulted in simulations of flow and transport through the fractured basalt that mimic the gross or general behavior observed in the results of the field test.

- The dual porosity model improved the match to the calibration targets but is not likely worth the additional computational burden unless the need for it is demonstrated otherwise.

- The effective porosity for the fractured basalt resulting from the calibration exercise was low, ranging from 0.01 to 0.05 , and is representative for vertical flow through an interconnected system of fractures.

- Placing a low-permeability clay zone at the top of the sedimentary interbed that was in contrast with the hydrologic properties of the sedimentary interbed was necessary to mimic the observed field results.

- The calibration results were non-unique and provide a range of possible parameter values. The midpoints from these ranges can be used for deterministic modeling, or the entire range could be considered for probabilistic modeling.

- Sensitivity analysis of a limited number of parameters, deemed likely to be important, showed that the calibration results were most sensitive to the effective porosity, permeability, and anisotropy ratio for the fractured basalts and to the permeability of the sedimentary interbed.

- While the elevation of the surface of the sedimentary interbed likely controlled the spread of perched water that developed during the test, the available information on this surface was not dense enough to construct an accurate representation of the surface for use in the simulations.

The fracture basalt effective porosity indicated by the calibration exercise is in contrast to the effective porosity generally accepted for the Snake River Plain aquifer, which is more on the order of 0.05 to 0.20 . The latter porosity includes the effect of rubble zones, which primarily control flow within the aquifer but do not to any large extent, at least in the infiltration test, affect vertical movement within the vadose zone. Infiltrating water which may have encountered rubble zones during the infiltration test apparently continued to migrate vertically.

For completeness, Table 7 contains the recommended single-point value of parameters that were treated as variable in this calibration study. The choice of a basalt fracture effective porosity of 0.03 was based on a compromise between the best match to the observed B ring BTC with $\theta_{b}=0.01$ and a better match to the hydrographs with $\theta_{b}=0.05$. 
Table 7: Recommended parameters based on calibration results.

\begin{tabular}{|l|l|}
\hline \multicolumn{1}{|c|}{ Parameter } & \multicolumn{1}{c|}{ Value } \\
\hline \hline Basalt fracture effective porosity, $\theta_{b}$ & 0.03 \\
\hline Fracture vertical permeability, $k_{v, b}$ & $175 \mathrm{mD}$ \\
\hline Fracture horizontal permeability, $k_{h, b}$ & $90,000 \mathrm{mD}$ \\
\hline Clay permeability, $k_{c}$ & $1.0 \mathrm{mD}$ \\
\hline Basalt matrix permeability (dual porosity), $k_{b m}$ & $0.05 \mathrm{mD}$ \\
\hline Longitudinal dispersivity & $5 \mathrm{~m}$ \\
\hline
\end{tabular}

The calibration targets chosen in this study were found to be insensitive to the dispersivity values. A recommendation was made to use a longitudinal dispersivity of $5 \mathrm{~m}$ for longitudinal (primarily vertical) transport in the vadose zone. The basis for this recommendation is not overwhelming, and monitoring or sampling results from the SDA, or elsewhere on the INEL, may well indicate the use of a different dispersivity value.

The results of this modeling study indicate that the large-scale infiltration test was successful in providing measurements upon which to base a description of flow and transport through the fractured basalt portion of the vadose zone. The methodology proposed for simulating fate and transport in the SDA Waste Area Group 7 Comprehensive Remedial Investigation/Feasibility Study Baseline Risk Assessment (Huntley, 1995) calls for using this calibrated fractured basalt hydrologic description to allow for a more realistic representation of flow and transport. This methodology also indicates that comparisons of simulated water behavior to observed shallow and deep perched water behavior (Hubbell, 1990; 1992; 1993) beneath the SDA will serve as a further test of the fractured basalt hydrologic description under conditions of ambient infiltration. 


\section{REFERENCES}

Baca, R. G., S. O. Magnuson, H. D. Nguyen, and P. Martian, 1992, A Modeling Study of Water Flow in the Vadose Zone Beneath the Radioactive Waste Management Complex, EGGGEO-10068, EG\&G Idaho, Inc., Idaho Falls, D.

Bishop, C. W., 1991, Hydraulic Properties of Vesicular Basalt, Masters Thesis, University of Arizona, Tucson, AZ.

Bishop, C. W., 1995, Soil Moisture Monitoring Results at the Radioactive Waste Management Complex of the Idaho National Engineering Laboratory, FY-1995 and FY-1994, INEL-95/ 261, EDF-RWMC-850, Lockheed Martin Idaho Technologies, Idaho Falls, ID.

Brooks, R. H. and A. T. Corey, 1966, "Properties of Porous Media Affecting Fluid Flow," J. Irrig. Drain. Div., Am Soc. Civil Eng., Vol. 92 (IR2), pp. 61-88.

Burgess, J. D., 1995, Results of the Neutron and Natural Gamma Logging, Stratigraphy, and Perched Water Data Collected During a Large-Scale Infiltration Test, INEL-95/062, EDFER-WAG7-60, Lockheed Martin Idaho Technologies, Idaho Falls, ID.

Burns, D. E., B. H. Becker, R. M. Huntley, C. A. Loehr, S. M. Rood, P. Sinton, and T. H. Smith, 1994, Revised Preliminary Scoping Risk Assessment for Waste Pits, Trenches, and Soil Vaults at the Subsurface Disposal Area, Idaho National Engineering Laboratory, EGGER-11395, EG\&G Idaho, Inc., Idaho Falls, ID.

Cecil, L. D., J. R. Pittman, T. M. Beasley, R. L. Michel, P. W. Kubik, P. Sharma, U. Fehn, and H. Gove, 1992, "Water Infiltration Rates in the Unsaturated Zone at the Idaho National Engineering Laboratory Estimated from Chlorine-36 and Tritium Profiles, and Neutron Logging," in Proceedings of the 7th International Symposium on Water-Rock Interaction - WRI-7, Y. K. Kharaka and A. S. Meest (eds.), Park City, UT.

Dunnivant, F. M., G. D. Mecham, and J. Giles, 1994, Results from the Large-Scale Aquifer Pumping and Infiltration Test: Down-Hole Gamma Spectroscopic Monitoring, INEL-94/064, Lockheed Martin Idaho Technologies, Idaho Falls, ID.

Dunnivant, F. M. and M. E. Newman, 1995, Migration of Radionuclide Tracers Through Fractured Media: Preliminary Modeling Results of Breakthrough Curves Obtained During the Large-Scale Aquifer Pumping and Infiltration Tests, INEL-95/288, Lockheed Martin Idaho Technologies, Idaho Falls, ID.

Freeze, R. A. and J. A. Cherry, 1979, Groundwater, Prentice-Hall, Inc., NJ.

Hubbell, J. M., 1990, Perched Ground Water at the Radioactive Waste Management Complex of the Idaho National Engineering Laboratory, EGG-ER-8779, EG\&G Idaho, Inc., Idaho Falls, $\mathbb{D}$. 
Hubbell, J. M., 1992, Perched Water at the Radioactive Waste Management Complex, EDFVVED-ER-098, EG\&G Idaho, Inc., Idaho Falls, ID.

Hubbell, J. M., 1993, Perched Ground Water Monitoring in the Subsurface Disposal Area of the Radioactive Waste Management Complex, FY-1993, EDF-ER\&WM-EDF-002293, EG\&G Idaho, Inc., Idaho Falls, ID.

Huntley, R. M. 1995, Draft Work Plan for Operable Unit 7-13/14 Waste Area Group 7

Comprehensive Remedial Investigation/Feasibility Study, INEL-95/0343, Revision 0, Lockheed Martin Idaho Technologies, Idaho Falls, ID.

Knutson, C. F., K. A. McCormick, J. C. Crocker, M. A. Glenn, and M. L. Fishel, 1992, 3D RWMC Vadose Zone Modeling (Including FY-89 to FY-90 Basalt Characterization Results), EGGERD-10246, EG\&G Idaho, Inc., Idaho Falls, ID.

Leverett, M. C., 1941, Trans. AIME, 142, pp. 152.

Maheras, S. J., A. S. Rood, S. O. Magnuson, M. E. Sussman, and R. N. Bhatt, 1994, Radioactive Waste Management Complex Low-Level Waste Radiological Performance Assessment, EGG-WM-8773, EG\&G Idaho, Inc., Idaho Falls, ID.

McCarthy, J. M. and R. M. Neupauer, 1993, WAG 10 Preliminary Groundwater Flow Model Calibration, EDF ER-WAG10-33, EG\&G Idaho, Inc., Idaho Falls, ID.

McElroy, D. L. and J. M. Hubbell, 1990, Hydrologic and Physical Properties of Sediments at the Radioactive Waste Management Complex, EGG-BG-9147, EG\&G Idaho, Inc., Idaho Falls, ID.

McElroy, D. L., 1993, FY-1993 Soil Moisture Monitoring Results at the Radioactive Waste Management Complex of the Idaho National Engineering Laboratory, EGG-WM-11066, EG\&G Idaho Falls, Inc., Idaho Falls, ID.

Newman, M. E. and F. M. Dunnivant, 1995, Results from the Large-Scale Infiltration Test: Transport of Radionuclide Tracers, EDF-ER-WAG7-77, INEL-95/146, Lockheed Martin Idaho Technologies, Idaho Falls, ID.

Norrell, G. T., I. Porro, F. M. Dunnivant, J. M. Hubbell, M. C. Pfeifer, R. C. Starr, M. E. Newman, and C. W. Bishop, 1994, Conceptual Design of the Large-Scale Infiltration Test, EGG-ER11363, Rev. 0., EG\&G Idaho, Inc., Idaho Falls, ID.

Parker, J. C., R. J. Lenhard, and T. Kuppusamy, 1987, “A Parametric Model for Constitutive Properties Governing Multiphase Flow in Porous Media," Water Resources Research, Vol. 23, No. 4, pp. 618-624.

Pfeifer, M. C. and H. T. Andersen, 1995, Report on the Electrical Resistivity Monitoring During the Aquifer Pumping and Infiltration Test, INEL-95/010, Rev: 0, Lockheed Martin Idaho 
Technologies, Idaho Falls, D.

Porro, I. and C. W. Bishop, 1995, Large Scale Infiltration Test CPN Data Analysis, EDF-WAG758, INEL-94/040, Lockheed Martin Idaho Technologies, Idaho Falls, ID.

Robertson, J. B., 1974, Digital Modeling of Radioactive and Chemical Waste Transport in the Snake River Plain Aquifer at the National Reactor Testing Station, Idaho, IDO-22054, U.S. Geological Survey Open File Report.

Rood, A. S., R. C. Arnett, and J. T. Barraclough, 1989, Contaminant Transport in the Snake River Plain Aquifer: Phase I, Part 1: Simple Analytical Models of Individual Plumes, EGG-ER8623, EG\&G Idaho, Inc., Idaho Falls, ID.

Rood, A. S., 1994, GWSCREEN: A Semi-Analytical Model for Assessment of the Groundwater Pathway from Surface or Buried Contamination, Theory and User's Manual, Version 2.0, EGG-GEO-10797, EG\&G Idaho, Inc., Idaho Falls, ID.

Schmalz, B. L., 1969, Injection of Gas into the Lithosphere at the National Reactor Testing Station, IDO-12069, Idaho Operations Office, U.S. Atomic Energy Commission.

Shook, G. M., 1995, Development of an Environmental Simulator from Existing Petroleum Technology, INEL-94/0283, Lockheed Martin Idaho Technologies, Idaho Falls, ID.

Starr, R. C. and M. J. Rohe, 1995, Large-Scale Aquifer Stress Test and Infiltration Test: Water Management System Operation and Results, INEL-95/059, Lockheed Martin Idaho Technologies, Idaho Falls, $\mathbf{D}$.

Van Genuchten, M. Th., 1980, "A closed-form equation for predicting the hydraulic conductivity of unsaturated soils," Soil Science Society of America Journal, 44, pp. 892-898.

Vinsome, P. K. W. and G. M. Shook, 1993, "Multi-purpose Simulation," Journal of Petroleum - Science and Engineering, Volume 9, pp. 29-38.

Walton, J. C., R. G. Baca, and T. L. Rasmussen, 1989, "Flow and Transport of Radionuclides in Unsaturated Fractured Basalt," Waste Management '89, Tucson, AZ, pp. 775-780.

Warren, J. E. and P. J. Root, 1963, "The behavior of naturally fractured reservoirs," Transactions Society of Petroleum Engineers AIME, 228, pp. 245-255.

Wylie, A. H., T. R. Wood, and G. T. Norrell, 1994, Conceptual Design of the Large-Scale Aquifer Pumping Test, ER-WAG7-48, EG\&G Idaho, Inc., Idaho Falls, ID.

Wylie, A. H., J. M McCarthy, E. Neher, and B. D. Higgs, 1995, Large-Scale Aquifer Pumping Test Results, INEL-95/012 Lockheed Martin Idaho Technologies, Idaho Falls, ID. 


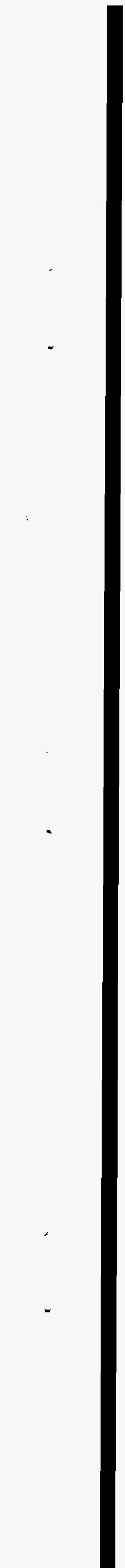




\section{Appendix A: TETRAD Simulation Decks}

For completeness this appendix contains the complete TETRAD input decks which contain the recommended model calibration parameters. Since most of the dual porosity input deck is the same as the single porosity input deck, the changes in the dual porosity input deck are bolded.

\section{Single Porosity Input Deck}

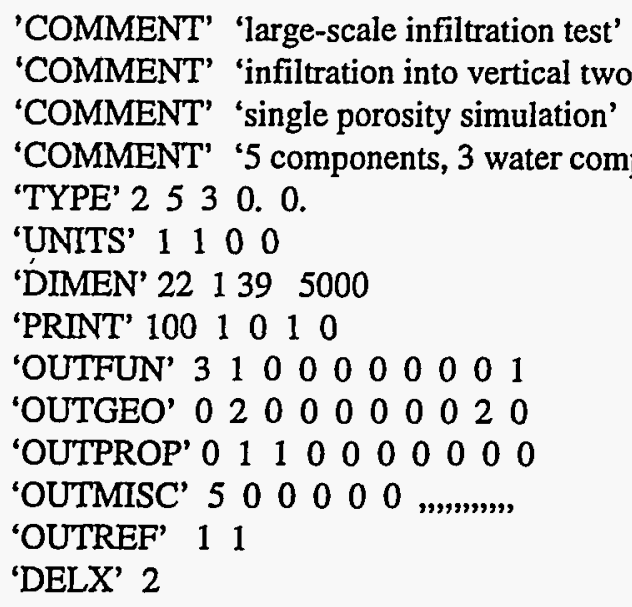




\begin{tabular}{|c|c|c|c|}
\hline 0.362000 & $5.20810 e-08$ & 0.246573 & 767.212 \\
\hline 0.372000 & $1.21221 \mathrm{e}-07$ & 0.242427 & 594.116 \\
\hline 0.382000 & $2.55412 e-07$ & 0.238197 & 474.090 \\
\hline 0.392000 & $4.97603 e-07$ & 0.233883 & 387.363 \\
\hline 0.402000 & $9.09799 \mathrm{e}-07$ & 0.229487 & 322.602 \\
\hline 0.412000 & $1.57864 \mathrm{e}-06$ & 0.225011 & 272.928 \\
\hline 0.422000 & $2.62149 \mathrm{e}-06$ & 0.220458 & 233.966 \\
\hline 0.432000 & $4.19366 \mathrm{e}-06$ & 0.215829 & 202.823 \\
\hline 0.442000 & $6.49615 e-06$ & 0.211 & 177.523 \\
\hline 0.452000 & $9.78488 \mathrm{e}-06$ & & 156.679 \\
\hline 0.462000 & $1.43814 \mathrm{e}-05$ & 0.201518 & .295 \\
\hline 0.472000 & $2.06824 \mathrm{e}-05$ & 0.196616 & 4.637 \\
\hline 0.482000 & $2.91756 \mathrm{e}-05$ & 0.191655 & 112.158 \\
\hline 0.492000 & $4.04491 e-05$ & 0.186638 & 101.441 \\
\hline 0.502000 & $5.52116 e-05$ & 0.181568 & 92.1664 \\
\hline 0.512000 & $7.43074 e-05$ & 0.176451 & 84.0819 \\
\hline 0.522000 & $9.87344 \mathrm{e}-05$ & 0.171291 & 76.9895 \\
\hline 0.532000 & 0.000129666 & 0.166092 & 70.7305 \\
\hline 0.542000 & 0.000168478 & 0.160860 & 65.1768 \\
\hline 0.552000 & 0.000216771 & 0.155599 & 60.2241 \\
\hline 0.562000 & 0.000276395 & 0.150316 & 55.7866 \\
\hline 0.572000 & 0.000349492 & 0.145016 & 51.7937 \\
\hline 0.582000 & 0.000438527 & 0.139705 & 48.1861 \\
\hline 0.592000 & 0.000546323 & 0.134388 & 44.9142 \\
\hline 0.602000 & 0.000676115 & 0.129073 & 41.9363 \\
\hline 0.612000 & 0.000831596 & 0.12 & 39.2169 \\
\hline 0.622000 & 0.0010 & 0.1 & 36.7255 \\
\hline 0.632000 & 0.0012 & 0.11 & 34.4362 \\
\hline 0.642000 & 0.00149719 & 0.107961 & 32.3266 \\
\hline 0.652000 & 0.00180364 & 0.102755 & 30.3772 \\
\hline 0.662000 & 0.00216338 & 0.0975930 & 28.5713 \\
\hline 0.672000 & 0.00258433 & 0.0924818 & 26.8940 \\
\hline 0.682000 & 0.00307548 & 0.0874296 & 25.3326 \\
\hline 0.692000 & 0.00364704 & 0.0824442 & 23.8755 \\
\hline 0.702000 & 0.00431054 & 0.0775336 & 22.5128 \\
\hline 0.712000 & 0.00507909 & 0.0727060 & 21.2356 \\
\hline 0.722000 & 0.00596760 & 0.0679694 & 20.0360 \\
\hline 0.732000 & 0.00699296 & 0.0633320 & 18.9070 \\
\hline 0.742000 & 0.00817446 & 0.0588022 & 17.8422 \\
\hline 0.752000 & $0.00953409^{\circ}$ & 0.0543881 & 16.8361 \\
\hline 0.762000 & 0.011097 .0 & 0.0500979 & 15.8834 \\
\hline 0.772000 & 0.0128920 & 0.0459398 & 14.9797 \\
\hline 0.782000 & 0.0149522 & 0.0419217 & 14.1207 \\
\hline 0.792000 & 0.0173160 & 0.0380518 & 13.3027 \\
\hline 0.802000 & 0.0200277 & 0.0343376 & 12.5220 \\
\hline 0.811999 & 0.0231388 & 0.0307867 & 11.7756 \\
\hline 0.821999 & 0.0267099 & 0.0274064 & 11.0605 \\
\hline 0.831999 & 0.0308122 & 0.0242036 & 10.3739 \\
\hline 0.841999 & 0.0355299 & 0.0211848 & 9.71321 \\
\hline 0.851999 & 0.0409642 & 0.0183563 & 9.07602 \\
\hline 0.861999 & 0.0472366 & 0.0157234 & 8.45998 \\
\hline 0.871999 & 0.0544957 & 0.0132912 & 7.86284 \\
\hline 0.881999 & 0.0629248 & 0.0110638 & 7.28236 \\
\hline 0.891999 & 0.0727536 & 0.00904462 & 6.71628 \\
\hline
\end{tabular}




$\begin{array}{llll}0.901999 & 0.0842750 & 0.00723602 & 6.16229 \\ 0.911999 & 0.0978703 & 0.00563917 & 5.61791 \\ 0.921999 & 0.114049 & 0.00425394 & 5.08042 \\ 0.931999 & 0.133512 & 0.00307853 & 4.54661 \\ 0.941999 & 0.157267 & 0.00210926 & 4.01260 \\ 0.951999 & 0.186840 & 0.00134006 & 3.47325 \\ 0.961999 & 0.224718 & 0.000761923 & 2.92122 \\ 0.971999 & 0.275418 & 0.000362038 & 2.34475 \\ 0.981999 & 0.348758 & 0.000122300 & 1.72139 \\ 0.991999 & 0.475495 & 1.64195 \mathrm{e}-05 & 0.992151\end{array}$

'RELANAL' 21201.

25. 25. 1. 0. 1. 0 .

.01 .1 .001

0. 0.1 .132 .1 .5

.011 .1 .2

0. 0.1 .1 0. 1 .

'COMMENT' ' setting APCGO to 0.0 makes PCaw equal to the sum of PCow and PCao'

'RKREG' 113211

'RKREG' 13361612

'RKREG' 61785811

'DENCS' 1000.0 1000.1000.1.22 55 .

$\begin{array}{llllll}1 & 1 & 1 & 2 & 1\end{array}$

18.0218 .0218 .0229 .80$.

'LIQDEN'

\section{"'?"',}

"',"'"

",',",

85.,",",

850.,,,,,

'CRITG' 1

"1,"s,

"'?"?"

"'","',

$\begin{array}{lll}3771.8 & 132.8 & 0032\end{array}$

22100. 650. .0034

'LIQVIS'

",". .

"'"

","'

.50 .

1. 0 .

'GASVIS'

.0160 .1 . 0. 1 .

.0160 .1 .0 .1 .

.0160 . 1. 0. 1 .

.0160 .1 . 0.1 .

.0160 .1 . 0.1 .

$\begin{array}{llllll}\text { 'KVAL' } & 0.0 & 0.0 & 0.0 & 0.001 & .01\end{array}$

$\begin{array}{lllll}1.186219 \mathrm{e} 7 & -2.095847 \mathrm{e} 1 & 2.548592 \mathrm{e}-3 & 3816.44 & 46.130\end{array}$

$\begin{array}{lllll}1.186219 \mathrm{e} 7 & -2.095847 \mathrm{e} 1 & 2.548592 \mathrm{e}-3 & 3816.44 & 46.130\end{array}$

$\begin{array}{llllll}1.186219 \mathrm{e} 7 & -2.095847 \mathrm{e} 1 & 2.548592 \mathrm{e}-3 & 3816.44 & 46.130\end{array}$

8.6212E8 0. 0.3103 .40 .16

1.E6 0. 0.2597 .548 .78

$\begin{array}{llll} & \text { 'PRES' } \quad 101.325 \quad 0 . & 0.012\end{array}$ 


\begin{tabular}{|c|c|c|}
\hline 'SATZLAY' & 1 & .394353 \\
\hline 'SATZLAY' & $\cdot 2$ & .389980 \\
\hline 'SATZLAY' & 3 & .384965 \\
\hline 'SATZLAY' & 4 & .379323 \\
\hline 'SATZI_AY' & 5 & .372828 \\
\hline 'SATZLAY' & 6 & .365535 \\
\hline 'SATZLAY' & 7 & .999832 \\
\hline ‘SATZLAY' & 8 & .999832 \\
\hline 'SATZLAY' & 9 & 999832 \\
\hline 'SATZLAY' & 10 & .999832 \\
\hline 'SATZLAY' & 11 & .999832 \\
\hline 'SATZLAY' & 12 & .999832 \\
\hline 'SATZLAY' & 13 & .999832 \\
\hline 'SATZLAY' & 14 & .999832 \\
\hline 'SATZLAY' & 15 & .999832 \\
\hline 'SATZLAY' & 16 & .999832 \\
\hline 'SATZLAY' & 17 & .999832 \\
\hline 'SATZLAY’ & 18 & .999832 \\
\hline 'SATZLAY' & 19 & 999832 \\
\hline 'SATZLAY' & 20 & 999832 \\
\hline 'SATZLAY' & 21 & 999832 \\
\hline 'SATZLAY' & 22 & 999832 \\
\hline 'SATZLAY' & 23 & .999832 \\
\hline 'SATZLAY' & 24 & .999832 \\
\hline 'SATZLAY' & 25 & .999832 \\
\hline 'SATZLAY' & 26 & .999832 \\
\hline 'SATZLAY' & 27 & 999827 \\
\hline 'SATZLAY’ & 28 & (998537 \\
\hline 'SATZLAY' & 29 & .097156 \\
\hline 'SATZLAY' & 30 & .425244 \\
\hline ‘SATZLAY’ & 31 & .425244 \\
\hline 'SATZLAY’ & 32 & .425244 \\
\hline 'SATZLAY' & 33 & .425244 \\
\hline ‘SATZLAY’ & 34 & .425244 \\
\hline 'SATZLAY’ & 35 & .425244 \\
\hline 'SATZLAY' & 36 & .425244 \\
\hline 'SATZLAY' & 37 & .425242 \\
\hline 'SATZLAY' & 38 & .425234 \\
\hline 'SATZLAY' & 39 & .425202 \\
\hline
\end{tabular}

'TEMPMOD' 1858125.

'WMOD' 1858 1 1. 0.0 .0 .0$. 'YMOD' 1858 1.0. 0. 0. 1. 0.

'XMOD' 1858 1 0.0 .0 .0 .01 .1

'REFAREA' 920311121291

'RECUR'

'TIMEYR' 1

'TIME' -1000. 0.0001

'GVWRTE' -1 2000

4 'SW' 'W1' 'W2' 'W3'

'COMMENT' ' $0.01 \mathrm{~m} / \mathrm{yr}$ is the same as $0.02738 \mathrm{~kg} / \mathrm{m}^{2} /$ day'

'MFLUX' 122130.02738 0. 0.0 .0 .0$.

'TIME' 0. .00001

'TTMEYR' 0

'TIME' $0.0000001-1$. 
'COMMENT' ' $0.12 \mathrm{~m} /$ day is the same as $116.6 \mathrm{~kg} / \mathrm{m}^{2} /$ day' 'MFLUX' 11013 0. 116.60 .0 .0$.

'DISPER' 5. 0.0 .0 .0 .0$.

'TIME' $0.1-1$

'TIME' $1.0-1$

'TTME' $2.0-1$

'TIME' $3.0-1$

'TIME' $3.5-1$

'TTME' $4.0-1$

'TIME' $4.5-1$

'TIME' $5.0-1$

'TIME' $5.5-1$

'TIME' $6.0-1$

'MFLUX' 11013 0. $0.116 .6 \quad 0.0$.

'TIME' $6.01-1$

'TIME' $7.0-1$

'TIME' $8.0-1$

'TIME' $9.0-1$

'TIME' $10.0-1$

'TIME' $12.0-1$

'TIME' $14.0-1$

'TIME' $16.0-1$

'TIME' $17.0-1$

'MFLUX' 11013 0. 116.60 .0 .0$.

'TIME' $17.01-1$

'TIME' $18.0-1$

'TIME' $20.0-1$

'TIME' $22.5-1$

'TIME' $25.0-1$

'TIME' $27.5-1$

'TIME' $30.0-1$

'TIME' $33.0-1$

'TIME' $35.5-1$

'MFLUX' 110130.02738 0. $0 . \quad 0.0$.

'TIME' $35.5001 \quad 0.02$

'TIME' $36.0-1$

'TIME' $40.0-1$

'TIME' $45.0-1$

'TIME' $48.0-1$

'TIME' $51.0-1$

'TIME' $54.0-1$

'TIME' $57.0-1$

'TIME' $60.0 \quad 0$. 


\section{Dual Porosity Input Deck}

'COMMENT' 'large-scale infiltration test'

'COMMENT' 'infiltration into vertical two dimensional axi-symmetrix domain '

'COMMENT' 'dual porosity simulation'

'COMMENT' '5 components, 3 water components'

'TYPE' 2530.0.

'UNTS' 11100

'DIMEN' 221395000

'PRINT' 10010020

'OUTFUN' 3110000000001

'OUTGEO' $02 \begin{array}{lllllllll} & 0 & 0 & 0 & 0 & 0 & 0 & 2 & 0\end{array}$

'OUTPROP' 0111100000000

'OUTMISC' 5000000

'OUTREF' 11

'DELX' 2

11 13. 13. 13. 13. 13. 11. 7. 4. 2.5 2. 2.

112.5 4. 6. 9. 13. 20. 30. 40. 50.60. 72.

'DELY' 1

11.

'DELZ' 4

$6 \quad 6 * 0.25$

$9 \quad 0.250 .50 .751 .2 .4 .8 .10 .8 .75$

13 6. $4.2 .1 .51 .00 .750 .56 * 0.25$

$\begin{array}{llllllllll}11 & 0.25 & 0.5 & 0.5 & 0.75 & 1.0 & 1.5 & 2.25 & 3.35 & 3 * 5.0\end{array}$

'RADIAL' 10.

'FTOPS' 00

'DUAL' 0. 2. 6. 0.0 .0 .50 .50 .50 .

'COMMENT' 'fracture properties first'

'PORMOD' 113210.2435

'PORMOD' $133616 \quad 10.03$

$\begin{array}{lllll}\text { 'PORMOD' } 617858 & 1 & 0.2435\end{array}$

'PERMMOD' $113213 * 78$.

'PERMMOD' $133330 \quad 12 * 175.175$.

'PERMMOD' $33161612 * 90000.175$.

'PERMMOD' $617638 \quad 1 \quad 3 * 1.00$

'PERMMOD' $63985813 * 78$.

'COMMENT' ' matrix properties follow'

'PORMOD' 85999010.2435

'PORMOD' $9911474 \quad 10.228$

'PORMOD' $14751716 \quad 10.2435$

'PERMMOD' $85999013 * 78$.

'PERMMOD' $9911474 \quad 1 \quad 3 * 0.05$

'PERMMOD' $1475149613 * 1.00$

'PERMMOD' $1497171613 * 78$.

'COMMENT" “ "

'BVMULT' 8378581 1.E5

'BVMULT' 169517161 1.E5

'PROPERTY'

'COMMENT' 'using GWSCREEN sediment van genuchten params tabulated into RELGW '

'RELGW' 170178.0 .487

$$
\begin{array}{llll}
0.302000 & 2.43201 \mathrm{e}-13 & 0.269608 & 31704.5
\end{array}
$$

$\begin{array}{llll}0.312000 & 1.89190 \mathrm{e}-11 & 0.265991 & 8424.19\end{array}$ 


\begin{tabular}{|c|c|c|c|}
\hline 0.322000 & $2.45166 \mathrm{e}-10$ & 0.262285 & 3879.84 \\
\hline 0.332000 & $1.51177 \mathrm{e}-09$ & 0.258489 & 2238.14 \\
\hline 0.342000 & $6.19707 \mathrm{e}-09$ & 0.254605 & 1460.60 \\
\hline 0.352000 & $1.96423 \mathrm{e}-08$ & 0.250632 & 1030.49 \\
\hline 0.362000 & $5.20810 \mathrm{e}-08$ & 0.246573 & 767.212 \\
\hline 0.372000 & $1.21221 \mathrm{e}-07$ & 0.242427 & 594.116 \\
\hline 0.382000 & $2.55412 \mathrm{e}-07$ & 0.238197 & 474.090 \\
\hline 0.392000 & $4.97603 e-07$ & 0.233883 & 387.363 \\
\hline 0.402000 & $9.09799 e-07$ & 0.229487 & 322.602 \\
\hline 0.412000 & $1.57864 \mathrm{e}-06$ & 0.225011 & 272.928 \\
\hline 0.422000 & $2.62149 \mathrm{e}-06$ & 0.220458 & 233.966 \\
\hline 0.432000 & 4.19366e-06 & 0.215829 & 202.823 \\
\hline 0.442000 & $6.49615 \mathrm{e}-06$ & 0.211127 & 177.523 \\
\hline 0.452000 & 9.78488e-06 & 0.206356 & 156.679 \\
\hline 0.462000 & $1.43814 \mathrm{e}-05$ & 0.201518 & 139.295 \\
\hline 0.472000 & $2.06824 \mathrm{e}-05$ & 0.196616 & 124.637 \\
\hline 0.482000 & $2.91756 \mathrm{e}-05$ & 0.191655 & 112.158 \\
\hline 0.492000 & $4.04491 \mathrm{e}-05$ & 0.186638 & 101.441 \\
\hline 0.502000 & $5.52116 \mathrm{e}-05$ & 0.181568 & 92.1664 \\
\hline 0.512000 & $7.43074 e-05$ & 0.176451 & 84.0819 \\
\hline 0.522000 & $9.87344 \mathrm{e}-05$ & 0.171291 & 76.9895 \\
\hline 0.532000 & 0.000129666 & 0.166092 & 70.7305 \\
\hline 0.542000 & 0.000168478 & 0.160860 & 65.1768 \\
\hline 0.552000 & 0.000216771 & 0.155599 & 60.2241 \\
\hline 0.562000 & 0.000276395 & 0.150316 & 55.7866 \\
\hline 0.572000 & 0.000349492 & 0.145016 & 51.7937 \\
\hline 0.582000 & 0.000438527 & 0.139705 & 48.1861 \\
\hline 0.592000 & 0.000546323 & 0.134388 & 44.9142 \\
\hline 0.602000 & 0.000676115 & 0.129073 & 41.9363 \\
\hline 0.612000 & 0.000831596 & 0.123766 & 39.2169 \\
\hline 0.622000 & 0.00101697 & 0.118474 & 36.7255 \\
\hline 0.632000 & 23702 & 0.113203 & 34.4362 \\
\hline 0.642000 & 0.00149719 & 0.10 & 32.3266 \\
\hline 0.652000 & 0.001 & 0.10 & 30.3772 \\
\hline 0.662000 & 0.002 & 0.0975930 & 28.5713 \\
\hline 0.672000 & 0.002 & 0.0924818 & 26.8940 \\
\hline 0.682000 & 0.00307548 & 0.0874296 & 25.3326 \\
\hline 0.692000 & 0.00364704 & 0.0824442 & 23.8755 \\
\hline 0.702000 & 0.00431054 & 0.0775336 & 22.5128 \\
\hline 0.712000 & 0.00507909 & 0.0727060 & 21.2356 \\
\hline 0.722000 & 0.00596760 & 0.0679694 & 20.0360 \\
\hline 0.732000 & 0.00699296 & 0.0633320 & 18.9070 \\
\hline 0.742000 & 0.00817446 & 0.0588022 & 17.8422 \\
\hline 0.752000 & 0.00953409 & 0.0543881 & 16.8361 \\
\hline 0.762000 & 0.0110970 & 0.0500979 & 15.8834 \\
\hline 0.772000 & 0.0128920 & 0.0459398 & 14.9797 \\
\hline 0.782000 & 0.0149522 & 0.0419217 & 14.1207 \\
\hline 0.792000 & 0.0173160 & 0.0380518 & 13.3027 \\
\hline 0.802000 & 0.0200277 & 0.0343376 & 12.5220 \\
\hline 0.811999 & 0.0231388 & 0.0307867 & 11.7756 \\
\hline 0.821999 & 0.0267099 & 0.0274064 & 11.0605 \\
\hline 0.831999 & 0.0308122 & 0.0242036 & 10.3739 \\
\hline 0.841999 & 0.0355299 & 0.0211848 & 9.71321 \\
\hline 0.851999 & 0.0409642 & 0.0183563 & 9.07602 \\
\hline
\end{tabular}




$\begin{array}{llll}0.861999 & 0.0472366 & 0.0157234 & 8.45998 \\ 0.871999 & 0.0544957 & 0.0132912 & 7.86284 \\ 0.881999 & 0.0629248 & 0.0110638 & 7.28236 \\ 0.891999 & 0.0727536 & 0.00904462 & 6.71628 \\ 0.901999 & 0.0842750 & 0.00723602 & 6.16229 \\ 0.911999 & 0.0978703 & 0.00563917 & 5.61791 \\ 0.921999 & 0.114049 & 0.00425394 & 5.08042 \\ 0.931999 & 0.133512 & 0.00307853 & 4.54661 \\ 0.941999 & 0.157267 & 0.00210926 & 4.01260 \\ 0.951999 & 0.186840 & 0.00134006 & 3.47325 \\ 0.961999 & 0.224718 & 0.000761923 & 2.92122 \\ 0.971999 & 0.275418 & 0.000362038 & 2.34475 \\ 0.981999 & 0.348758 & 0.000122300 & 1.72139 \\ 0.991999 & 0.475495 & 1.64195 e-05 & 0.992151\end{array}$

'COMMENT' " 'using GWSCREEN basalt matrix van genuchten params tabulated into RELGW ' $\begin{array}{llllll}\text { 'RELGW' } 2 & 93 & 1 & 1.0 & 0.0\end{array}$

$\begin{array}{llll}.0 .0760000 & 5.88175 \mathrm{e}-15 & 0.308908 & 36647.7 \\ 0.0860000 & 6.36851 \mathrm{e}-13 & 0.307137 & 8491.04 \\ 0.0960000 & 9.63291 \mathrm{e}-12 & 0.305331 & 3609.57 \\ 0.106000 & 6.61697 \mathrm{e}-11 & 0.303487 & 1967.26 \\ 0.116000 & 2.95920 \mathrm{e}-10 & 0.301603 & 1228.55 \\ 0.126000 & 1.00794 \mathrm{e}-09 & 0.299675 & 836.219 \\ 0.136000 & 2.84066 \mathrm{e}-09 & 0.297701 & 604.013 \\ 0.146000 & 6.96941 \mathrm{e}-09 & 0.295677 & 455.672 \\ 0.156000 & 1.53847 \mathrm{e}-08 & 0.293602 & 355.363 \\ 0.166000 & 3.12404 \mathrm{e}-08 & 0.291471 & 284.485 \\ 0.176000 & 5.92819 \mathrm{e}-08 & 0.289282 & 232.613 \\ 0.186000 & 1.06406 \mathrm{e}-07 & 0.287034 & 193.550 \\ 0.196000 & 1.82246 \mathrm{e}-07 & 0.284723 & 163.423 \\ 0.206000 & 2.99981 \mathrm{e}-07 & 0.282347 & 139.717 \\ 0.216000 & 4.77111 \mathrm{e}-07 & 0.279903 & 120.737 \\ 0.226000 & 7.36556 \mathrm{e}-07 & 0.277391 & 105.314 \\ 0.236000 & 1.10756 \mathrm{e}-06 & 0.274807 & 92.6158 \\ 0.246000 & 1.62725 \mathrm{e}-06 & 0.272150 & 82.0401 \\ 0.256000 & 2.34180 \mathrm{e}-06 & 0.269418 & 73.1415 \\ 0.266000 & 3.30827 \mathrm{e}-06 & 0.266609 & 65.5850 \\ 0.276000 & 4.59607 \mathrm{e}-06 & 0.263722 & 59.1149 \\ 0.286000 & 6.28906 \mathrm{e}-06 & 0.260756 & 53.5337 \\ 0.296000 & 8.48779 \mathrm{e}-06 & 0.257709 & 48.6862 \\ 0.306000 & 1.13116 \mathrm{e}-05 & 0.254581 & 44.4498 \\ 0.316000 & 1.49021 \mathrm{e}-05 & 0.251370 & 40.7263 \\ 0.326000 & 1.94242 \mathrm{e}-05 & 0.248075 & 37.4364 \\ 0.336000 & 2.50711 \mathrm{e}-05 & 0.244697 & 34.5155 \\ 0.346000 & 3.20673 \mathrm{e}-05 & 0.241235 & 31.9104 \\ 0.356000 & 4.06709 \mathrm{e}-05 & 0.237689 & 29.5772 \\ 0.366000 & 5.11798 \mathrm{e}-05 & 0.234058 & 27.4795 \\ 0.376000 & 6.39341 \mathrm{e}-05 & 0.230344 & 25.5865 \\ 0.386000 & 7.93227 \mathrm{e}-05 & 0.226546 & 23.8724 \\ 0.396000 & 9.77885 \mathrm{e}-05 & 0.222665 & 22.3153 \\ 0.406000 & 0.000119831 & 0.218703 & 20.8965 \\ 0.416000 & 0.000146017 & 0.214660 & 19.6001 \\ 0.426000 & 0.000176986 & 0.210537 & 18.4122 \\ 0.436000 & 0.000213454 & 0.206337 & 17.3210 \\ 0.446000 & 0.000256228 & 0.202061 & 16.3162\end{array}$




$\begin{array}{llll}0.456000 & 0.000306211 & 0.197710 & 15.3888 \\ 0.466000 & 0.000364411 & 0.193288 & 14.5309 \\ 0.476000 & 0.000431953 & 0.188797 & 13.7357 \\ 0.486000 & 0.000510093 & 0.184240 & 12.9971 \\ 0.496000 & 0.000600226 & 0.179620 & 12.3097 \\ 0.506000 & 0.000703903 & 0.174939 & 11.6688 \\ 0.516000 & 0.000822853 & 0.170203 & 11.0702 \\ 0.526000 & 0.000958980 & 0.165414 & 10.5101 \\ 0.536000 & 0.00111441 & 0.160577 & 9.98527 \\ 0.546000 & 0.00129148 & 0.155696 & 9.49262 \\ 0.556000 & 0.00149281 & 0.150775 & 9.02949 \\ 0.566000 & 0.00172126 & 0.145821 & 8.59346 \\ 0.576000 & 0.00198002 & 0.140837 & 8.18236 \\ 0.586000 & 0.00227261 & 0.135830 & 7.79421 \\ 0.596000 & 0.00260294 & 0.130805 & 7.42724 \\ 0.606000 & 0.00297531 & 0.125769 & 7.07983 \\ 0.616000 & 0.00339450 & 0.120726 & 6.75051 \\ 0.626000 & 0.00386580 & 0.115685 & 6.43794 \\ 0.636000 & 0.00439507 & 0.110651 & 6.14090 \\ 0.646000 & 0.00498881 & 0.105633 & 5.85828 \\ 0.656000 & 0.00565421 & 0.100636 & 5.58905 \\ 0.666000 & 0.00639930 & 0.0956684 & 5.33227 \\ 0.676000 & 0.00723297 & 0.0907381 & 5.08709 \\ 0.686000 & 0.00816513 & 0.0858529 & 4.85271 \\ 0.696000 & 0.00920686 & 0.0810208 & 4.62840 \\ 0.706000 & 0.0103705 & 0.0762501 & 4.41348 \\ 0.716000 & 0.0116698 & 0.0715491 & 4.20731 \\ 0.726000 & 0.0131204 & 0.0669266 & 4.00933 \\ 0.736000 & 0.0147397 & 0.0623910 & 3.81898 \\ 0.746000 & 0.0165473 & 0.0579512 & 3.63575 \\ 0.756000 & 0.0185654 & 0.0536160 & 3.45919 \\ 0.766000 & 0.0208194 & 0.0493942 & 3.28883 \\ 0.776000 & 0.0233378 & 0.0452948 & 3.12426 \\ 0.786000 & 0.0261534 & 0.0413266 & 2.96509 \\ 0.796000 & 0.0293041 & 0.0374983 & 2.81094 \\ 0.806000 & 0.0328332 & 0.0338186 & 2.66145 \\ 0.816000 & 0.0367913 & 0.0302960 & 2.51628 \\ 0.825999 & 0.0412372 & 0.0269387 & 2.37509 \\ 0.835999 & 0.0462405 & 0.0237547 & 2.23756 \\ 0.845999 & 0.0518833 & 0.0207516 & 2.103371 \\ 0.855999 & 0.0582641 & 0.0179365 & 1.97221 \\ 0.865999 & 0.0655019 & 0.0153161 & 1.84375 \\ 0.875999 & 0.0737422 & 0.0128964 & 1.71766 \\ 0.885999 & 0.0831659 & 0.0106826 & 1.59360 \\ 0.895999 & 0.0940006 & 0.00867905 & 1.47120 \\ 0.905999 & 0.106539 & 0.00688895 & 1.35005 \\ 0.915999 & 0.121168 & 0.00531433 & 1.22968 \\ 0.925999 & 0.138407 & 0.00395566 & 1.10955 \\ 0.935999 & 0.158990 & 0.00281159 & 0.988972 \\ 0.9759999 & 0.183991 & 0.00187854 & 0.867058 \\ 0.985999 & 0.35590 & 0.00115020 & 0.742571 \\ & 0.392405 & 7.00219 \mathrm{e}-05 & 0.325878\end{array}$




\section{$0.995999 \quad 0.562741 \quad 3.12163 \mathrm{e}-06 \quad 0.137217$}

'RELANAL' 21301.

25. 25. 1. 0. 1. 0 .

.01 .1 .001

0. 0.1 .132 .1 .5

.011 .1 .2

$0.0 .1 .1 \quad 0.1$.

'COMMENT' ' setting APCGO to 0.0 makes PCaw equal to the sum of PCow and PCao'

'COMMENT' 'fracture domain first'

'RKREG' 113211

'RKREG' 13361613

'RKREG' 61785811

'COMMENT' 'matrix domain second'

'RKREG' 85999011

'RKREG' 991147412

'RKREG' 1475171611

'DENCS' 1000.01000 .1000 .01 .2255$.

$\begin{array}{lllll}1 & 1 & 1 & 1\end{array}$

$\begin{array}{llll}18.02 & 18.02 & 18.02 & 29.80 .\end{array}$

'LIQDEN'

"',","

,",?",

"',"',

85.,,",",

850.,",",

'CRITG' 1

",",?"

",",","

",",",

$3771.8 \quad 132.8 \quad 0032$

22100. 650. .0034

'LIQVIS'

","

"'"

",",

.50 .

1. 0 .

'GASVIS'

.0160 .1 . 0.1 .

.0160 . 1. 0. 1 .

.0160 . 1. 0.1 .

.0160 . 1. 0. 1 .

.0160 .1 .0 .1 . 1 .

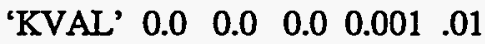

$\begin{array}{lllll}1.186219 \mathrm{e} 7 & -2.095847 \mathrm{e} 1 & 2.548592 \mathrm{e}-3 & 3816.44 & 46.130\end{array}$

$\begin{array}{llllll}1.186219 \mathrm{e} 7 & -2.095847 \mathrm{e} 1 & 2.548592 \mathrm{e}-3 & 3816.44 & 46.130\end{array}$

$\begin{array}{lllll}1.186219 \mathrm{e} 7 & -2.095847 \mathrm{e} 1 & 2.548592 \mathrm{e}-3 & 3816.44 & 46.130\end{array}$

8.6212E8 0. 0.3103 .40 .16

1.E6 0. 0. 2597.548 .78

$\begin{array}{llll} & \text { 'PRES' } \quad 101.325 & 0 . & 0.012\end{array}$

'COMMENT' 'fracture gaseous and oleic saturations by layer'

$\begin{array}{llll}\text { 'SATZLAY' } 1 & .430298 & .0\end{array}$

$\begin{array}{llll}\text { 'SATZLAY' } 2 & .427258 & .0\end{array}$

$\begin{array}{llll}\text { 'SATZLAY' } 3 & .424040 \quad .0\end{array}$ 


\begin{tabular}{|c|c|c|c|}
\hline 'SATZLAY' & 4 & .420688 & .0 \\
\hline 'SATZLAY' & 5 & .417199 & .0 \\
\hline 'SATZLAY' & 6 & .413686 & .0 \\
\hline 'SATZLAY' & 7 & .999833 & .0 \\
\hline 'SATZLAY' & 8 & .999833 & .0 \\
\hline 'SATZLAY' & 9 & .999833 & .0 \\
\hline 'SATZLAY' & 10 & .999834 & .0 \\
\hline 'SATZLAY' & 11 & .999834 & .0 \\
\hline 'SATZLAY' & 12 & .999836 & .0 \\
\hline 'SATZLAY' & 13 & .999840 & .0 \\
\hline 'SATZLAY' & 14 & .999845 & .0 \\
\hline 'SATZLAY' & 15 & .999849 & .0 \\
\hline 'SATZLAY' & 16 & .999852 & .0 \\
\hline 'SATZLAY' & 17 & .999854 & .0 \\
\hline 'SATZLAY' & 18 & 999855 & .0 \\
\hline 'SATZLAY' & 19 & .999856 & .0 \\
\hline 'SATZLAY' & 20 & .999856 & .0 \\
\hline 'SATZLAY' & 21 & .999856 & .0 \\
\hline 'SATZLAY' & 22 & 999856 & .0 \\
\hline 'SATZLAY' & 23 & .999856 & .0 \\
\hline 'SATZLAY' & 24 & .999857 & .0 \\
\hline 'SATZLAY' & 25 & 999857 & .0 \\
\hline 'SATZLAY' & 26 & .999857 & .0 \\
\hline 'SATZLAY' & 27 & .999852 & .0 \\
\hline 'SATZLAY' & 28 & .998150 & .0 \\
\hline 'SATZLAY' & 29 & .119433 & .0 \\
\hline 'SATZLAY' & 30 & .448455 & .0 \\
\hline 'SATZLAY' & 31 & .449019 & .0 \\
\hline 'SATZLAY' & 32 & .449215 & .0 \\
\hline 'SATZLAY' & 33 & .449247 & .0 \\
\hline 'SATZLAY' & 34 & .449202 & .0 \\
\hline 'SATZLAY' & 35 & .449028 & .0 \\
\hline 'SATZLAY' & 36 & .448392 & .0 \\
\hline 'SATZLAY' & 37 & .445388 & .0 \\
\hline 'SATZLAY' & 38 & .445388 & .0 \\
\hline 'SATZLAY' & 39 & .445388 & .0 \\
\hline \multicolumn{4}{|c|}{ 'COMMENT' 'matrix gaseous and oleic saturations by layer } \\
\hline 'SATZLAY' & 40 & .426243 & .0 \\
\hline 'SATZLAY' & 41 & .424863 & .0 \\
\hline 'SATZLAY' & 42 & .422319 & .0 \\
\hline 'SATZLAY' & 43 & .418734 & .0 \\
\hline 'SATZLAY' & 44 & .413565 & .0 \\
\hline 'SATZLAY' & 45 & .406209 & .0 \\
\hline 'SATZLAAY' & 46 & .304547 & .0 \\
\hline 'SATZLAY' & 47 & .323256 & .0 \\
\hline 'SATZLAY' & $48^{\circ}$ & .356225 & .0 \\
\hline 'SATZLAY' & 49 & .399488 & .0 \\
\hline 'SATZLAY' & 50 & .440001 & .0 \\
\hline 'SATZLAY' & 51 & .450150 & .0 \\
\hline ‘SATZLAY' & 52 & .454838 & .0 \\
\hline 'SATZLAY' & 53 & .460324 & .0 \\
\hline 'SATZLAY' & 54 & .465167 & .0 \\
\hline 'SATZLAY' & 55 & .468493 & .0 \\
\hline ‘SATZLAY' & 56 & .470707 & .0 \\
\hline
\end{tabular}




\begin{tabular}{|c|c|}
\hline 'SATZLAY' 5 & .471409 \\
\hline 'SATZLAY' 5 & .464615 \\
\hline 'SATZLAY' 5 & .420576 \\
\hline 'SATZLAY' 6 & .355624 \\
\hline 'SATZLAY' 6 & .301447 \\
\hline 'SATZLAY' 6 & .268270 \\
\hline 'SATZLAY' 6 & .246920 \\
\hline 'SATZLAY' 6 & .226786 \\
\hline 'SATZLAY' 6 & .207792 \\
\hline 'SATZLAY' 6 & .189845 \\
\hline 'SATZLAY' 6 & .172847 \\
\hline 'SATZLAY' 6 & .122390 \\
\hline 'SATZLAY' 6 & .450990 \\
\hline 'SATZLAY' 7 & .449807 \\
\hline 'SATZLAY' 7 & .449392 \\
\hline 'SATZLAY' 7 & .449275 \\
\hline 'SATZLAY' 7 & .449205 \\
\hline 'SATZLAY' 7 & .449029 \\
\hline 'SATZLAY' 7 & .448393 \\
\hline 'SATZLAY' 7 & .445389 \\
\hline 'SATZLAY' 7 & .445389 \\
\hline 'SATZLAY' 7 & .445389 \\
\hline
\end{tabular}

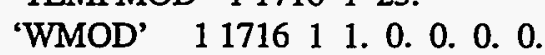

'YMOD' 117161 0. 0.0 .1 .0$.

'XMOD' 11716110.0 .0 .01 .1

'REFAREA' 920311121291

'RECUR'

'TIMEYR' 1

'TIME' -1000. 0.0001

'GVWRITE' -1 2000.

6 'SWFR' 'SWMA' 'WMA2' 'WFR2' 'WMA3' 'WFR3'

'COMMENT' ' $0.01 \mathrm{~m} / \mathrm{yr}$ is the same as $0.02738 \mathrm{~kg} / \mathrm{m}^{2} /$ day'

'COMMENT' 'MFLUX' 12213.02738 0. 0.0 .0 .0$.

'COMMENT' 'MFLUX' 85988013.02738 0. 0.0 .0 .0$.

'MFLUX' 12213.01369 0. 0.0 .0 .0$.

'MFLUX' 85988013.01369 0. 0.0 .0 .0$.

'TIME' 0. .00001

'TIMEYR' 0

'TIME' 0.0000001 -1.

'COMMENT' ' $0.12 \mathrm{~m} /$ day is the same as $116.6 \mathrm{~kg} / \mathrm{m}^{2} /$ day'

'COMMENT' 'MFLUX' 11013 0. 116.6 0. 0.0.

'COMMENT' 'MFLUX' 85986813 0. 116.6 0. 0.0.

'MFLUX' 1101330.58 .30 .0 .0$.

'MFLUX' $8598681330.58 .3 \quad 0.0 .0$.

'DISPER' 5. 0. 0. 0. 0.0 .

'TIME' $0.1-1$

'TIME' $1.0-1$

'TIME' $2.0-1$

'TIME' $3.0-1$

'TIME' $3.5-1$

'TIME' $4.0-1$

'TIME' $4.5-1$

'TIME' $5.0-1$ 
'TIME' $5.5-1$

'TIME' $6.0^{\circ}-1$

'COMMENT' 'MFLUX' 11101330.0 .116 .6 0. 0.

'COMMENT' 'MFLUX' 859868130.0 .116 .60 .0$.

'MFLUX' 11013 1 $130.0 .58 .3 \quad 0.0$.

'MFLUX' $8598681330.0 .58 .3 \quad 0.0$.

'TIME' $6.01-1$

'TIME' $7.0-1$

'TIME' $8.0-1$

'TIME' $9.0-1$

'TIME' $10.0-1$

'TIME' $12.0-1$

'TIME' $14.0-1$

'TIME' $16.0-1$

'TIME' $17.0-1$

'COMMENT' 'MFLUX' 1101330.116 .6 0. 0.0.

'COMMENT' 'MFLUX' 8598681330.116 .6 0. 0.0.

'MFLUX' $11010130.58 .3 \quad 0.0 .0$.

'MFLUX' $8598681330.58 .3 \quad 0.0 .0$.

'TIME' $17.01-1$

'TIME' $18.0-1$

'TIME' $20.0-1$

'TIME' $22.5-1$

'TIME' $25.0-1$

'TIME' $27.5-1$

'TIME' $30.0-1$

'TIME' $33.0-1$

'TIME' $35.5-1$

'COMMENT' 'MFLUX' 111013.02738 0. 0.0 .0 .0$.

'COMMENT' 'MFLUX' 85986813.02738 0. 0.0 .0$.

'MFLUX' 11013.01369 0. 0.0 .0$.

'MFLUX' 85986813.01369 0. 0.0 .0$.

'TIME' $35.5001 \quad 0.02$

'TIME' $36.0-1$

'TIME' $40.0-1$

'TIME' $45.0-1$

'TIME' 48.0 -1

'TIME' 51.0 -1

'TIME' 54.0 -1

'TIME' $57.0-1$

'TIME' 60.00 . 
